\title{
Trade and the Spatial Distribution of Transport Infrastructure
}

Gabriel J. Felbermayr \& Alexander Tarasov

\section{Highlights}

- When national planners decide non-cooperatively, the spatial distribution of transport infrastructure is inefficiently biased towards central regions of adjacent countries.

- This bias is magnified by discrete border frictions caused by cultural or institutional differences or tariffs.

- Calibrating the model to European data, the mechanism explains about $20 \%$ of the so called border effect, i.e., the observation that intranational trade strongly dominates international one.

- Corroborating the main implications of the model, regression analysis shows that the estimated border effect shrinks when accounting for transport infrastructure. 


\section{Abstract}

The distribution of transport infrastructure across space is the outcome of deliberate government planning that reflects a desire to unlock the welfare gains from regional economic integration. Yet, despite being one of the oldest government activities, the economic forces shaping the endogenous emergence of infrastructure have not been rigorously studied. This paper provides a stylized analytical framework of open economies in which planners decide non-cooperatively on transport infrastructure investments across continuous space. Allowing for intra- and international trade, the resulting equilibrium investment schedule features underinvestment that turns out particularly severe in border regions and that is amplied by the presence of discrete border costs. In European data, the mechanism explains about a fifth of the border effect identified in a conventionally specied gravity regression. The framework sheds light on the welfare costs of second best investment schedules, on the effects of intercontinental trade or of privatized infrastructure provision.

\section{Keywords}

Economic Geography, International Trade, Infrastructure Investment, Border Effect Puzzle.

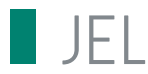

$\mathrm{F} 11, \mathrm{R} 42, \mathrm{R} 13$

\section{Working Paper}

\section{CEPI}

CEPII (Centre d'Etudes Prospectives et $d^{\prime}$ 'Informations Internationales) is a French institute dedicated to producing independent, policyoriented economic research helpful to understand the international economic environment and challenges in the areas of trade policy, competitiveness, macroeconomics, international finance and growth.
CEPII Working Paper

Contributing to research in international economics

(c) CEPII, PARIS, 2015

All rights reserved. Opinions expressed in this publication are those of the author(s) alone.

$\begin{array}{ll}\text { Editorial Director: } & \text { CEPII } \\ \text { Sébastien Jean } & 113, \text { rue de Grenelle } \\ & 75007 \text { Paris } \\ \text { Production: } & +33153685500 \\ \text { Laure Boivin } & \\ \text { No ISSN: } 1293-2574 & \text { Prw.cepii.fr }\end{array}$




\title{
TRADE AND THE SPATIAL DISTRIBUTION OF TRANSPORT IN FRASTRUCTURE'
}

\author{
Gabriel J. Felbermayr ${ }^{2}$ \& Alexander Tarasov ${ }^{3}$
}

\begin{abstract}
(1) We would like to thank Kristian Behrens, Holger Breinlich, Kerem Cosar, Dalia Marin, Diego Puga, Philip Ushchev, seminar participants at the universities of Zurich, St. Gallen, Konstanz, Tübingen, Giessen, TU Darmstadt, Linz, Rotterdam, Luxembourg, Ifo Munich, Paris School of Economics, Nottingham, Hohenheim, Milano, and the European University Institute as well as participants at the Conference of the Society of Economic Dynamics (SED) in Warshaw, the Congress of the European Economic Association (Toulouse), the European Trade Study Group (Munich), the $17^{\text {th }}$ Conference of the SFB/TR (Munich), the Congress of the German Economic Association (Hamburg), and the workshop "Imperfect Competition and Spatial Economics: Theoretical and Empirical Aspects" (Saint-Petersburg) for valuable comments and discussions. Alexander Tarasov is grateful to the Deutsche Forschungsgemeinschaft through SFB/TR 15 for financial support.

(2) Address: Ifo Institute for Economic Research at the University of Munich, Poschingerstra e 5, 81679 München, Germany.

Tel.: +49(0)89/9224-1428. Email: felbermayr@ifo.de

(3) National Research University Higher School of Economics, Faculty of Economics, Shabolovka 26, 119049, Moscow, Russia. E-mail: atarasov@hse.ru
\end{abstract}


This paper was partly written when Gabriel Felbermayr was visiting CEPII in July 2015 . He wishes to thank the Institute for its hospitality and support.

\section{Introduction}

The provision of transport infrastructure is one of the oldest and most basic government activities. The roads built by the Inca in South America or by the Romans in Europe bear testimony to this fact. Indeed, any known civilization has devoted resources to the construction of roads presumably with the objective to unlock the welfare gains from regional integration. ${ }^{1} \mathrm{On}$ average, OECD countries spend about 1\% of GDP on inland transportation infrastructure and maintenance. This amounts to about 3\% of countries' public budgets. Emerging or transition economies spend up to $10 \%$ of their budgets on transport infrastructure. ${ }^{2}$

A large mostly empirical literature demonstrates the important role of infrastructure on trade costs, trade flows, and welfare. It makes massive efforts to address the suspected endogeneity of infrastructure but does not model the processes that determine these costs. So, in their authoritative handbook chapter, Redding and Turner (2014) ask for "further research ... examining the political economy of transport infrastructure investments". The present paper is a first step towards endogenizing the spatial distribution of transport infrastructure. ${ }^{3}$

In this paper we focus on land-borne transportation, by far the most important mode for intracontinental trade in the EU or in North America. Much transport infrastructure spending is decided decentrally, in particular in the EU, where only about $1 \%$ of total spending is at the Union level and central planning is limited to a small number of projects. For this reason, we assume that welfare-maximizing national governments allocate infrastructure spending over space in a non-cooperative fashion. However, while political space is fragmented, consumers demand goods from all locations in our continuous, linear two-country economy. We show that, in such a setup, there is inefficiently low global investment in infrastructure. Underinvestment is particularly severe in border regions. The reason is that national governments do not internalize the benefits from reductions in domestic transportation costs that accrue to foreign consumers, and these unaccounted benefits are largest the closer a location is to a national border.

As a consequence, trade across national borders entails higher transportation costs than trade within countries, holding bilateral distances and market sizes constant. This effect materializes even in the absence of discrete border costs caused by tariffs or non-tariff measures. However, the effect is magnified by the existence of such costs. The endogenous emergence of broad border zones may contribute towards explaining the empirical fact that international borders tend

\footnotetext{
${ }^{1}$ A fascinating account of the history of road construction and operation is provided by Lay (1992).

2ITF-OECD (2012), p. 4. These investment costs pale in comparison to total social road transport costs (including time costs and externalities), which have been estimated to amount to 20-25\% of GDP (Persson and Song, 2010).

${ }^{3}$ We formalize the non-cooperative behavior of welfare-maximizing national governments in continuous space. However, we argue that our main results generalize to the median voter model.
} 
to restrict international trade much more severely than what observable border costs together with plausible trade elasticities would suggest (Anderson and van Wincoop, 2003).

We employ data on intra-EU trade flows and transportation costs to calibrate our model and illustrate our theoretical arguments. We use the setup to simulate a data set of trade flows, and apply a conventional gravity model. The obtained border effect significantly overestimates the true border costs; about half of the bias is due to omitting infrastructure; the second half is a statistical artefact that arises from the high correlation between distance and border. Hence, endogenous infrastructure investment can explain part of the border effect.

In an intermediate step of our theoretical analysis, we propose a useful mapping between the spatial distribution of infrastructure spending within an interval into transportation costs between the two endpoints of this interval. This mapping is consistent with the concave relationship between geographical distance and transport costs documented in the data. The link between infrastructure investment over space and transportation costs is shaped by the elasticity of substitution between investment at different locations. We embed this structure into a simple model of intra- and international trade, where each location produces a unique differentiated product which is subject to transportation costs.

We find that the optimal infrastructure investment at some point in space is not only determined by local conditions at that point, but also - and predominantly - by the situation in other locations that produce and demand goods which transit through that point. The enlargement of a country - e.g., the reunification of Germany - leads to a reallocation of investment away from formerly central regions towards the former border. A higher degree of substitutability between investments at different addresses has an ambiguous effect on investment while a higher elasticity of substitution between goods produced at different location reduces investment.

Using real data on EU trade flows, we provide econometric support for the role of transport infrastructure in shaping the border effect. Employing road distance or, even better, travel time, as proxies for transportation costs instead of great-circle distance, the estimated trade-inhibiting effect of the border falls by about a quarter. We provide various sensitivity checks to make sure that our empirical result is not driven by reverse causation.

We extend our analysis by adding a non-contiguous country which supplies and demands goods to and from our two-country continent. We find that an increase in the economic mass of this overseas trading partner induces a reallocation of spending towards coastal regions and away from the hinterland, strengthening the border effect.

Our main result is robust to a number of model variations. First, we discuss how privately operated toll roads would change our results. Second, we study a special case where governments outsource the design and operation of roads to domestic private monopolists but regulate the fee system. These firms care only about profits and not about welfare. However, the central issue leading to inefficient investment variation persists: the monopolists underinvest more in locations 
close to the border where the positive externality on foreign infrastructure operators is largest. Third, we argue that allowing for labor mobility does not undo underinvestment at the border relative to first best. However, whether the non-cooperative equilibrium features a bimodal investment pattern depends on the size of discrete border costs. Fourth, we demonstrate that our central planner results are similar to the outcome expected from a median voter model.

Our paper is related to at least four important strands of literature. First, it connects with papers that study the importance of geographical frictions and transportation costs for trade and welfare. Typically, the literature has treated those costs as exogenous. Limao and Venables (2001) find that up to 60 percent of the cross-country variation in transport costs is due to transport infrastructure and that high cost of land-borne transportation is a more relevant trade barrier than the costs of maritime transportation. Venables (2005) argues that infrastructure explains a larger share of spatial income inequality than sheer geography. Many existing papers assume that countries (or regions) do not have a geographical extension. Recent work provides more spatial detail, but continues to treat infrastructure as exogenous. Cosar and Demir (2014) show that the upgrading of motorways in Turkey significantly increases exports of transport-intensive goods of landlocked cities. Allen and Arkolakis (2014) incorporate realistic topographical features into a spatial model of trade. They find that the introduction of the US interstate highway system has reduced the costs of a coast-to-coast shipment by about a third. Duranton et al. (2014) use data on US interstate highways to show that highways within cities cause them to specialize in sectors that have high weight to value ratios. Using a multi-region general equilibrium model of trade, Donaldson (2014) and Donaldson and Hornbeck (2015) analyze the welfare gains from railroads in India and the United States, respectively. They find that improved market access through reduced transport costs creates trade and generates welfare gains, but that it also leads to trade diversion. Behar and Venables (2011) and Redding and Turner (2014) provide excellent surveys. While they cite empirical work on the determinants of transportation costs, they do not provide theoretical references on their endogenous emergence.

Second, our paper is related to a small literature that endogenizes transportation costs, usually by introducing a proper transportation sector. Using an economic geography model, Behrens and Picard (2011) show that the prices for transporting differentiated goods increase in the degree of spatial specialization of the economy and that this channel dampens core-periphery patterns. While their model has a competitive transport sector, Hummels et al. (2009) provides evidence that monopolistic market structure in the transport sector restricts trade. These papers do not analyze the endogenous emergence of road infrastructure.

Third, our paper is related to literature that jointly considers international and intranational aspects of trade. Courant and Deardorff (1992) emphasize the importance of trade within countries for trade patterns across countries. Rossi-Hansberg (2005) studies the effects of small border costs on the regional distribution of workers within a country and assesses the implications of the equilibrium population distribution on intra- versus international trade flows. However, his focus is not on infrastructure investment. 
Fourth, our paper relates to work on the border puzzle. Transport costs are usually related to geographical distance while the border effect is attributed to some lumpy cost that materializes when crossing a border. Anderson and van Wincoop (2003) estimate that the US-Canadian border reduces international trade relative to intranational trade by a factor of 4.7. ${ }^{4}$ Explanations for fixed border costs abound. Among other things, they are related to informational costs (Casella and Rauch, 2003), networks (Combes et al., 2005), or exchange rates (Rose and van Wincoop, 2001). Border effects exist also within countries, where the above explanations do not help. ${ }^{5}$ Our setup shows that border effects can arise even in the absence of explicit costs at the border.

The structure of the paper is as follows. Section 2 presents some stylized facts on the transportation sector that inform our modeling choices. Section 3 explains our formulation of the mapping between the spatial distribution of infrastructure investment and transport costs. Section 4 sets up the general equilibrium environment which motivates intra- and international trade and analyzes the optimal infrastructure investment schedule in a closed economy. Section 5 moves to a setting of two symmetric open economies and derives our core results on the endogenous emergence of border regions. Section 6 provides empirical evidence supporting our analysis while Section 7 discusses several extensions. Section 8 concludes.

\section{Stylized facts}

Here, we present some stylized facts on transportation costs and transport infrastructure.

Fact 1: Transport costs vary across space. Direct data on transportation costs is scarce. Representative marginal costs for freight transportation amount to 1.54 Euro per kilometer on average around 2008 in the United Kingdom. Fuel (including taxes) and travel time account for $44 \%$ and $38 \%$ of the total, respectively (Braconier et al., 2013). Combes and Lafourcade (2005) provide generalized transportation cost data for a sample of 8742 French city pairs in 1993. Average road transportation costs are 5.16 French Francs per kilometer. ${ }^{6}$ The data also reveals a strong degree of variation in bilateral transportation costs: transportation costs

\footnotetext{
${ }^{4}$ Prior to Anderson and van Wincoop (2003), McCallum (1995) compares trade flows within Canada to flows between Canadian provinces and U.S. states, controlling for distance and regional GDPs. Everything else equal, crossing the border reduces trade by a factor as high as 22. For Europe, Nitsch (2000) finds that on average intranational trade is about 10 times higher than international one. Nitsch arrives at his results after controlling for cultural proximity (language), along other conventional gravity covariates. Wei (1996) constructs measures for imports of countries to themselves and compares this with imports from a statistically identical foreign country. He finds that the former magnitude is 2.5 times larger than the latter. Helliwell (1998) offers a comprehensive overview of the pre Anderson and van Wincoop state of the econometric literature.

${ }^{5}$ Okubo (2004) shows a border effect for trade between Japanese regions, Wolf (2000) for the US, and Combes et al. (2005) for their sample of French departments.

${ }^{6}$ Assuming an inflation rate of $3 \%$ a year and applying the FF/Euro conversion rate of 6.55957 , this would amount to about 1.25 Euro in 2008 current prices.
} 


\section{Figure 1 - Transportation costs and distance: a concave relationship}

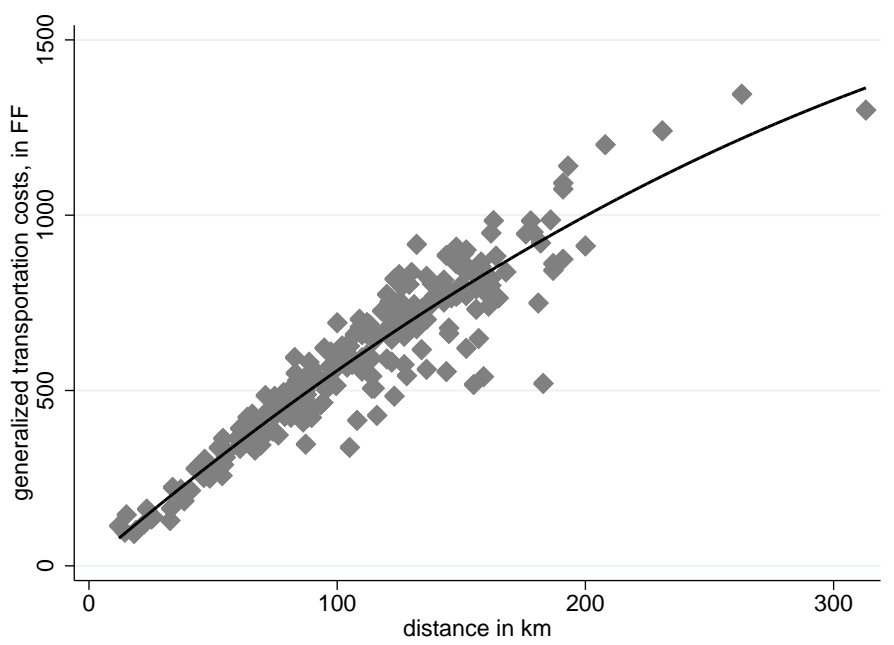

Notes. Generalized transportation costs between capitals of French departements in French Francs (1993) as a function of geographical distance in $\mathrm{km}$.

at the $5 \%$ percentile are 4.54 while at the $95 \%$ percentile they are 5.86 per kilometer. The standard deviation is 0.43 . Looking at the average per kilometer cost of transiting one of the 94 French departments, ${ }^{7}$ one discovers an even higher standard deviation of 1.12 . Only part of this variation is explained by variables such as economic activity, density, or topography. ${ }^{8}$

Fact 2: Transport costs are non-convex in distance. Usually, in economic geography models (Fujita et al., 1999), transportation costs are modeled as exponential functions of distance. ${ }^{9}$ However, the data reject convexity. Figure 1 provides an illustration based on data by Combes and Lafourcade (2005). Regressing the log of transportation costs between capitals of French départements on the log of geographical distance reveals an elasticity of 0.90 with a standard error of 0.02 . The hypothesis of the elasticity being equal to unity is rejected at the $1 \%$ level. ${ }^{10}$

\footnotetext{
${ }^{7}$ To obtain a measure of transit costs, we average total variable transport costs per kilometer between neighboring departements, using the neighbors' area as weights.

${ }^{8}$ In Appendix B (Table .1), we relate average transit costs to GDP, area and population of the respective department, the ruggedness of territory, and to geographical remoteness. We find that average transportation costs are higher in geologically difficult, less densely populated and poorer departments. Everything else equal, they are also higher in less central regions. Geography explains about 16\% of transport cost variation; adding GDP, area and population drives the explanatory power of the model up to $58 \%$. Hence, such a 'naive' model leaves about $40 \%$ of variance unexplained.

${ }^{9}$ See McCann (2005) for criticism.

${ }^{10}$ Using robust regression methods to punish outliers leads to an elasticity of 0.92 , still different from 1.00 at the $1 \%$ level. The same holds true if one restricts the sample to distances below 200, 150 or $100 \mathrm{~km}$.
} 
Table 1 - Intercontinental merchandise trade by transport mode: NAFTA and EU

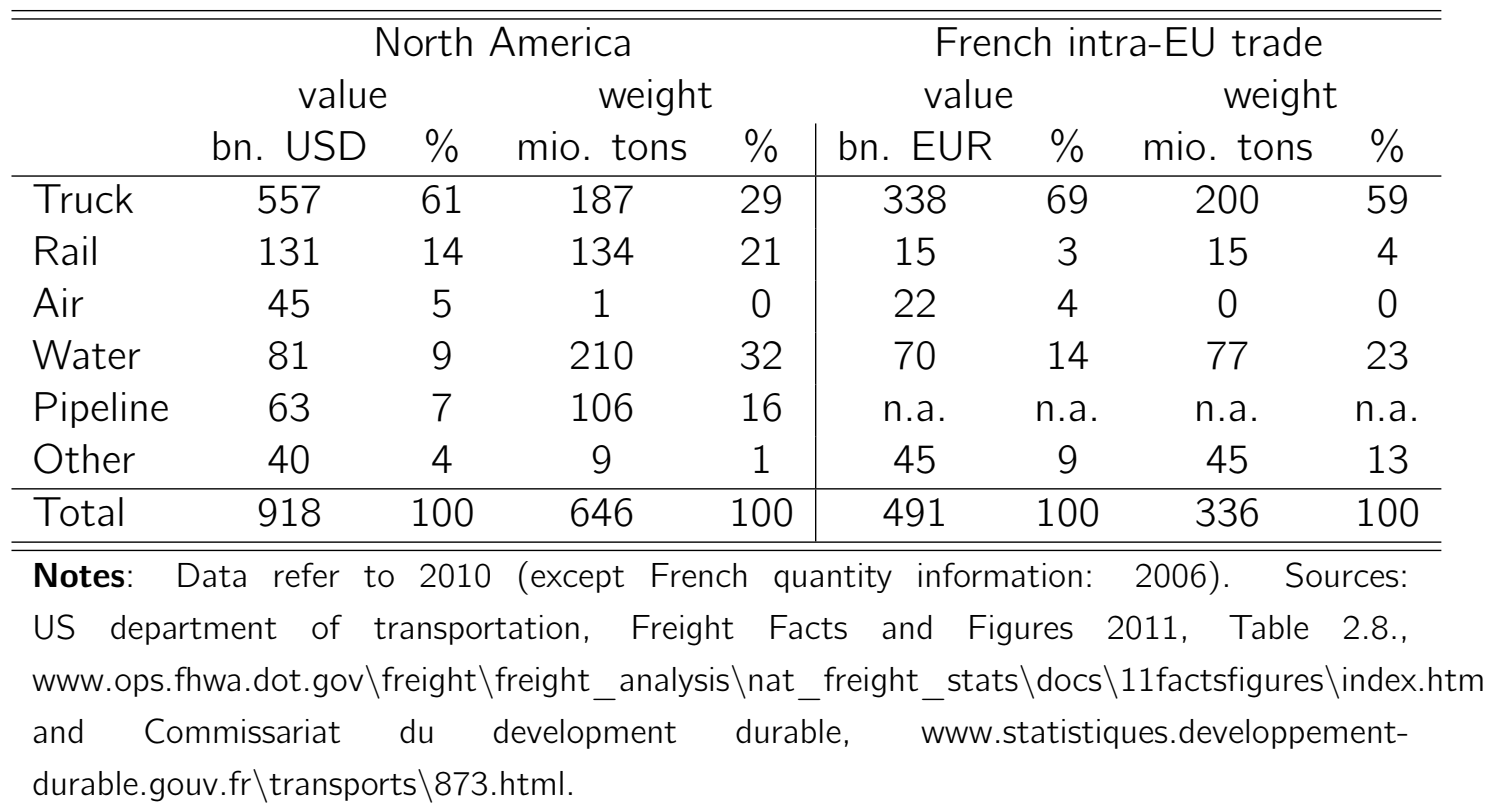

Fact 3: Infrastructure investment and transportation costs are closely related. A large empirical literature, already discussed in the introduction, establishes a close link between infrastructure investment, transportation costs, and the benefits of economic integration; see Limao and Venables (2001) on cross-country evidence, Allen and Arkolakis (2014) or Duranton et al. (2014) on US interstate highways, Donaldson (2014) and Donaldson and Hornbeck (2015) on railroads in India and the US, respectively, or Cosar and Demir (2015) on roads in Turkey.

Fact 4: Intracontinental trade flows are mostly land-borne. Table 1 reports data for merchandise trade within NAFTA and Europe. In 2010, between 72 and $75 \%$ of the value of total regional trade is transported on roads or railways. Measured by tonnage, the shares are lower as much bulk transportation is water-borne. While the importance of air-borne traffic is increasing, it still is almost irrelevant in intracontinental trade.

Fact 5: Transport infrastructure is publicly provided. Infrastructure and maintenance spending on roads amounts to about 1\% of GDP across OECD countries (average across 20012009). ${ }^{11}$ Countries with difficult territory (such as Japan, Switzerland or Italy) have higher than average spending. Almost all spending on roads and railways is financed by governments, even if private public partnership agreements are becoming increasingly popular.

\footnotetext{
${ }^{11}$ OECD Economic Outlook 91 database. There is some disagreement about measurement; the Congressional Budget Office puts total public spending for transportation and water infrastructure between $1.2 \%$ and $1.5 \%$ of GDP in the 1956-2007 period.
} 
Fact 6: Regional governments influence interregional infrastructure projects substantially. Within countries, there is a substantial amount of centralization of infrastructure planning and spending. Nonetheless, local governments matter, too. In the US, about $90 \%$ of all spending on infrastructure and equipment falls on the local or state level, but federal transfers have become quite important over time (Congressional Budget Office, 2010). In Europe, member states decide almost exclusively on their own about transport infrastructure investment projects. There is some coordination at the Union level through the so called Trans-European Transport Network, but the budget has been limited to about 1 billion Euro per year over the 2007-2013 spending period. This is less than $1 \%$ of overall spending on infrastructure in the EU (120 billion Euro). ${ }^{12}$

Fact 7: Distance elasticities and border effects in gravity models. A voluminous empirical literature finds that geographical distance restricts trade flows; see Head and Mayer (2014). In their meta analysis across appropriately specified gravity models, the authors find a median elasticity of trade flows with respect to great circle distance of about -1.1 and a median border effect (i.e., the trade inhibiting effect of a border as compared to trade within a country) of -1.6. In our empirical application using very recent European data, the distance elasticity is also -1.1 , but the border effect is $-0.8 .^{13}$

\section{Modeling transportation costs}

Models of international trade and economic geography typically employ Samuelson's (1952) iceberg trade costs assumption: in order to receive one unit of the good at some location $x$, $T(x, z) \geq 1$ units of that good have to leave the factory at location $z .{ }^{14}$ A share $1-T(x, z)^{-1}$ of the good 'melts' in transport; the share $T(x, z)^{-1}$ arrives at $x$ when one unit of the good is shipped at $z$. This formulation represents a dramatic simplification (McCann, 2005). But it has proved convenient, because it makes the introduction of a specific transportation sector redundant.

In this paper, we stick to the iceberg formulation, but we let transportation costs between two addresses $x$ and $z$ depend on cumulative infrastructure investment. Public infrastructure investment refers to the process of investing some resource at specific locations $s$ with the aim of reducing transportation costs. ${ }^{15}$ We assume that the set of geographic locations, $S$,

\footnotetext{
${ }^{12} \mathrm{http}: / /$ ec.europa.eu/transport/infrastructure/tentec/tentec-portal/site/en/abouttent.htm. In the period 20142020 , centralized spending rises about threefold. However, this still keeps decentralized spending at about $97 \%$ of total spending.

${ }^{13}$ We describe the data, methodology and results in Section 6 but mention our findings here, because they will inform the numerical illustrations of our theory.

${ }^{14} \mathrm{~A}$ popular specification in continuous space is $T(x, z)=e^{a|x-z|}$, with $a>0$; see Krugman (1991) or Fujita et al. (1999).

${ }^{15}$ Our model is static; hence, we use the terms infrastructure investment and stock of infrastructure interchangeably.
} 
is given by an interval, $[0, \bar{s}]$, where $\bar{s}$ characterizes the geographical size of the economy. In contrast to a circular economy, the linear specification appears preferable since it features a natural periphery. ${ }^{16}$

We model the effectively available stock of infrastructure over some interval $[x, z] \in S$ using a constant elasticity of substitution aggregator function

$$
I(x, z)=\left[\int_{x}^{z} i(s)^{1-\delta} d s\right]^{\frac{1}{1-\delta}}, \delta>1, x \leq z,
$$

where $i(s)$ is the level/stock of infrastructure at location $s \in[x, z]$ and $\delta>1$ is a constant technology parameter (which will turn out to be the elasticity of substitution between investments at different locations). $I(x, z)$ increases in distance. This formulation has the natural implication that spreading a constant investment budget $B$ over increasing distance $z-x$ lowers the available stock of $I(x, z)$. Note also that if $i(s)$ is equal to zero on some subset (with a positive measure) of $[x, z]$, then the available stock of infrastructure over the whole interval $[x, z]$ is zero.

The costs of transporting a product from $z$ to $x$ is linked to infrastructure by

$$
T(x, z)=\left(1+\frac{1}{\delta-1}|I(x, z)|^{1-\delta}\right)^{\gamma}, \delta>1, \gamma>0, x \leq z .
$$

Transportation costs are symmetric in the sense that delivering a product from $x$ to $z$ costs the same as delivering a product from $z$ to $x$. The parameter $\gamma$ governs the effect of the total stock of infrastructure on transportation costs.

The choice of functional forms (1) and (2) proves convenient, as will become transparent below. Moreover, the formulation has properties long discussed (but rarely formally modelled in a general equilibrium context) by transport economists (Winston, 1985, or Gramlich, 1994).

Lemma 1 Generalized iceberg trade costs $T(x, z)$ have the following properties:

(i) $T(x, z) \geq 1$ with $T(x, x)=1$ and $T(x, y) T(y, z) \geq T(x, z)$.

(ii) $T(x, z)=(1+a|z-x|)^{\gamma}$, if $i(s)$ is a constant $T$ over the interval $[x, z]$, and $a=\bar{\imath}^{1-\delta} /(\delta-1)$.

(iii) $T(x, z)=\infty$, if $i(s)=0$ on some subset (with a positive measure) of $[x, z]$.

(iv) $T(x, z)$ is increasing in distance: i.e. for fixed $x$ a more distant location $z$ results in higher transportation costs. Moreover, if $i(s)$ is a differentiable function on $S, T(x, z)$ is concave in distance if the distance-induced increment to the trade cost gradient is outweighed by an improvement in infrastructure. That is, if $(\gamma-1)[a(z)]^{2} /(T(x, z))^{1 / \gamma}<i^{\prime}(z) i(z)^{-\delta}$ where $a(z)=i(z)^{1-\delta} /(\delta-1)$.

\footnotetext{
${ }^{16}$ Unlike in a symmetric circular economy, in a linear economy, symmetry in terms of endowments or available technologies does not entail symmetry in infrastructure investments.
} 
(v) The (interregional) elasticity of substitution between infrastructure investment at different locations is $0<1 / \delta<1$, so that investments at different locations are gross complements.

(vi) Investment smoothing property: if investment costs do not vary across locations, then the cost-efficient way to achieve some exogenous target level of transportation costs involves a flat spatial investment profile

$$
i(s)=\left\{(z-x) /\left[(\delta-1)\left(\bar{T}^{1 / \gamma}-1\right)\right]\right\}^{1 /(\delta-1)} .
$$

where $\bar{T}>1$ is the target level of iceberg transportation costs.

Proof The first three properties directly follow from the definition of the trade costs in (2). The last three properties are proved in Appendix $A$.

Property (i) establishes that, for any $x, y$, and $z$, the triangle inequality holds: $T(x, y) T(y, z) \geq$ $T(x, z)$ (the strict inequality holds, if $x, y$, and $z$ represent different locations). So, it is cheaper to transport products directly to a destination address, rather than through some intermediate address.

Property (ii) shows that equation (2) collapses to the specification almost exclusively used in empirical gravity models (with $a=1$ ); see Head and Mayer (2014). Our specification also allows for concavity of transportation costs with respect to distance documented in the data. Iceberg transportation costs are concave in distance, as long as the component of $d T(x, z) / d z$ driven by variation in infrastructure investment outweighs the pure distance component of $d T(x, z) / d z$ (see property (iv) in the above lemma). Hence, in general, whether $T(x, z)$ is concave in distance depends on the spatial allocation of infrastructure investment and the values of $\gamma$ and $\delta$.

Properties (v) and (vi) exploit an isomorphism between (2) and the usual representation of utility in an optimal growth model. The parameter $\delta$ measures the ease with which infrastructure investment at some address can substitute for investment at another place. The restriction $\delta>1$ ensures that investments at different places are gross complements: investment at some address makes investment at some other place more worthwhile, which seems realistic and is consistent with the data. ${ }^{17}$

\section{Infrastructure investment and intraregional trade}

In a first step, we incorporate our modeling of transportation costs and infrastructure into a simple model of intranational trade. Later we introduce international trade.

\footnotetext{
${ }_{17}$ We do not allow for incremental transport costs incurred at address $s$ to depend on the volume of traffic transiting through $s$. Actually, in equilibrium, the contrary will hold: more traffic at $s$ will encourage the planner to invest more in infrastructure, thereby driving down the gradient of $T$. This lowers the incremental trade costs at $s$ for all units of goods that transit through $s$.
} 


\subsection{Geographical space and goods space}

We assume that, at each location $s \in S$, there is a representative household who inelastically supplies $m(s)>0$ units of labor. The total endowment of labor in the economy is then equal to $\int_{s \in S} m(s) d s$, which we define as $L$.

Each location produces both a homogeneous agricultural and a spatially differentiated industrial good. Consumers consume both goods and perceive industrial goods produced at specific locations as imperfect substitutes. There are no costs of transporting the agricultural good. Moreover, the agricultural good serves as an input into infrastructure provision. ${ }^{18}$ Each location $s$ is home of consumers and producers. We denote addresses of consumers by $x$ and addresses of producers by $z$.

We assume that locations may differ with respect to topological circumstances. Specifically, infrastructure at address $s$ is produced according to a linear production function $i(s)=b(s) / q(s)$, where $b(s)$ denotes the input of the agricultural good used for infrastructure investment, and $1 / q(s)>0$ measures the rate at which that resource is transformed into infrastructure. We restrict $q(s)$ to be continuously differentiable. Feasibility of an investment policy $i(s)$ requires $\int_{s \in S} q(s) i(s) \leq B$, where $B$ is the amount of agricultural good invested in infrastructure and will be endogenously determined by government policy.

\subsection{Consumption}

The utility function of a representative household at location $x$ is a monotone transformation of a Cobb-Douglas aggregate over the homogeneous agricultural good and a Dixit-Stiglitz aggregate over industrial goods:

$$
U(x)=\left[c^{A}(x)\right]^{\frac{\alpha \rho}{(1-\alpha)(1-\rho)}}\left(\int_{z \in S} c^{\prime}(x, z)^{\rho} d z\right)^{\frac{1}{1-\rho}},
$$

with $\alpha \in(0,1), 0<\rho<1$, where $c^{A}(x)$ denotes the total quantity of the agricultural good consumed at address $x$ and $c^{\prime}(x, z)$ is the quantity of an industrial variety produced at address $z$ and consumed at $x .^{19}$

Let $Y^{n}(x)$ denote household $x^{\prime} s$ net income in terms of a numeraire to be defined below. Then, the budget constraint of household $x$ is $Y^{n}(x)=c^{A}(x) p^{A}(x)+\int_{z \in S} c^{\prime}(x, z) p^{\prime}(x, z) d z$, where

\footnotetext{
${ }^{18}$ The assumption of a freely tradable agricultural good which is produced at every location is frequently used in models of economic geography. It provides tractability as wages are equalized across space (in nominal terms). An alternative/equivalent way to model infrastructure provision is to assume that the only input into infrastructure is labor, which in turn is perfectly mobile between locations (within an economy). But consumption takes place at the place of origin. This will equalize wages across locations (which is in the present model done by the presence of the homogenous agricultural good) making the presence of the agricultural good redundant.

${ }^{19}$ Notice that $U(x)$ is a positive monotonic transformation $U(x)=[\tilde{U}(x)]^{\rho /((1-\alpha)(1-\rho))}$ of the usual Cobb-Douglas formulation $\tilde{U}(x)=\left[c^{A}(x)\right]^{\alpha}\left[u^{\prime}(x)\right]^{1-\alpha}$. The transformation makes the theoretical analysis of the model more tractable (without qualitatively changing the main conclusions).
} 
$p^{A}(x)$ is the price of the agricultural good at location $x$ and $p^{\prime}(x, z)$ is the price of a variety imported from location $z$ and consumed at $x$.

The utility maximization problem implies that the demand functions for the agricultural good and a certain variety of the industrial good are respectively

$$
c^{A}(x)=\frac{\alpha Y^{n}(x)}{p^{A}(x)} \text { and } c^{\prime}(x, z)=(1-\alpha) Y^{n}(x) \frac{p^{\prime}(x, z)^{-\sigma}}{P^{\prime}(x)^{1-\sigma}}
$$

where $\sigma \equiv 1 /(1-\rho)$ and

$$
P^{\prime}(x)=\left[\int_{z \in S} p^{\prime}(x, z)^{1-\sigma} d z\right]^{\frac{1}{1-\sigma}}
$$

is the price index for industrial goods at location $x$.

The indirect utility attainable at prices $p^{A}(x), p^{\prime}(x, z)$ and income $Y^{n}(x)$ can be written as

$$
V(x)=A\left[p^{A}(x)\right]^{-\alpha \rho /((1-\alpha)(1-\rho))}\left[P^{\prime}(x)\right]^{1-\sigma}\left(Y^{n}(x)\right)^{\rho /((1-\alpha)(1-\rho))},
$$

where $A \equiv\left(\alpha^{\alpha /(1-\alpha)}(1-\alpha)\right)^{\rho /(1-\rho)}$

\subsection{Production}

At each location $z \in S$, the agricultural and the industrial good are produced under conditions of perfect competition. The only input of production is labor. Production functions for the two types of goods are linear $y^{A}(z)=b l^{A}(z)$ and $y^{\prime}(z)=l^{\prime}(z)$, where $b>0$ is a productivity parameter common to all locations. Output quantities are denoted by $y^{A}(z)$ and $y^{\prime}(z)$, and labor inputs by $I^{A}(z)$ and $I^{\prime}(z)$, respectively.

We assume that, within addresses, workers are perfectly mobile across agricultural and industrial firms. This in turn implies that $p^{A}(z)=w(z) / b$ and $p^{\prime}(z)=w(z)$, where $w(z)$ is the wage rate (expressed in units of numeraire) at address $z$. Industrial goods bear transportation costs. We assume that there are no trade costs other than transportation costs. ${ }^{20}$ Hence, the c.i.f. prices faced by consumers differ from the f.o.b. (ex-factory) prices. In particular, a household at $x$ faces the price $p^{\prime}(x, z)=p^{\prime}(z) T(x, z)$ for a variety of the industrial good imported from location $z$. In contrast, the agricultural good can be transported freely.

\subsection{Equilibrium}

In this paper, we impose a non-full-specialization (NFS) assumption: there is always a strictly positive quantity of agricultural production at each location. The NFS assumption introduces

\footnotetext{
${ }^{20}$ In Section 5, when we consider international trade, we will introduce a discrete trade friction at the border.
} 
factor price equalization in terms of the agricultural good. ${ }^{21}$ We may therefore choose the agricultural good as the numeraire and set $p^{A}(z)=1$ for all $z \in S$. Since $p^{A}(z)=1$ for any $z$, we drop the superscripts $A$ and $/$ in the following.

As the price of the agricultural good is normalized to unity, the wage rate at location $z, w(z)$, is equal to $b$. The gross income at location $x$ in terms of the numeraire is then $Y(x)=b m(x)$. Finally, from our assumption on technology, the c.i.f. prices of industrial goods are $p(x, z)=$ bT $(x, z)$.

The government imposes a lump-sum tax with rate $t$, which is assumed identical across addresses $s \in S$. Thus, the net income at location $x, Y^{n}(x)$, is $(1-t) b m(x)$. Total tax income is

$$
B=b t \int_{s \in S^{c}} m(s) d s=b t L .
$$

Substituting the expressions for net household income and for the price index, we can now rewrite the indirect utility function in (6) as

$$
V(x)=\Omega(1-t)^{(\sigma-1) /(1-\alpha)} \tilde{m}(x)\left[\int_{z \in S} T(x, z)^{1-\sigma} d z\right]
$$

where $\tilde{m}(x)=m(x)^{(\sigma-1) /(1-\alpha)}$ and $\Omega \equiv\left(\alpha^{\alpha /(1-\alpha)}(1-\alpha) b^{\alpha /(1-\alpha)}\right)^{\rho /(1-\rho)}$ is a constant.

\subsection{The choice of infrastructure investment}

In this section, we characterize optimal policies $\left\{i^{a}(s), t^{a}\right\}_{s \in S}$ in a closed economy. The social planner chooses the infrastructure investment and the tax rate to maximize total welfare - the sum of individual utilities - in the economy. Ignoring the irrelevant constant, we have

$$
\left\{i^{a}(x), t^{a}\right\}_{x \in S}=\arg \max \left\{(1-t)\left(\int_{x \in S} \tilde{m}(x) v(x) d x\right)^{\frac{1-\alpha}{\sigma-1}} \mid \int_{x \in S} q(x) i(x) d x \leq b t L\right\},
$$

where

$$
v(x)=\int_{z \in S} T(x, z)^{1-\sigma} d z
$$

A sufficient condition for concavity of the objective function in (8) is

$$
1+(\gamma(\delta-1))^{-1}>\sigma>2-\alpha .
$$

The first inequality means that $T(x, z)^{1-\sigma}$ is concave with respect to infrastructure investments, implying that the consumption utility, $v(x)$, is concave in infrastructure investments as well. ${ }^{22}$

\footnotetext{
${ }^{21}$ Relaxing the NFS assumption would allow to study the interaction between infrastructure investment policies and regional specialization patterns. This is an interesting issue that raises additional complications. It is therefore left to future research.

${ }^{22}$ The function $\left(1+\frac{1}{\delta-1} x^{1-\delta}\right)^{\gamma(1-\sigma)}$ is strictly concave on $[0, \infty)$ if and only if $\gamma(\sigma-1)(\delta-1)<1$. In turn, $T(x, z)^{1-\sigma}$ is concave with respect to infrastructure investment.
} 
The second inequality, which would be always met if $\sigma \geq 2$, implies that the objective function is concave in $v(x)$. As a result, the objective function is concave with respect to infrastructure investments. ${ }^{23}$

Next, we characterize the solution of the planner's problem. Note that, without loss of generality, we find the solution among continuous functions on $[0, \bar{s}]$. That is, social welfare is maximized with respect to $i^{a}(x)$, where $i^{a}(x)$ is continuous.

Proposition 1 The optimal allocation of infrastructure spending across space and the optimal tax rate chosen by a social planner under autarky are implicitly determined by the following system of equations:

$$
\begin{aligned}
i^{a}(x)^{\delta} & =\frac{b \gamma(1-\alpha)\left(1-t^{a}\right) L}{q(x)}\left[\phi^{L}(x)+\phi^{R}(x)\right], \\
t^{a} & =\frac{\int_{s \in S} q(s) i^{a}(s) d s}{b L},
\end{aligned}
$$

where $\phi^{L}(x)$ and $\phi^{R}(x)$ denote aggregate marginal utilities from investing to the left or the right of $x$, respectively, and are defined as

$$
\begin{aligned}
\phi^{L}(x) & =\frac{\int_{0}^{x} \tilde{m}(s)\left[\int_{x}^{\bar{s}}\left(1+\frac{1}{\delta-1} \int_{s}^{t} i^{a}(r)^{1-\delta} d r\right)^{\gamma(1-\sigma)-1} d t\right] d s}{\int_{s \in S} \tilde{m}(s) v(s) d s}, \\
\phi^{R}(x) & =\frac{\int_{x}^{\bar{s}} \tilde{m}(s)\left[\int_{0}^{x}\left(1+\frac{1}{\delta-1} \int_{t}^{s} i^{a}(r)^{1-\delta} d r\right)^{\gamma(1-\sigma)-1} d t\right] d s}{\int_{s \in S} \tilde{m}(s) v(s) d s} .
\end{aligned}
$$

Proof In the Appendix.

The investment at location $x$ is higher, the larger the sum $\phi^{L}(x)+\phi^{R}(x)$ or the lower the cost of infrastructure at the location, $q(x)$. In the next proposition, we summarize some additional properties of the optimal infrastructure investment function, $i^{a}(x)$, and the consumption utility, $v(x)$.

Proposition 2 The optimal infrastructure investment function, $i^{a}(x)$, and the consumption utility, $v(x)$, have the following properties:

(i) The infrastructure investments are zero at the borders of the region: $i^{a}(\bar{s})=i^{a}(0)$.

\footnotetext{
${ }^{23}$ Our results are qualitatively robust to changes in the functional form of the transportation costs as long as $T(x, z)^{1-\sigma}$ is concave in $i(s), s \in[x, z]$, and has an unbounded derivative at $i(s)=0$.
} 
(ii) If $q(x)$ is continuously differentiable, $i^{a}(x)$ is increasing in the neighborhood of zero and decreasing in the neighborhood of one: specifically, $\left(i^{a}(x)\right)_{x=0}^{\prime}=\infty$ and $\left(i^{a}(x)\right)_{x=\bar{s}}^{\prime}=-\infty$.

(iii) If there is no variation in the cost of infrastructure investment and the household size across the locations: $q(x)=q$ and $m(x)=m$ for any $x \in S$, then $v(x)$ and $i^{a}(x)$ are symmetric around $x=\bar{s} / 2$ and have a hump shape with maximum at $x=\bar{s} / 2$.

Proof The first property immediately follows from the definitions of $\phi^{L}(x)$ and $\phi^{R}(x)$. Specifically, we have that $\phi^{L}(\bar{s})=\phi^{L}(0)=\phi^{R}(\bar{s})=\phi^{R}(0)=0$. The last two properties are established in the Appendix.

According to the proposition, if there is no variation in the cost of infrastructure and in household size, the optimal infrastructure is symmetric around the middle point of the $[0, \bar{s}]$-interval. So, transportation costs in central parts of the country are lower than in peripheral parts and, thereby, households located closer to the middle point have higher indirect utility. The intuition is that, at the optimum, the sum of marginal benefits from investment needs to be equalized to the constant cost of investment at each location and this is achieved by higher investment in central locations.

\subsection{Comparative statics}

The optimal infrastructure investment at location $x$ is implicitly determined by

$$
\begin{aligned}
i^{a}(x) & =\left(\frac{\gamma(1-\alpha)\left(b L-\int_{s \in S} q(s) i^{a}(s) d s\right)}{q(x)}\left(\phi^{L}(x)+\phi^{R}(x)\right)\right)^{1 / \delta} \\
& \equiv i^{a}\left(x, I^{a}, \epsilon\right),
\end{aligned}
$$

where $I^{a}$ represents the infrastructure profile in the economy and $\epsilon$ is the set of parameters in the model. Thus, changes in $i^{a}(x)$ due to changes in $\epsilon$ are implicitly determined by

$$
\frac{\partial i^{a}(x)}{\partial \epsilon}=\frac{\partial i^{a}\left(x, I^{a}, \epsilon\right)}{\partial \epsilon}+\frac{\partial i^{a}\left(x, I^{a}, \epsilon\right)}{\partial l^{a}} \frac{\partial l^{a}}{\partial \epsilon} .
$$

The first term in the right-hand side of (14) captures the direct effect of $\epsilon$ on $i^{a}(x)$, while the second term stands for the indirect effects.

Proposition 3 Changes in the parameters in the model have the following effects on the optimal infrastructure profile in a closed economy:

(i) A rise in $b$ increases $i^{a}(x)$ for all $x$.

(ii) Assuming that $m(x)=m$ for all $x$, a rise in $m$ increases $i^{a}(x)$ for all $x$.

(iii) Assuming that $q(x)=q$ for all $x$, a rise in $q$ decreases $i^{a}(x)$ for all $x$. 
Figure 2 - Closed economy equilibrium investment loci: comparative statics

(a) Moving $\bar{s}$ from 500 to 700

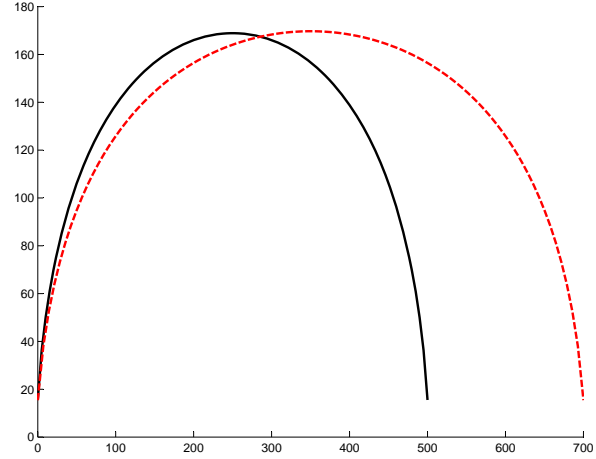

(c) Moving $\sigma$ from 2.7 to 2.0

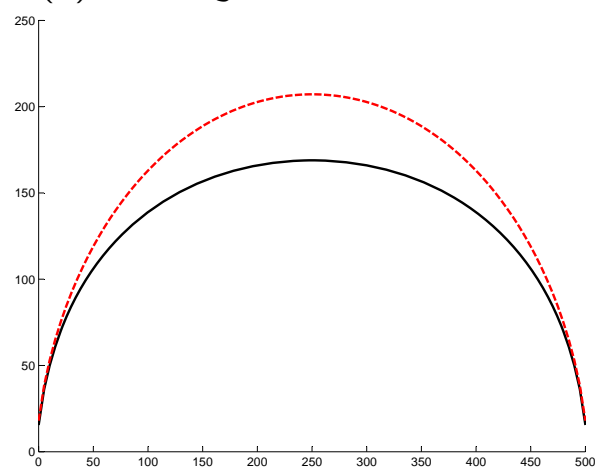

(b) Moving $\gamma$ from 0.86 to 0.7

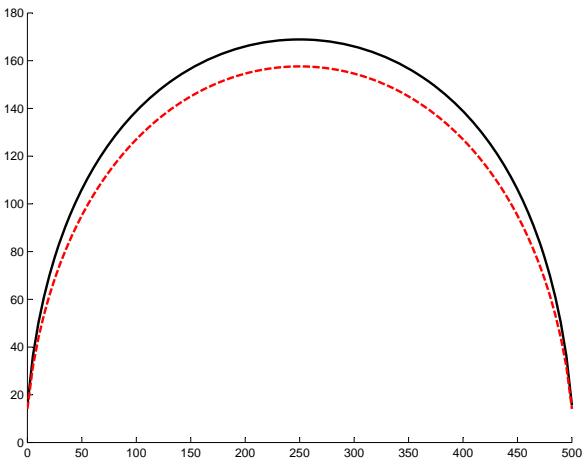

(d) Moving $\delta$ from 1.65 to 1.5

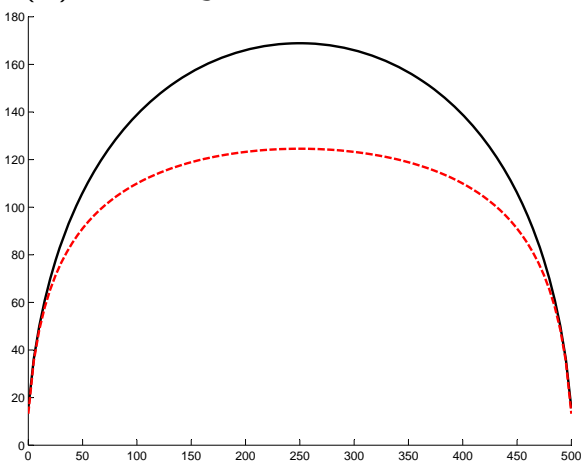

Notes. Solid black curve: default investment distribution with $\sigma=2.7, \delta=1.65, \gamma=0.86, \alpha=0.5$, $q(x)=q=1, m(x)=m=1000, b=1$, and $\bar{s}=500$. Dashed red curves: distributions resulting from alternative parameterizations. See Table 2 for calibration details.

(iv) Assuming that $m(x)=m$ for all $x$, a rise in $\bar{s}$ has a positive direct effect on $i^{a}(x)$ for $x$ close to the right border and has an ambiguous impact on the investments at the other locations. If in addition $q(x)=q$ for all $x$, then a rise in $\bar{s}$ has a positive direct effect on $i^{a}(x)$ for all $x \in S$.

Proof In the Appendix.

While parts (i) to (iii) of Proposition 3 account for direct and indirect effects, part (iv) describes only the direct effect of an increase in $\bar{s}$ (which, holding population density constant, amounts to an enlargement of a country, such as the reunification of Germany in 1990). Figure 2(a) provides a numerical illustration of the overall effect of a rise in $\bar{s}$ on the infrastructure profile. ${ }^{24}$ Enlargement of a country diverts investment away from locations sufficiently far from the added

\footnotetext{
${ }^{24}$ In the figure we consider a discrete variation of the model that has similar properties as the continuous model (see more on the choice of the parameterization in Section 5.3).
} 
territory. This is consistent with the German post-reunification experience. ${ }^{25}$

The formal analysis of the comparative statics with respect to $\gamma, \delta$, and $\sigma$ is not tractable; so, we turn to numerical experiments. A lower value of $\gamma$ makes the dependence of transportation costs on infrastructure investments weaker. Therefore, the returns from investing in infrastructure at all locations are smaller, leading to lower $i^{a}(x)$ at all locations (Figure 2(b)). Lower $\sigma$ makes the varieties of the differentiated product less substitutable, increasing the benefits of intra- and international trade. As a result, incentives to invest in infrastructure go up and, therefore, $i^{a}(x)$ rises ((Figure $2(c)$ ). In contrast, changing $\delta$ has an ambiguous impact on infrastructure investment. With the chosen parameterization, a decrease in $\delta$ from 1.65 to 1.5 makes investments at different locations more easily substitutable. This decreases infrastructure investments at all locations and also lowers the spatial variance of investment (Figure 2(d)).

\section{Infrastructure investment and international trade}

Now, we assume that the world economy consists of two independent countries, each with its own government that decides on infrastructure investment in a non-cooperative way. However, consumers demand goods from all over the world. Thus, we have a situation with 'globalized markets, but regional politics'. Otherwise, we maintain all earlier assumptions. To start with, we assume that countries are symmetric. In particular, the world geography is described by the $[0,2 \bar{s}]$-interval, where locations from $[0, \bar{s}]$ and $(\bar{s}, 2 \bar{s}]$ represent the home and the foreign country, respectively. To isolate a pure border effect on the equilibrium infrastructure profile we assume away any variation in the costs of infrastructure and in household size across locations: i.e., $q(x)=q$ and $m(x)=m$ for all $x \in[0,2 \bar{s}] .{ }^{26}$ Finally, we suppose that trade between locations in different countries is subject to an exogenous discrete (i.e., independent from distance) border friction denoted by $\tau \geq 1$. That is, the cost of delivering one unit of a product produced at foreign location $z$ to domestic location $x$ is $\tau T(x, z)$, where $T(x, z)$ is modeled as before.

\subsection{World planner problem}

We start with a description of the first-best situation, in which economic and political space coincide. Such a world planner problem is characterized as follows:

$$
\left\{i^{w}(x), t^{w}\right\}_{x \in[0,2 \bar{s}]}=\arg \max _{i(x), t}\left\{(1-t)\left(\int_{0}^{2 \bar{s}} v(x) d x\right)^{\frac{1-\alpha}{\sigma-1}} \mid q \int_{0}^{2 \bar{s}} i(x) d x \leq 2 b L t\right\},
$$

\footnotetext{
${ }^{25}$ See the information on www. bmvi.de/SharedDocs/DE/Artikel/StB/entwicklung-der-autobahnen-in-deutschland-seit-derwiedervereinigung.html.

${ }^{26}$ The framework can be easily extended to the case when $q(x)$ and $m(x)$ are symmetric around $x=\bar{s}$.
} 
where $v(x)$ is utility at address $x$ given by $v(x)=\int_{0}^{2 \bar{s}} \tau^{(1-\sigma) l(x, z)} T(x, z)^{1-\sigma} d z$ and $L$ is population size in each country. ${ }^{27}$ The world planner problem looks very similar to the social planner problem in the case of a closed economy. The only difference is that geographical space is now given by the $[0,2 \bar{s}]$-interval and trade between locations in different countries incurs extra costs. Hence, we can formulate the following proposition.

Proposition $4 \quad$ The optimal allocation of infrastructure spending across the world geography and the optimal tax rate chosen by the world planner are implicitly determined by the following system of equations:

$$
\begin{aligned}
i^{w}(x)^{\delta} & =\frac{2 b L \gamma(1-\alpha)\left(1-t^{w}\right)}{q}\left(\phi^{L, w}(x, \tau)+\phi^{R, w}(x, \tau)\right), \\
t^{w} & =\frac{q \int_{0}^{2 \bar{s}} i^{w}(s) d s}{2 b L},
\end{aligned}
$$

where

$$
\begin{aligned}
\phi^{L, w}(x, \tau) & =\frac{\int_{0}^{x}\left[\int_{x}^{2 \bar{s}} \tau^{(1-\sigma) /(t, s)}\left(1+\frac{1}{\delta-1} \int_{s}^{t} i^{w}(r)^{1-\delta} d r\right)^{\gamma(1-\sigma)-1} d t\right] d s}{\int_{0}^{2 \bar{s}} v(s) d s}, \\
\phi^{R, w}(x, \tau) & =\frac{\int_{x}^{2 \bar{s}}\left[\int_{0}^{x} \tau^{(1-\sigma) /(t, s)}\left(1+\frac{1}{\delta-1} \int_{t}^{s} i^{w}(r)^{1-\delta} d r\right)^{\gamma(1-\sigma)-1} d t\right] d s}{\int_{0}^{2 \bar{s}} v(s) d s},
\end{aligned}
$$

where $I(t, s)=1$ if locations $t$ and $s$ belong to different countries and 0 otherwise.

Proof The proof is exactly the same as that for Proposition 1.

When $\tau$ is equal to unity, the properties of the world planner solution are the same as those for the autarky planner case; see Proposition 2. In particular, the infrastructure profile has a hump shape with maximum at $\bar{s}$. However, when $\tau>1$, the infrastructure profile chosen by the world planner has a double-hump shape (see details in the Appendix). At Home it is decreasing around the border $\bar{s}$, at Foreign it is increasing. Due to the presence of the border friction, the infrastructure profile in the countries is skewed towards internal locations compared to the case with no border friction.

\subsection{Global economics, regional politics}

We assume that two independent governments play a Nash game and set their infrastructure investment schedules non-cooperatively.

\footnotetext{
${ }^{27}$ The constraint in the maximization problem is $q \int_{0}^{2 \bar{s}} i(x) d x \leq b t \int_{0}^{2 \bar{s}} m(x) d x=2 b \bar{s} m=2 b L$, where $L$ is the size of the countries.
} 
The game is defined as $\Gamma=\left(I, U_{i}, \Theta_{i}\right)$, where $I=\{H, F\}$ represents the set of countries, $\Theta_{i}$ is country i's strategy set $(i \in I)$, and $U_{i}$ is country i's payoff functional defined on $\Theta_{H} \times \Theta_{F}$. In the context of the present framework, Home's strategy set, $\Theta_{H}$, is given by $\left\{i^{H}(x), t^{H}\right\}_{x \in[0, \bar{s}]}$, where $i^{H}(x) \geq 0, \int_{0}^{\bar{s}} i^{H}(x) d x \leq b L t^{H} / q$, and $t^{H} \in[0,1]$. Similarly, $\Theta_{F}$ is the set of $\left\{i^{F}(x), t^{F}\right\}_{x \in[\bar{s}, 2 \bar{s}]}$, where $i^{F}(x) \geq 0, \int_{\bar{s}}^{2 \bar{s}} i^{F}(x) d x \leq b L t^{F} / q$, and $t^{F} \in[0,1]$. Here, $i^{H}(x)$ and $i^{F}(x)$ are continuous on $[0, \bar{s}]$ and $[\bar{s}, 2 \bar{s}]$, respectively. Finally, the countries' payoffs are represented by the corresponding countries' total welfare functions. ${ }^{28}$

Since the countries are symmetric, in the following analysis we focus on the home country only. Given the infrastructure profile and the tax rate in the foreign country, the social planner at home solves the following maximization problem:

$$
\left\{i^{H}(x), t^{H}\right\}_{x \in[0, \bar{s}]}=\arg \max _{t, i(x)}\left\{(1-t)\left(\int_{0}^{\bar{s}} v(x) d x\right)^{\frac{1-\alpha}{\sigma-1}} \mid q \int_{0}^{\bar{s}} i(x) d x \leq b L t\right\},
$$

where

$$
v(x)=\int_{0}^{2 \bar{s}} \tau^{(1-\sigma) l(x, z)} T(x, z)^{1-\sigma} d z .
$$

As agents consume both domestic and foreign products, consumption utility, $v(x)$, depends not only on domestic infrastructure investment, but also on the foreign investment. As a result, foreign infrastructure investment affects the choice of infrastructure investment in the home country, and vice versa. The next lemma describes the best response of the home social planner given a certain infrastructure profile in the foreign country.

\footnotetext{
${ }^{28}$ As the Nash equilibrium in the above game, we consider the limit of the Nash equilibrium in the corresponding discrete approximation $\Gamma_{n}=\left(I, U_{i n}, \Theta_{i n}\right)$ (in other words, the equilibrium in game $\Gamma$ is considered as the limit $(n \rightarrow \infty)$ of the equilibrium in game $\left.\Gamma_{n}\right)$. To formulate $\Gamma_{n}$, we consider a uniform partition of the $[0,2 \bar{s}]$-interval given by $\left\{x_{i}\right\}_{i=0.2 n}$, where $x_{0}=0, x_{n}=\bar{s}$, and $x_{2 n}=2 \bar{s}$. In this case, the set of strategies of the home country, $\Theta_{H n}$ in country $i$ is given by $\left\{i^{H}\left(x_{i}\right), t^{H}\right\}_{i=0 . . n}$, where $i^{H}\left(x_{i}\right) \geq 0, \sum_{i=0}^{n} i^{H}\left(x_{i}\right) \triangle_{n} \leq b L t^{H} / q$, and $t^{H} \in[0,1]$ (here, $\triangle_{n}=\bar{s} / n$ is the partition size). In the same way, $\Theta_{F n}$ is the set of $\left\{i^{F}\left(x_{i}\right), t^{F}\right\}_{i=[n+1,2 n]}$ (without loss of generality, we assume that location $n$ belongs to the home country), where $i^{F}\left(x_{i}\right) \geq 0, \sum_{i=n+1}^{2 n} i^{F}\left(x_{i}\right) \triangle_{n} \leq b L t^{F} / q$, and
} $t^{F} \in[0,1]$. The countries' payoffs are then the following:

$$
\begin{aligned}
& U_{H n}=\left(1-t^{H}\right)\left(\sum_{i=0}^{n} v\left(x_{i}\right) \triangle_{n}\right)^{\frac{1-\alpha}{\sigma-1}}, \\
& U_{F n}=\left(1-t^{F}\right)\left(\sum_{i=n+1}^{2 n} v\left(x_{i}\right) \triangle_{n}\right)^{\frac{1-\alpha}{\sigma-1}},
\end{aligned}
$$

where

$$
v\left(x_{i}\right)=\sum_{j=0}^{2 n} \tau^{(1-\sigma) l\left(x_{i}, x_{j}\right)} T\left(x_{i}, x_{j}\right)^{1-\sigma} \triangle_{n} .
$$

It is straightforward to see that the game $\Gamma_{n}$ has a Nash equilibrium in pure strategies. This is due to the fact that the strategy sets are non-empty, convex, and compact subsets of a metric vector space and the payoff functions are continuous on $\Theta_{H n} \times \Theta_{F n}$ and concave in the own strategy of a player: i.e., $U_{i n}$ is concave on $\Theta_{i n}$. 
Lemma 2 Given an infrastructure profile in the foreign country, $\left\{i^{F}(x)\right\}_{x \in(\bar{s}, 2 \bar{s}]}$, the home social planner chooses an infrastructure investment schedule and a tax rate, $\left\{i^{H}(x), t^{H}\right\}_{x \in[0, \bar{s}]}$, such that the following equations are satisfied:

$$
\begin{aligned}
i^{H}(x)^{\delta} & =\frac{b L \gamma(1-\alpha)\left(1-t^{H}\right)}{q}\left(\tilde{\phi}^{L}(x, \tau)+\tilde{\phi}^{R}(x, \tau)\right), \\
t^{H} & =\frac{q \int_{0}^{\bar{s}} i^{H}(x) d x}{b L},
\end{aligned}
$$

where

$$
\begin{aligned}
\tilde{\phi}^{L}(x, \tau)= & \frac{\int_{0}^{x}\left[\int_{x}^{\bar{s}}\left(1+\frac{1}{\delta-1} \int_{s}^{t} i^{H}(r)^{1-\delta} d r\right)^{\gamma(1-\sigma)-1} d t\right] d s}{\int_{0}^{\bar{s}} v(s) d s} \\
& +\frac{\tau^{1-\sigma} \int_{0}^{x}\left(\int_{\bar{s}}^{2 \bar{s}}\left(1+\frac{1}{\delta-1} \int_{s}^{\bar{s}} i^{H}(r)^{1-\delta} d r+\frac{1}{\delta-1} \int_{\bar{s}}^{t} i^{F}(r)^{1-\delta} d r\right)^{\gamma(1-\sigma)-1} d t\right) d s}{\int_{0}^{\bar{s}} v(s) d s}, \text { and } \\
\tilde{\phi}^{R}(x, \tau)= & \frac{\int_{x}^{\bar{s}}\left[\int_{0}^{x}\left(1+\frac{1}{\delta-1} \int_{t}^{s} i^{H}(r)^{1-\delta} d r\right)^{\gamma(1-\sigma)-1} d t\right] d s}{\int_{0}^{\bar{s}} v(s) d s} .
\end{aligned}
$$

Proof In the Appendix.

The optimal infrastructure profile in an open economy has a similar form as the one of a closed economy. The main difference is the expression for $\tilde{\phi}^{L}(x, \tau)$ which represents the aggregate marginal welfare gains from a rise in $i^{H}(x)$ to the left of location $x$. The reason is that infrastructure investments at location $x$ affect the transportation costs from all foreign locations to the locations on the left of $x$ (as the foreign country is located on the right of $x$ ). This leads to additional welfare gains from a rise in infrastructure investment at location $x$ compared to the closed economy case. As a result, in contrast to the closed economy case, $i^{H}(x)$ is strictly greater than zero at $x=\bar{s}$ if and only if $i^{F}(x)$ is strictly positive in some right neighborhood of $x=\bar{s}$. If $i^{F}(x)$ is equal to zero in some right neighborhood of $x=\bar{s}$, then $\tilde{\phi}^{L}(x)$ is exactly the same function as in the case of a closed economy, because the transportation costs from foreign locations are infinitely high. Finally, as in the closed economy case, the infrastructure investment at location $x=0$ is zero: $i^{H}(0)=0$.

In the symmetric Nash equilibrium of the game, countries' equilibrium infrastructure profiles are symmetric around $x=\bar{s}$, such that $i^{F}(x)=i^{H}(2 \bar{s}-x)$ for $x \in[\bar{s}, 2 \bar{s}]$. Using Lemma 2, we may formulate the next proposition.

Proposition $5 \quad$ In the symmetric Nash equilibrium, the equilibrium home infrastructure profile 
and tax rate are implicitly determined by the following system of equations:

$$
\begin{aligned}
i^{H}(x)^{\delta} & =\frac{b L \gamma(1-\alpha)\left(1-t^{H}\right)}{q}\left(\tilde{\phi}^{L, N}(x, \tau)+\tilde{\phi}^{R, N}(x, \tau)\right), \\
t^{H} & =\frac{q \int_{0}^{\bar{s}} i^{H}(x) d x}{b L},
\end{aligned}
$$

where $\tilde{\phi}^{L, N}(x, \tau)=\tilde{\phi}^{L}(x, \tau)$ and $\tilde{\phi}^{R, N}(x, \tau)=\tilde{\phi}^{R}(x, \tau)$ from Lemma 2 and $i^{F}(r)=i^{H}(2 \bar{s}-r)$.

Proof The proof directly follows from Lemma 2 and the fact that in the symmetric equilibrium $i^{F}(x)=i^{H}(2 \bar{s}-x)$.

In the symmetric equilibrium, there always exists some left (right) neighborhood of $x=\bar{s}$ where $i^{H}(x)\left(i^{F}(x)\right)$ is strictly greater than zero. Indeed, if it is not true, then $i^{H}(x)$ is equal to zero around $x=\bar{s}$. This implies that $i^{F}(x)$ is equal to zero around $x=\bar{s}$ as well (due to symmetry). As a result, there is no trade with the foreign country and the equilibrium infrastructure profile corresponds to the optimal infrastructure profile in the closed economy, which is, as was shown, strictly positive for any $x \in(0, \bar{s})$. This constitutes a contradiction. Thus, we can conclude that, in contrast to the closed economy case, the infrastructure investment at $x=\bar{s}$ is strictly positive due to the possibility of trade with the foreign country. Specifically,

$$
i^{H}(\bar{s})^{\delta}=\frac{b L \gamma(1-\alpha)\left(1-t^{H}\right)}{q} \tilde{\phi}^{L, N}(\bar{s}, \tau)>0 .
$$

Next, we explore the behavior of the infrastructure profile around the border. The following proposition holds.

Proposition 6 In the symmetric Nash equilibrium, $\left(i^{H}(x)\right)_{x=0}^{\prime}=\infty$ and $\left(i^{H}(x)\right)_{x=\bar{s}}^{\prime}$ is negative, but finite.

Proof In the Appendix.

In the presence of a foreign country, the distribution of infrastructure investment has more mass in regions closer to the border (compared to the closed economy case). Nevertheless, the infrastructure profile still is hump-shaped (as $\left(i^{H}(x)\right)_{x=0}^{\prime}>0$ and $\left.\left(i^{H}(x)\right)_{x=\bar{s}}^{\prime}<0\right)$. Hence, investment close to the border is lower than in central locations. Compared to the first-best solution, the non-cooperative solution features underinvestment at the border.

We now discuss how discrete border costs $\tau$ affect the endogenous allocation of infrastructure spending within economies and how failing to account for infrastructure biases the border effect measured in the traditional econometric specifications of the gravity model. Focusing on direct 
effects of changes in $\tau$ on infrastructure investment, we explore how $\tau$ changes the infrastructure profile at given total spending. ${ }^{29}$ The following proposition holds:

Proposition 7 The direct effect of a rise in $\tau$ is a decrease in $i^{H}(x)$ in some left neighborhood of the border and an increase in $i^{H}(x)$ at locations that are relatively far from that border.

\section{Proof In the Appendix.}

The existence of explicit border costs $\tau$ skews the equilibrium infrastructure profile away from the border as gains from trade with the foreign country are lower and the marginal returns from investing around the border are smaller. This offers a natural explanation for the large border effect observed in the data. Indeed, a rise in $\tau$ not only increases the trade costs with the foreign country, but also decreases the stock of infrastructure around the border. As a result, the trade trade cost effect of the discrete border cost is larger than the one implied by $\tau$ alone.

\subsection{Calibration and numerical illustrations}

To provide numerical illustrations of the role of infrastructure in explaining the border effect, we calibrate the model. Due to the stylized nature of our theory, this is not a proper quantitative exercise. Nonetheless, we set parameters such that the model replicates some key moments estimated on European data. For simulation purposes, we work with a discrete formulation of our model; see Appendix B for details.

For the calibration, we normalize some parameters. Particularly crucial parameters such as $\delta, \gamma$ and $\tau$ are set such that the model replicates key moments obtained from EU data. Assuming symmetry within countries $(m(x)=m, q(x)=q)$, and noting that per capita income $b$ and the cost of infrastructure $q$ affect investment only through $b L / q$ (where $L=m \bar{s}$ ), we set $m(x)$ to 1000 and normalize $q=1$ and $b=1$. To guarantee enough variation in distance between locations generated by the model, we set $\bar{s}$ at 500 . We set the share of income spent on the agricultural product, $\alpha$, to $0.5 .^{30}$

We set parameters $\delta, \gamma, \tau$ such that the model replicates key empirical moments. To this end, we apply a gravity equation of the type

$$
\ln X_{i j}=\mu_{1} \ln D_{i j}+\mu_{2} B_{i j}+e x_{i}+i m_{j}+\epsilon_{i j},
$$

to data generated by our model and to actual data. $X_{i j}$ represents trade volumes from location $i$ to $j, D_{i j}$ denotes the distance between the locations, $B_{i j}$ is a border dummy that is equal to one

\footnotetext{
${ }^{29}$ In the numerical exercise below, we take account of indirect effects. Quantitatively, they are of absolutely minor importance.

${ }^{30}$ In Table 4 we report robustness checks pertaining to these choices.
} 
Table 2 - Calibration strategy

\begin{tabular}{lcl}
\hline \hline & \multicolumn{2}{c}{ (a) Normalizations } \\
\hline Parameter & Value & Explanation \\
\hline$m(x)$ & 1000 & arbitrary choice \\
$\bar{S}$ & 500 & arbitrary choice \\
$b$ & 1 & symmetry \\
$q(x)$ & 1 & symmetry \\
$\alpha$ & 0.5 & arbitrary choice \\
\hline \multicolumn{4}{c}{ Parameter } & Value & Moment \\
\hline$\gamma$ & 0.86 & Distance elasticity of transport costs in French data \\
& \multicolumn{3}{c}{ (Combes and Lafourcade, 2005): 0.9 } \\
$\delta$ & 1.65 & Distance elasticity $\mu_{1}$ estimated in EU trade data: -1.1 \\
$\tau$ & 1.32 & Border effect $\mu_{2}$ estimated in EU trade data: -0.8 \\
$\sigma$ & 2.70 & Set to satisfy (10) given calibrated values of $\gamma, \delta, \tau$ \\
\hline \hline
\end{tabular}

if $i$ and $j$ belong to different countries, $e x_{i}$ and $i m_{j}$ are exporter and importer fixed effects, and $\epsilon_{i j}$ is the error term. We use European trade data to estimate the empirical counterpart of (19); see Section 6. This yields estimates $\hat{\mu}_{1}=-1.1$ and $\hat{\mu}_{2}=-0.8$. We parameterize the model such that the trade data generated from it produces exactly the same values for $\mu_{1}$ and $\mu_{2}$ as those obtained from real data. The parameter $\gamma$ is chosen such that the generated elasticity of internal transportation costs with respect to distance matches the value of 0.9 estimated in French data. ${ }^{31}$ We use parameter restriction (10) to set the elasticity of substitution $\sigma$ at the maximum admissible level.

Table 2 summarizes the calibration strategy and outcomes. The border friction implies an ad valorem tax equivalent of $32 \%$, which is a reasonable magnitude compared with estimates presented in Anderson and van Wincoop (2004). The interregional elasticity of substitution is $1 / \delta=0.61$, implying a fairly strong degree of complementarity of investments between different locations. The parameter governing the curvature of the transportation cost - distance relationship is $\gamma=0.86$. Finally, the maximum value of $\sigma$ that satisfies the parameter restriction (10) is 2.7. ${ }^{32}$ We use this parameterization as our benchmark configuration.

We are now ready to run numerical exercises. We start with the counterfactual situation where $\tau$ is equal to unity. Figure 3 compares optimal schedules for infrastructure investment and

\footnotetext{
${ }^{31}$ We do not match spending on infrastructure investment $t$, because due to the one-period nature of our model $i(x)$ measures capital stocks while the empirical value of $t$ discussed in Section 2 refers to the flow of (gross) investment.

${ }^{32}$ This is a low value compared to findings in the literature; see Costinot and Rodriguez-Clare (2014) for a survey. As equation (10) is only a sufficient condition, we can set $\sigma$ at higher levels, but may end up violating the (unknown) necessary condition for the existence of an interior solution. We work with $\sigma=3.4$ in the robustness checks below.
} 
aggregate price levels, denoting the outcome under autarky by $i^{a}(x)$, the world-planner solution by $i^{w}(x)$, and non-cooperative Nash outcome by $\left(i^{H}(x), i^{F}(x)\right)$. In line with our analytical results, the world-planner schedule has a unique maximum at the location of the border, while the non-cooperative schedule has a double-hump shape with underinvestment around the border (compared to the world-planner outcome). This shape generates a border effect even without having any discrete border costs.

Figure 3 - Infrastructure investment and price levels across space in the absence of explicit (discrete) border frictions (i.e., $\tau=1$ )

(a) Investment

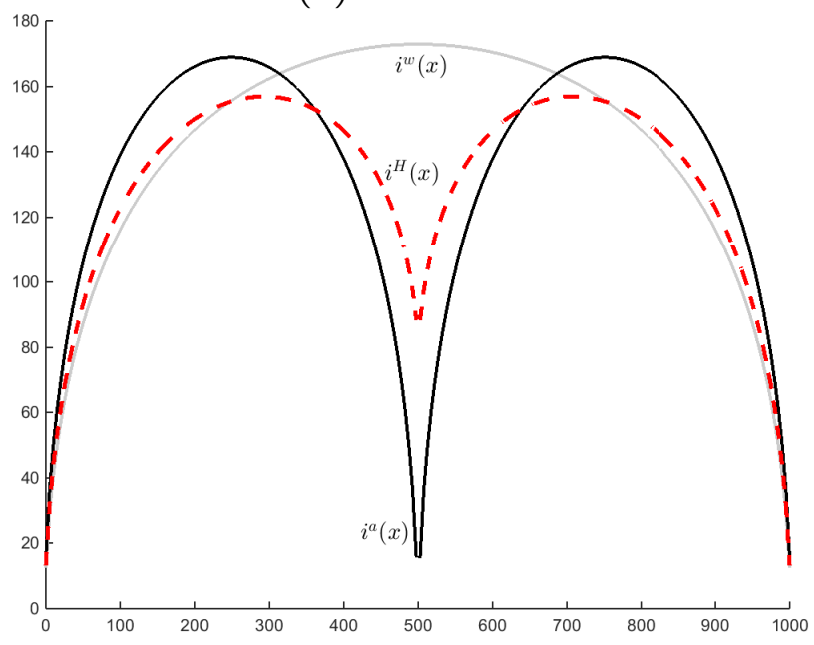

(b) Price levels

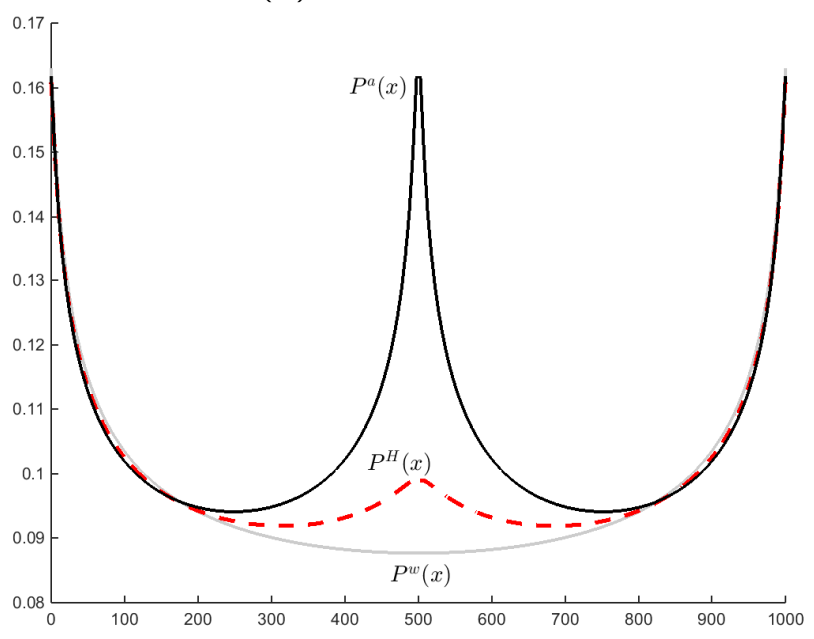

Notes. $i^{a}(x), i^{w}(x)$, and $i^{H}(x)$ refer to the autarky, central-planer, and non-cooperative optimal infrastructure investment distributions. Similarly for price levels. See Table 2 for the parameterization and Table 3 for numerical results.

Panel $b$ in Figure 3 depicts the distribution of the price index across locations in the autarky, world-planner, and Nash outcomes. In our framework, the price index at location $x$ depends on the 'remoteness' of the location (which determines the level of 'global' trade) and the level of infrastructure in the neighborhood (which determines the level of 'local' trade). Thus, in the world-planner outcome the price index is the lowest at the border, since the border is the least remote location in the world economy and the infrastructure investment is the highest there. In contrast, in the Nash equilibrium the price index has the lowest value at some internal location, rather than at the border (meaning that the local effect is stronger than the global one). This is caused by the skewness of the infrastructure profile towards internal locations in the Nash outcome. If we decrease the geographical size of countries $\bar{s}$ (making 'local' trade less important), the lowest value of the price index will be closer to the border.

Given our parameterization, Table 3 shows that underinvestment in border regions is quantitatively quite substantial, while global underinvestment is not. Compared to the first-best situation (row (2)), the non-cooperative outcome (row (3)) displays an investment gap of $49 \%$ at the 
Table 3 - Autarky versus first-best and Nash outcomes under trade

\begin{tabular}{|c|c|c|c|c|c|}
\hline & $\begin{array}{c}(1) \\
\text { border inv. } \\
i(500)\end{array}$ & $\begin{array}{c}(2) \\
\text { max. inv. } \\
\arg \max i(x) \\
\end{array}$ & $\begin{array}{c}(3) \\
\text { tax rate } \\
t\end{array}$ & $\begin{array}{c}(4) \\
\text { real income } \\
E[W]\end{array}$ & $\begin{array}{c}(5) \\
\text { inequality } \\
V[\ln W], \%\end{array}$ \\
\hline $\begin{array}{l}\text { Autarky: } \tau=\infty \\
\text { (1) } t^{a}, i^{a}(x)\end{array}$ & 0.0 & 250 & $13.4 \%$ & 1.0000 & 1,69 \\
\hline $\begin{array}{l}\text { No discrete borc } \\
\text { (2) } t^{w}, i^{w}(x) \\
\text { (3) } t^{H}, i^{H}(x)\end{array}$ & $\begin{array}{c}\text { er frictions: } \\
172.9 \\
88.5 \\
\end{array}$ & $\begin{array}{c}=1 \text { (counte } \\
500 \\
296\end{array}$ & $\begin{array}{r}\text { factual) } \\
14.1 \% \\
13.1 \%\end{array}$ & $\begin{array}{l}1.0707 \\
1.0563\end{array}$ & $\begin{array}{l}1.67 \\
1.20 \\
\end{array}$ \\
\hline $\begin{array}{l}\text { Discrete border } \\
\text { (4) } t^{w}, i^{w}(x) \\
\text { (5) } t^{H}, i^{H}(x)\end{array}$ & $\begin{array}{c}\text { frictions: } \tau \\
117.6 \\
63.6\end{array}$ & $\begin{array}{c}=1.32 \text { (data) } \\
322 \\
276\end{array}$ & $\begin{array}{l}13.8 \% \\
13.2 \%\end{array}$ & $\begin{array}{l}1.0419 \\
1.0335\end{array}$ & $\begin{array}{l}1.24 \\
1.14\end{array}$ \\
\hline
\end{tabular}

Notes: The parameterization is as in Figure 3. Two symmetric countries, $S=[0,1000]$. Autarky welfare is normalized to unity.

border (compare 88.5 to 172.9). Overall spending on infrastructure investment (measured by the equilibrium tax rate), falls only $7 \%$ short of the first-best. Compared to autarky, investment is about $5 \%$ higher in the first-best situation but about $2 \%$ lower in the Nash equilibrium. Real net per capita income at location $x$ being given by $W(x)=(1-t) b / P(x)$, we use average real per capita income, $E[W]$, as a measure of welfare (in Table 3 we normalize autarky welfare to unity). The gains from trade are about $7.1 \%$ when the infrastructure investment schedule is first-best and about 5.6\% when it is Nash; the cost of non-cooperation therefore amounts to about $1.4 \%$ of autarky welfare, or, equivalently to $20 \%$ of the gains from trade achievable when investment is first-best. ${ }^{33}$ Interestingly, inequality (as measured by the variance of the log of real net income multiplied by 100) is almost identical in autarky and in the first-best situation, but is substantially lower in Nash, where the income differential between the border region and the periphery is much smaller

In Figure 4 we set $\tau=1.32$. The world planner spends $4.5 \%$ more on infrastructure than country-level governments would, while the shortfall of investment at the border is around $46 \%$. The welfare loss (the difference between the average real per capita income in the first-best and non-cooperative outcome) constitute around $0.8 \%$. This suggests that lower border frictions increase the welfare loss from infrastructure misallocation (when $\tau=1$, the loss is around $1.3 \%$ ). The fall in the real income at the border is more substantial (around $8.7 \%$ ), suggesting that the welfare loss from underinvestment in infrastructure can be larger, if a country has more

\footnotetext{
${ }^{33}$ If we fix overall spending to the first-best level, but allow independent governments to decide about the spatial distribution of this spending, the welfare losses become minor. This outcome is robust across different parameterization, suggesting that welfare losses arising in case of the Nash equilibrium are mainly due to insufficient finance (a lower tax rate), rather than the distribution of infrastructure itself. The border investment is higher when overall spending is forced to be at the first-best level, but it still falls short from the optimum substantially.
} 
than one border. The border cost decreases average real per capita income by around $2 \%$. The presence of the border cost $\tau$ also changes the distribution of the price index (see panel $b$ of Figure 4). If there is a border friction, the prices of the foreign varieties rise compared to the prices of the local varieties and, infrastructure investment moves away from the border. As a result, the price index achieves its minimum in more remote (from the border) locations. In the extreme case with prohibitive border costs, we have the autarky case where the price index has a $U$-shape with the minimum at the central location.

\section{Figure 4 - How higher discrete border costs change the distribution of infrastructure invest- ment and price levels across space}

(a) Investment

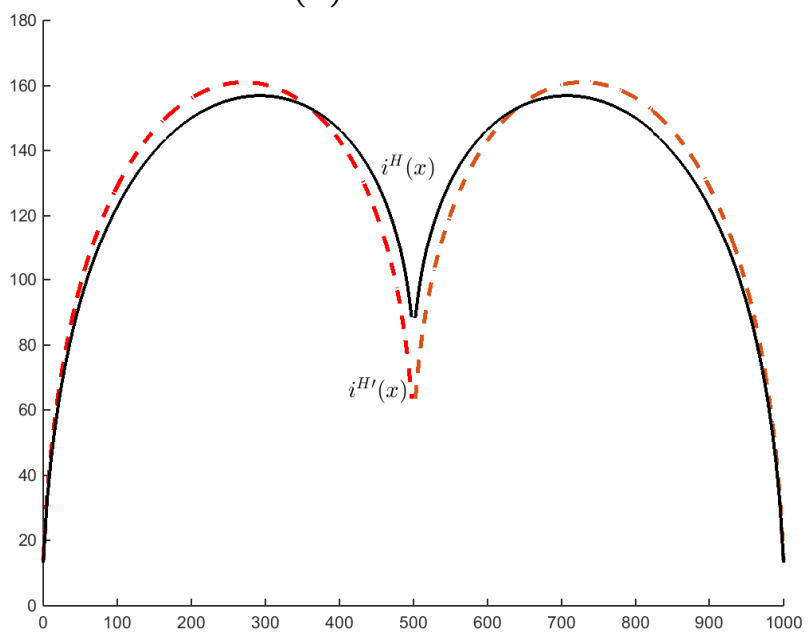

(b) Price levels

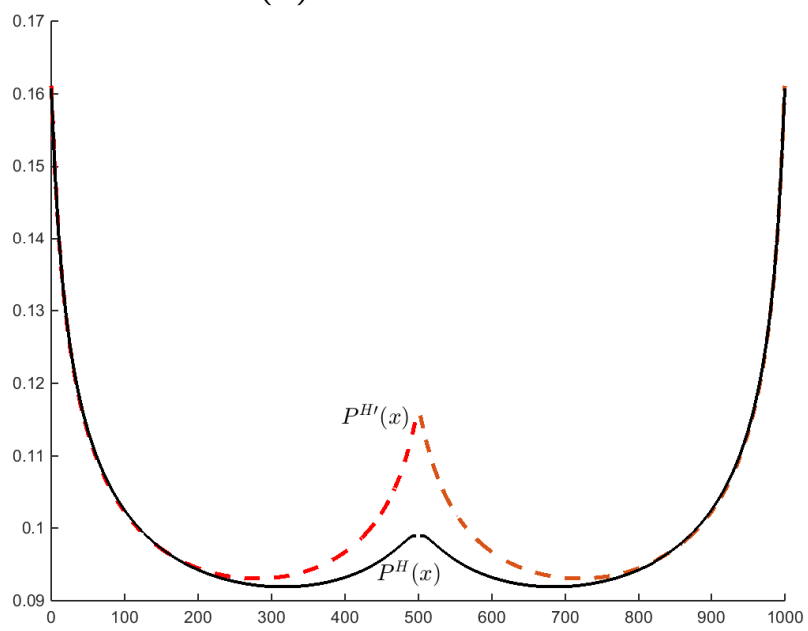

Notes. $i^{H}(x)$ and $i^{F}(x)$ refer to the non-cooperative (Nash) infrastructure investment distributions, and $i^{H \prime}(x)$ and $i^{F^{\prime}}(x)$ show the same loci with a higher border cost. See Table 2 for the parameterization and Table 3 for numerical results.

To assess the role of infrastructure in explaining the border effect, we perform the following experiment. We set the infrastructure investment $i(x)$ at all locations to its average value under the benchmark parameterization $\bar{i}$ (which is 131.8). In this case, the distribution of infrastructure is flat and does not affect the size of the border effect. All other parameters and variables remain fixed. Then, we simulate trade volumes within and between countries and estimate the border effect generated by the model. We find that the estimate of $\mu_{2}$ drops from 0.80 to 0.65 . This means that the variation in infrastructure investments explains around $19 \%$ of the border effect. The rest is explained by the border friction $\tau$ and the correlation between the border dummy and distance generated by the model. ${ }^{34}$ In other words, the border effect identified in a gravity model that ignores variation in transport infrastructure over space is biased upward by $19 \%$. The discrete border friction $\tau=1.32$ explains about $59 \%$ of the border effect, and $22 \%$ is due

\footnotetext{
${ }^{34}$ That correlation amounts to $71 \%$. It arises from the fact, that pairs of locations characterized by short distances tend to be within-country and, thus, have a border dummy of zero while the opposite is true for long distances.
} 
Table 4 - Robustness checks

\begin{tabular}{cl|ccc|cc}
\hline \hline & & $(1)$ & $(2)$ & $(3)$ & $(4)$ & $(5)$ \\
& & $\gamma$ & $\delta$ & $\tau$ & $\triangle W$ & Infra \\
\hline Benchmark: & $\begin{array}{c}m(x)=1000, \bar{s}=500, \\
n=100, \sigma=2.7\end{array}$ & 0.86 & 1.65 & 1.32 & $0.8 \%$ & $19 \%$ \\
\hline$(1)$ & $m(x)=10000$ & 0.85 & 1.50 & 1.35 & $0.7 \%$ & $13 \%$ \\
$(2)$ & $\bar{s}=700$ & 0.86 & 1.69 & 1.31 & $0.9 \%$ & $21 \%$ \\
$(3)$ & $n=70$ & 0.86 & 1.66 & 1.32 & $0.9 \%$ & $20 \%$ \\
$(4)$ & $\sigma=3.4$ & 0.80 & 1.83 & 1.12 & $1 \%$ & $22 \%$ \\
\hline \hline
\end{tabular}

Notes: We fix the moments measured in European and French data, modify our choice of free parameters, and obtain new calibrated values for $\gamma, \delta, \tau$, (columns (1), (2), (3)). Columns (4) and (5) show the welfare costs resulting from an inefficient infrastructure investment, and the relative importance of infrastructure in explaining the border effect, respectively.

to the correlation between the border dummy and distance. ${ }^{35}$

We also perform robustness checks regarding the chosen values of $m(x), \bar{s}, n$, and $\sigma$. In particular, we change the value of one of these parameters, re-calibrate the model, and assess the role of infrastructure in explaining the border effect as well as the size of welfare losses. Table 4 summarizes the results. As can be seen, a rise in the population density (see row (1) in the table) barely changes the calibrated values of $\gamma$ and $\tau$ and the welfare losses. The value of $\delta$ decreases from 1.65 to 1.50. Since the value of $\delta$ falls, the variation in infrastructure investments becomes less important and, consequently, the role of infrastructure in explaining the border effect becomes less pronounced. In contrast, an increase in the geographical size of countries $\bar{s}$ (row (2)) raises the value of $\delta$ and, thereby, increases the role of infrastructure. The values of $\gamma$ and $\tau$ and the welfare losses do not substantially change. A decrease in the number of internal regions $n$ from 100 to 70 (row (3)) has a minor impact on the values of the calibrated parameters, welfare losses, and the role of infrastructure. Finally, a rise in $\sigma$ (row (4)) has a substantial impact on the calibrated values of the parameters (especially, on $\tau$ ), while the impact on the role of infrastructure and welfare losses is small. The role of infrastructure increases from $19 \%$ to $22 \%$ and the welfare losses increase from $0.8 \%$ to $1 \%$.

\subsection{The role of country asymmetries}

We study asymmetries with respect to countries' populations (given area), or with respect to areas (holding population constant). Figure 5 illustrates these cases, where Home is always assumed the 'bigger' country, and we distinguish between cases with and without an explicit

\footnotetext{
${ }^{35}$ This as a statistical artefact that arises from the high correlation between distances and the border dummy. It implies that if $i(x)=\bar{i}$ and $\tau=1$, the model still generates a statistical border effect.
} 
discrete border friction $\tau$. In panels $a$ and $c$, both countries have the same geographical extension, but Home has a higher population (and, hence, a higher density). Specifically, we set $m^{H}(x)=1100$ and $m^{F}(x)=900 .{ }^{36}$ In panels $b$ and $d$, Home has a larger geographical extension, but the same density $m(x)$ as Foreign. The figures show that, regardless of whether or not there is a discrete border cost and regardless of the nature of the asymmetry, the larger country wishes to invest more (in the sense that the mode of the distribution is higher). However, in contrast to the symmetric case, the planner solution involves a concentration of investment in the 'bigger' economy; with an explicit border friction, the planner solution can even be bimodal (panel $d$ ). In all cases, the Nash equilibrium yields global underinvestment, including at the border. However, the spatial structure differs across scenarios. ${ }^{37}$ The 'bigger' country severely underinvests, but the 'smaller' one may overinvest relative to the planner solution. This is particularly pronounced when the source of asymmetry is density; in this case, the location with the strongest underinvestment typically is an interior location in Home. When asymmetry is caused by geographical size, the extent of underinvestment is strongest in the border region.

Interestingly, overinvestment in Foreign under Nash implies that the smaller country may gain from non-cooperation (assuming away any transfers between countries in the first-best outcome). In panel $c$, in the first-best outcome, average real per capita income at Foreign is 7.04 , while in the Nash outcome it is 8.37, i.e., non-cooperation outperforms cooperation by around $19 \%$. In contrast, Home's average income is 9.74 the first-best outcome, while it $9 \%$ lower under Nash (8.87). Hence, asymmetry in population density across countries may increase the welfare losses (caused by the misallocation of infrastructure in the Nash equilibrium) of the larger country and decrease those of the smaller country (that may even gain). Thus, under asymmetry, welfare effects of non-cooperation are substantially more substantial than in the symmetric case (where the average welfare loss was just about $0.8 \%$ ). A similar observation emerges in panel $d$, where Home's welfare loss under Nash relative to the first-best is around $2.7 \%$, while Foreign gains around $6 \%$ from non-cooperation. ${ }^{38}$

\subsection{Intercontinental trade}

So far, we have studied a world of two countries which are connected by land-borne trade. Now we study how the emergence of intercontinental trade affects the intracontinental distribution of infrastructure investment, trade, welfare, and the size of the border effect. We do this by assuming that there is a third country, call it China, which supplies and demands goods to and

\footnotetext{
${ }^{36}$ Compared to the benchmark configuration with $m^{H}(x)=m^{F}(x)=1000$, world income expressed in the numeraire is the same.

${ }^{37}$ In the Nash equilibrium, the infrastructure investment profile has a discontinuity at the border (caused by the asymmetry between the countries).

${ }^{38} \mathrm{We}$ also consider the case when both countries have the same total income with Home being larger in a geographical size, but less densely populated (the world total income remains fixed). In this case, we find that Foreign loses from non-cooperation, while Home gains. This suggests that the effect of population density on welfare losses is stronger than that of the geographical area. A number of robustness checks confirm this conclusion.
} 
Figure 5 - The distribution of infrastructure investment when Home is 'bigger' than Foreign

(a) Population size $(\tau=1)$

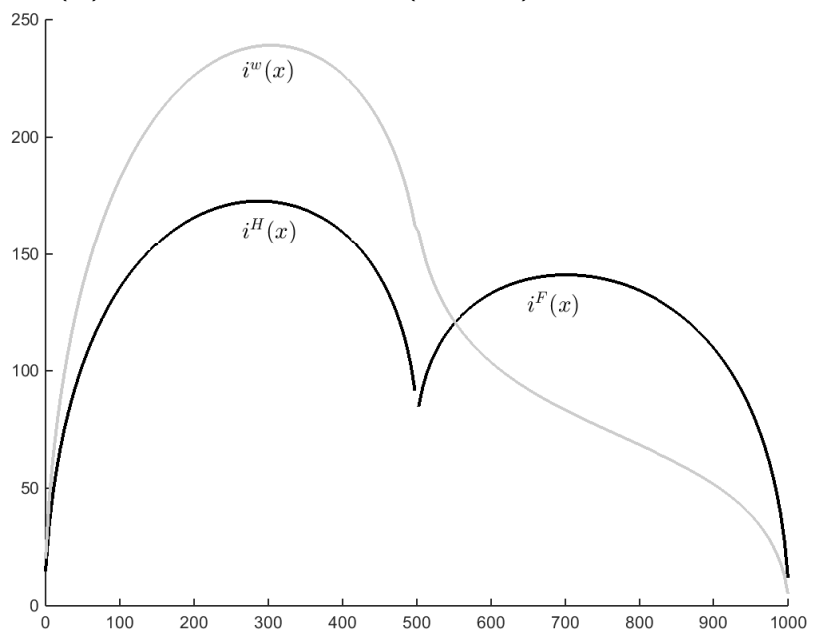

(c) Population size $(\tau=1.32)$

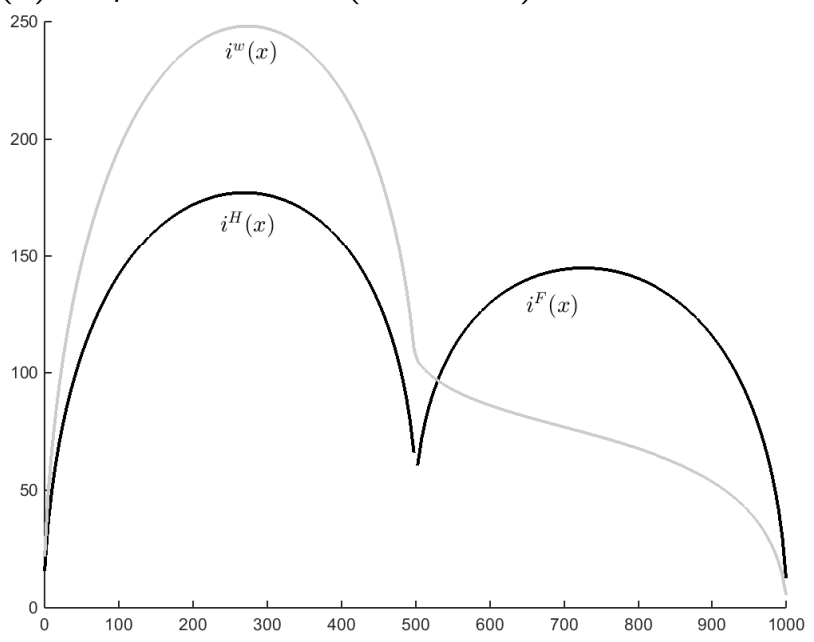

(b) Geographical size $(\tau=1)$

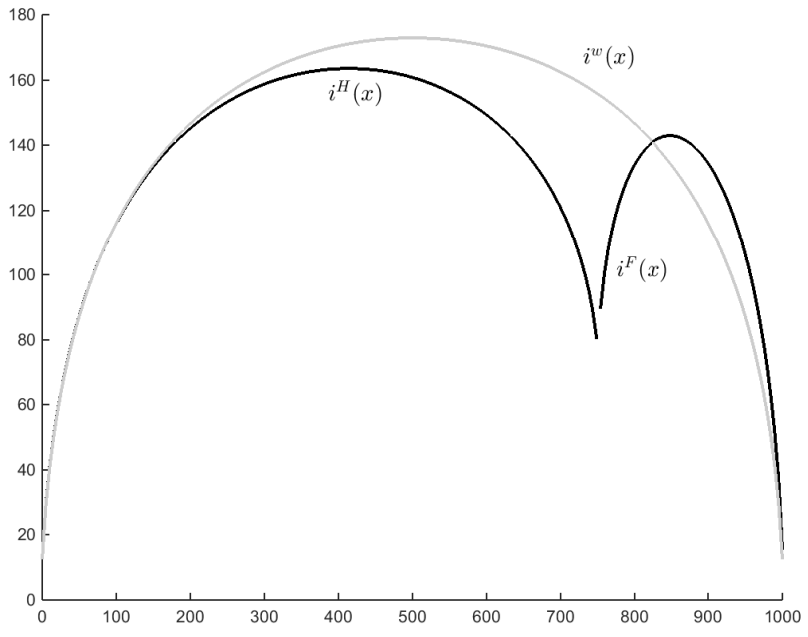

(d) Geographical size $(\tau=1.32)$

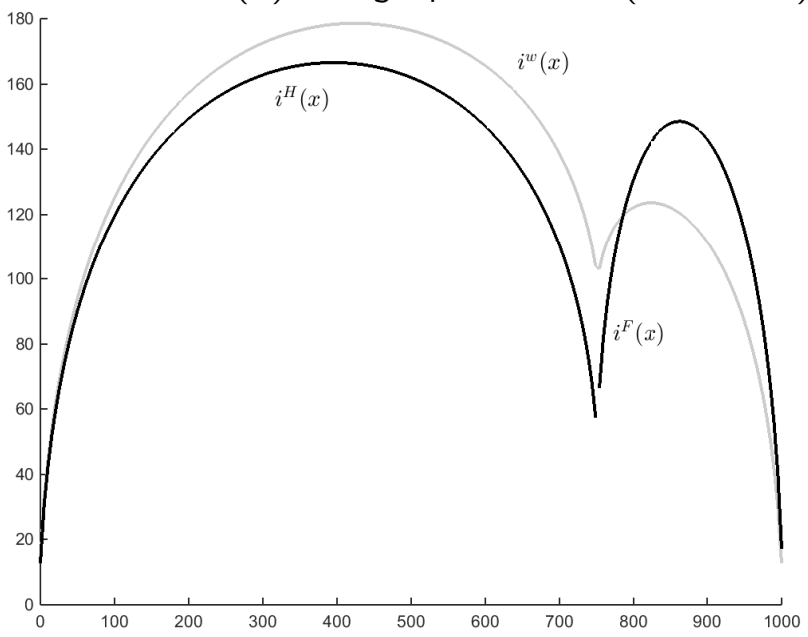

Notes. $i^{H}(x)$ and $i^{F}(x)$ refer to the non-cooperative and $i^{w}(x)$ to the central-planer and optimal infrastructure investment distributions. The default parameterization follows Table 2. Panels (a) and (c): $m(x)$ is 1100 and 900 for domestic and foreign locations, respectively. In the non-cooperative outcome with $\tau=1.32$, the tax rate is $13.2 \%$ in Home and $13.3 \%$ in Foreign. Average real per capita income is 8.87 and 8.37 , respectively. The level of inequality is 1.15 and 1.13. Panels (b) and (d): The geographical size of Home and Foreign is 750 and 250, respectively. In the non-cooperative outcome with $\tau=1.32$, the tax rate at Home and Foreign is $13.8 \%$ and $12.0 \%$, respectively. Average real per capita income is 8.87 and 8.08 , respectively. The level of inequality is 1.16 and 1.01 .

from Home and Foreign via a harbor that is located at address 0 in Home. We also assume that China's supply and demand capacity is exogenous to the outcomes in Home and Foreign. In particular, we do not model the spatial extension of China, and treat it as a mass point at location 0. 
By construction, this constellation creates a costal country (Home) and a hinterland (Foreign). It also breaks symmetry between Home and Foreign, as any location in Home now is more central than any region in Foreign, even with a uniform distribution of infrastructure investment: on average, consumer prices will be lower in Home than in Foreign. However, with endogenous infrastructure investment, there will be additional effects that tend to exacerbate inequality both between Home and Foreign as well as within them. ${ }^{39}$

Panels (a) and (b) in Figure 6 show how the intracontinental infrastructure investment distribution changes due to the emergence of intercontinental trade with China. In panel (a) China is considered to produce the same number of varieties as Home and Foreign together (that is, it has the mass of 1000). In this case, the share of trade volumes from China to Home and Foreign in the total income of those countries constitutes around $10 \%,{ }^{40}$ reflecting the share of imports (in total income) of EU from the rest of the world in 2010. In Home, there will be a massive reallocation of spending towards the coastal locations where the Chinese imports crowd out varieties from locations within Home and Foreign. Investment falls rapidly with increasing distance from the harbor and is lower than in the benchmark case (intracontinental trade only) in about $80 \%$ of all locations in Home. In particular. Home will invest substantially less at the border with Foreign. With the infrastructure schedule dramatically more skewed in Home, the distribution of real wages will also become more uneven, so that trade with China makes Home a more unequal economy.

Simulations show that in Foreign, now a hinterland, incentives for investment barely change, because there are two competing factors: On the one hand, all else equal, the presence of China should result in more investment. On the other hand, this effect is mitigated by the remoteness of China and the reallocation of infrastructure investment in Home away from the border with Foreign. However, the emergence of China increases the intracontinental border effect, because it diverts investment away from the border zone. This means that, in a standard gravity equation, the estimated border dummy should grow larger with the increasing importance of intercontinental trade despite the fact that border related trade costs have not changed. Specifically, under the benchmark parameterization the presence of China increases the size of the border effect by around $24 \%$ (from -0.8 to -0.99 ).

In panel (b) of Figure 6, we consider the case when China is much smaller than Home and Foreign (with a mass of 40). In this case, the infrastructure profile at Home still has a hump shape. However, there is more investment in coastal areas and less in the hinterland compared to the benchmark case (of intracontinental trade only).

A rise in trade with China increases welfare in the coastal country but has minor effects in the hinterland (Foreign), where inequality also remains essentially unchanged. In contrast, trade

\footnotetext{
${ }^{39}$ Another application of this model variant may be to poor coastal countries in Africa, which trade mostly intercontinentally, and where intracontinental infrastructure and trade are underdeveloped.

${ }^{40}$ Such a low share (taking into account the size of China) is explained by the remoteness of China and the fact that only $(1-\alpha)$ share of total income is spent on industrial goods.
} 
Figure 6 - Overseas trade and the distribution of intracontinental transport infrastructure investment

(a) "Large China"

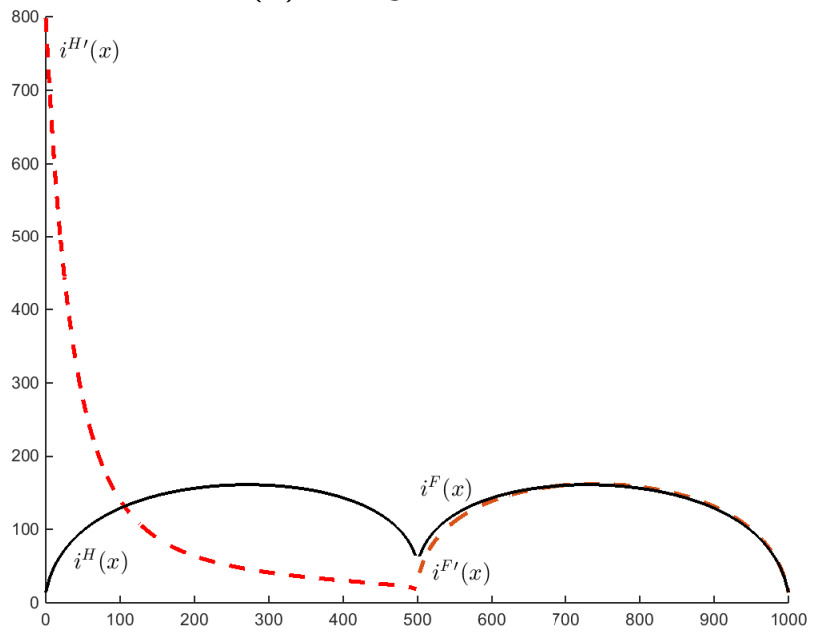

(b) "Small China"

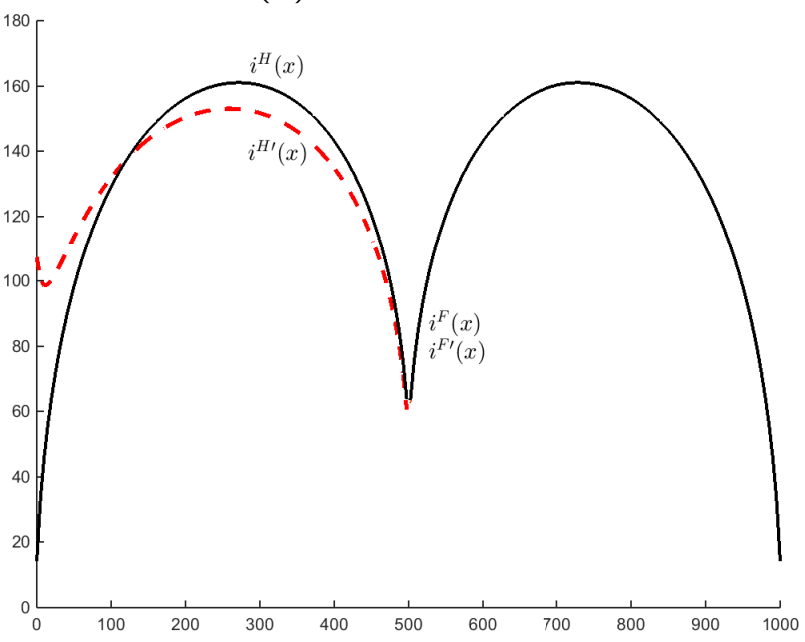

Notes. $i^{H}(x)$ and $i^{F}(x)$ refer to the Nash infrastructure investment distributions without a third country, while $i^{H \prime}(x)$ and $i^{F^{\prime}}(x)$ refer to those when there is trade with a third country (China). The parameterization is as follows: $\sigma=2.7, \delta=1.65, \gamma=0.86, \alpha=0.5, q(x)=q=1, b=1, \tau=1.32, m(x)=1000$ for all locations at Home and Foreign, and $\bar{s}=500$. In Panel (a) China has the mass of 1000, in (b) it has the mass of 40 .

with China has a substantial non-monotonic effect on inequality in Home. When the size of China is small, inequality in Home decreases (since the distribution of the infrastructure becomes flatter (see panel $b$ in Figure 6$)$ ). When China is big, inequality rises, as the infrastructure profile is highly skewed towards the border with China (see panel $a$ in Figure 6). Table 5 summarizes the effects of trade with China on Home and Foreign under the benchmark parameterization.

\section{Supporting evidence}

Two important prediction of our theoretical model are: (i) locations within jurisdictions are better connected by transport infrastructure than locations lying in two different jurisdictions, and (ii) inefficiently low infrastructure investment in border regions explains part of the so called border effect. In this section we use data from the European Union to provide some supporting evidence for these hypotheses.

Data. We use data provided by Pisu and Braconnier (2013) on bilateral minimum road distances and minimum travel times between 220 cities in 22 countries in continental Europe. ${ }^{41}$

\footnotetext{
${ }^{41}$ The countries are: Austria, Belgium, Bulgaria, Czech Republic, Denmark, Estonia, France, Germany, Greece, Italy, Hungary, Latvia, Lithuania, Luxembourg, Netherlands, Poland, Portugal, Romania, Slovenia, Slovak Republic,
} 
Table 5 - The Presence of China: Inequality and Welfare

\begin{tabular}{l|ccc|ccc}
\hline \hline & \multicolumn{3}{|c|}{ Home } & \multicolumn{3}{c}{ Foreign } \\
\hline \hline & Welfare & Inequality & Tax rate & Welfare & Inequality & Tax rate \\
\hline The size of China is 0: & 1.0000 & 1.14 & $13.2 \%$ & 1.0000 & 1.14 & $13.2 \%$ \\
The size of China is 40: & 1.0243 & 0.26 & $13.2 \%$ & 1.0000 & 1.14 & $13.2 \%$ \\
The size of China is 1000: & 1.4658 & 33.62 & $11.2 \%$ & 0.9949 & 1.25 & $13.1 \%$ \\
\hline \hline
\end{tabular}

Notes: Calibration as in Table 2; 'China' is modeled as a mass point at location 0 . Welfare when the size of China is zero is normalized to unity.

The data come from Bing Maps Route Service and relate to the year 2012. The authors provide population weighted proxies at the country-pair level which we use in our analysis. We merge this information with bilateral trade data for the year of 2010 provided in the World Input Output Database (WIOD) project (Timmer et al., 2015). Crucially, that data base provides accurate measures for domestic trade within countries. Unfortunately, there is no information on Switzerland, so that our analysis rests on $21^{2}=441$ country pairs. We focus on the 16 non-service sectors contained in WIOD. Finally, we obtain CES weighted geographical distance measures (based on great-circle distances), common language and contiguity measures from Mayer and Zignago (2011). ${ }^{42}$

Straight-line distance, road distance, and travel time. We start by showing direct evidence on relative underinvestment in European border regions. The left-hand diagram in Figure 7 shows that the ratio of road distance to the straight-line distance (the so called divergence) is on average higher between cities in different countries than between cities within the same country. Intranational road trips are $9 \%$ longer than what the great-circle (bird-flight) distance would indicate; international road trips are 30\% longer. The difference is statistically significant at the $1 \%$ level. As the mid panel in Figure 7 shows, the average travel speed on domestic roads is $88 \mathrm{~km} / \mathrm{h}$ while it is $100 \mathrm{~km} / \mathrm{h}$ on international road trips; the difference again being significant at the $1 \%$ level. However, this disadvantage for domestic trips does not outweigh the advantage of shorter connections. The hypothetical speed of traffic for overcoming the bird-flight distance is $83 \mathrm{~km} / \mathrm{h}$ in domestic links versus $77 \mathrm{~km} / \mathrm{h}$ in international links. This difference is statistically significant at the $5 \%$ level. ${ }^{43}$

\footnotetext{
Spain, Switzerland.

${ }^{42}$ Head and Mayer (2002) show that measuring distance between countries by a geometric (CES) average of distances between major cities dramatically reduces the border effects in European data. These authors, however, do not account for real transportation costs.

${ }^{43}$ Note that the hypothetical travel speed on the bird-flight distance is given by the ratio between the travel speed on the road and the excess length of the road trip over the bird-flight distance.
} 


\section{Figure 7 - Distance versus travel time in intra- and international bilateral links}
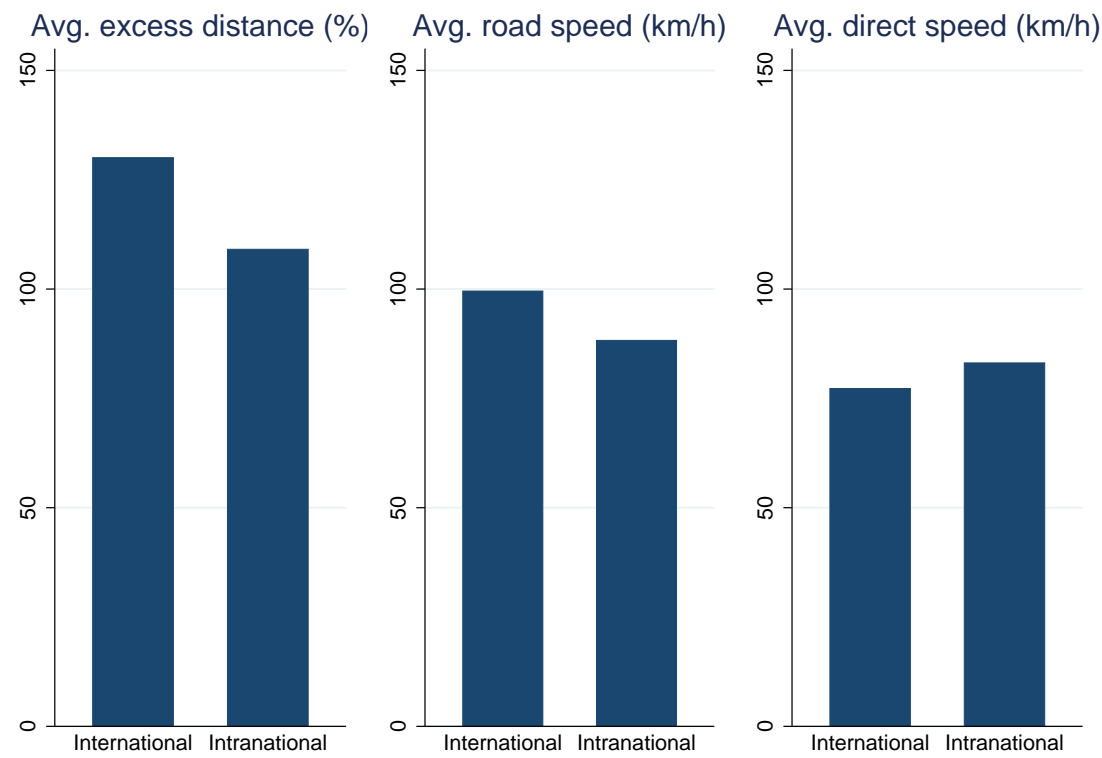

Notes. Average excess distance is the \%-ratio between road distance and bird-flight distance, both in $\mathrm{km}$. Avg. road speed denotes the average travel speed on the fastest road connection, in $\mathrm{km} / \mathrm{h}$, while avg. direct speed refers to the average theoretical speed on the most direct (= bird-flight distance), in $\mathrm{km} / \mathrm{h}$.

Table 6 conditions the difference between domestic and international trips on distance and also controls for destination and origin fixed effects. Column (1) reports a simple linear regression that correlates the log of travel time (in minutes) and the log of geographical (great-circle) distance. The obtained elasticity is 0.96. Moreover, column (2) shows that travel time is significantly larger between different countries than within countries, the difference being equal to about $28 \%$. Including the dummy variable for domestic connections brings down the elasticity of travel time with respect to distance to 0.89 , again hinting at some concavity in the relationship between distance and trade costs. ${ }^{44}$ Columns (3) and (4) repeat this exercise, but use the log of road distance (in $\mathrm{km} / \mathrm{h}$ ) as the dependent variable. It turns out that road distances that cross a political border are longer by some $22 \%$, controlling for bird-flight distance. Finally, columns (5) and (6) show that domestic travel time is longer by $8 \%$ given road distances.

The border effect. Finally, we turn to an investigation of the border effect. To this end, we use a generalization of equation (19)

$$
X_{i j s}=\exp \left[\mu_{1} \ln T_{i j}+\mu_{2} B_{i j}+e x_{i s}+i m_{j s}+\epsilon_{i j s}\right] \text {, }
$$

where $s$ indicates the sector. Bilateral trade costs are $T_{i j}$ and $B_{i j}$, where the latter is a dummy that takes value one if for an international and value zero for an intranational transaction. $T_{i j}=$

\footnotetext{
${ }^{44}$ The hypothesis of a unitary elasticity is rejected at the $1 \%$ level.
} 
Table 6 - Bird-flight distance, road distance, and travel time across EU countries

\begin{tabular}{|c|c|c|c|c|c|c|}
\hline \multirow[b]{2}{*}{ Dep.var.: } & (1) & (2) & (3) & (4) & \multicolumn{2}{|r|}{ (6) } \\
\hline & $\log$ tra & el time & log road & distance & $\log \operatorname{tr}$ & vel time \\
\hline Border $(0,1)$ & & $\begin{array}{c}0.282 * * * \\
(0.0418)\end{array}$ & & $\begin{array}{c}0.217^{* * *} \\
(0.0325)\end{array}$ & & $\begin{array}{c}0.0799 * * * \\
(0.0232)\end{array}$ \\
\hline In bird-flight distance & $\begin{array}{c}0.959 * * * \\
(0.0137)\end{array}$ & $\begin{array}{c}0.893 * * * \\
(0.0128)\end{array}$ & $\begin{array}{c}1.041^{* * *} \\
(0.0113)\end{array}$ & $\begin{array}{c}0.990 * * * \\
(0.00945)\end{array}$ & & \\
\hline In road distance & & & & & $\begin{array}{c}0.924 * * * \\
(0.0104)\end{array}$ & $\begin{array}{c}0.905^{* * *} \\
(0.00987)\end{array}$ \\
\hline Constant & $\begin{array}{l}-0.0795 \\
(0.0890)\end{array}$ & $\begin{array}{c}0.344 * * * \\
(0.0837)\end{array}$ & $\begin{array}{l}-0.0253 \\
(0.0727)\end{array}$ & $\begin{array}{c}0.300 * * * \\
(0.0613)\end{array}$ & $\begin{array}{l}-0.0721 \\
(0.0682)\end{array}$ & $\begin{array}{c}0.0526 \\
(0.0657)\end{array}$ \\
\hline R-squared & 0.983 & 0.986 & 0.992 & 0.994 & 0.994 & 0.994 \\
\hline
\end{tabular}

Notes: OLS regressions. All regressions contain complete sets of separate exporter and importer fixed effects. Robust standard errors (clustered at the pair-level) in parentheses, ${ }^{* * *} p<0.01,{ }^{* *} p<0.05,{ }^{*} p<0.1$. $N=441$.

$\left(1+D_{i j}\right)^{\delta_{0}} e^{\delta_{1} C L_{i j}+\delta_{2} C O N T_{i j}}$ models trade costs as a function of distance-related transportation costs $D_{i j}$, common language $C L_{i j}$ and contiguity $C O N T_{i j}$. $D_{i j}$ can either be the weighted great-circle distance between $i$ and $j$, or the shortest (similarly weighted) road distance, or the minimum (similarly weighted) travel time. Following current practice, we estimate Poisson models, as this setup is best suited do deal with zero trade flows and heteroskedasticity arising from additive error terms. ${ }^{45}$

Column (1) of Table 7 reports a frequently observed pattern in gravity models: the trade elasticity of bird-flight distance is close to -1 , and a common language or a adjacency (contiguity) have strongly positive effects on trade flows. The estimated border effect is -0.804 , signalling that international trade flows are by about 55\% $(1-\exp (-0.804)=0.55)$ smaller than intranational ones, holding other trade determinants (such as market sizes, multilateral distances - all captured by fixed effects - geographical distance, contiguity, and common language) constant. ${ }^{46}$

\footnotetext{
${ }^{45}$ See Head and Mayer (2014). As a default, we use a Poisson pseudo maximum likelihood estimator (PPML), but for the instrumental variable estimation we estimate the Poisson model using a a generalized methods of moments (PGMM) approach. Note that results do not qualitatively depend on using the Poisson approach. Log-linear OLS models yield qualitatively similar results; see Table .2 in the Appendix.

${ }^{46}$ The measured border effect seems small compared to earlier findings in the literature, e.g., by Nitsch (2000). This has several reasons: First, we use the more consistent distance measure proposed by Head and Mayer (2002), which has been shown to shrink the border effect in a sample of European data from the early 1990s (see footnote 42). Second, the use of PPML yields a substantially smaller border effect than OLS, which dominated the earlier literature; compare Table .2 in the Appendix. Third, thanks to the WIOD project, we have more accurate information on within-country trade. And fourth, our data refers to a very recent period (2010) and lower border effects probably simply show the effects of ongoing economic integration in the EU.
} 
Table 7 - The border effect and the role of infrastructure: Poisson models

\begin{tabular}{|c|c|c|c|c|c|c|c|c|c|}
\hline \multirow{4}{*}{$\begin{array}{l}\text { Dep.var.: } \\
\text { Sample }\end{array}$} & $\overline{(1)}$ & (2) & (3) & $\overline{(4)}$ & $\overline{(5)}$ & $\overline{(6)}$ & $\overline{(7)}$ & (8) & $\overline{(9)}$ \\
\hline & \multicolumn{6}{|c|}{ aggregate trade } & \multirow{2}{*}{\multicolumn{3}{|c|}{$\begin{array}{l}\text { sectoral trade } \\
\text { full }\end{array}$}} \\
\hline & \multicolumn{3}{|c|}{ full } & \multicolumn{3}{|c|}{ non-contingent pairs } & & & \\
\hline & PPML & PPML & PPML & PGMM & PGMM & PGMM-IV & PPML & PPML & PPML \\
\hline Border $(0,1)$ & $\begin{array}{c}-0.804^{* * * *} \\
(0.170)\end{array}$ & $\begin{array}{c}-0.547^{* * *} \\
(0.180)\end{array}$ & $\begin{array}{c}-0.422^{* *} \\
(0.176)\end{array}$ & $\begin{array}{c}-2.063 * * * \\
(0.458)\end{array}$ & $\begin{array}{c}-1.546 * * * \\
(0.428)\end{array}$ & $\begin{array}{c}-1.411 * * * \\
(0.462)\end{array}$ & $\begin{array}{c}-0.775^{* * * *} \\
(0.0915)\end{array}$ & $\begin{array}{c}-0.503^{* * *} \\
(0.101)\end{array}$ & $\begin{array}{c}-0.391^{* * *} \\
(0.101)\end{array}$ \\
\hline In great-circle distance & $\begin{array}{c}-1.112^{* * * *} \\
(0.128)\end{array}$ & & & $\begin{array}{c}-1.204 * * * \\
(0.135)\end{array}$ & & & $\begin{array}{c}-1.142 * * * \\
(0.0674)\end{array}$ & & \\
\hline In road distance & & $\begin{array}{c}-1.171 * * * \\
(0.123)\end{array}$ & & & & & & $\begin{array}{c}-1.211^{* * *} \\
(0.0693)\end{array}$ & \\
\hline In travel time & & & $\begin{array}{c}-1.361^{* * * *} \\
(0.124)\end{array}$ & & $\begin{array}{c}-1.365^{* * * *} \\
(0.139)\end{array}$ & $\begin{array}{c}-1.443 * * * \\
(0.163)\end{array}$ & & & $\begin{array}{r}-1.391^{* * *} \\
(0.0713)\end{array}$ \\
\hline Common language $(0,1)$ & $\begin{array}{c}0.761^{* * *} \\
(0.132)\end{array}$ & $\begin{array}{c}0.840 * * * \\
(0.134)\end{array}$ & $\begin{array}{c}0.841^{* * *} \\
(0.125)\end{array}$ & $\begin{array}{l}-0.295 \\
(0.414)\end{array}$ & $\begin{array}{l}-0.145 \\
(0.355)\end{array}$ & $\begin{array}{l}-0.134 \\
(0.367)\end{array}$ & $\begin{array}{c}0.763 * * * \\
(0.0803)\end{array}$ & $\begin{array}{l}0.843 * * \\
(0.0793)\end{array}$ & $\begin{array}{c}0.841 * * * \\
(0.0792)\end{array}$ \\
\hline Contiguity $(0,1)$ & $\begin{array}{l}0.326^{* *} \\
(0.157)\end{array}$ & $\begin{array}{c}0.215 \\
(0.154)\end{array}$ & $\begin{array}{c}0.134 \\
(0.141)\end{array}$ & & & & $\begin{array}{c}0.320 * * * \\
(0.0845)\end{array}$ & $\begin{array}{l}0.200 * * \\
(0.0843)\end{array}$ & $\begin{array}{c}0.131 \\
(0.0816)\end{array}$ \\
\hline Constant & $\begin{array}{c}14.92 * * * \\
(0.881) \\
\end{array}$ & $\begin{array}{c}15.58 * * * \\
(0.872) \\
\end{array}$ & $\begin{array}{c}16.07 * * * \\
(0.802) \\
\end{array}$ & $\begin{array}{c}17.66^{* * *} \\
(0.835) \\
\end{array}$ & $\begin{array}{c}17.66^{* * * *} \\
(0.835)\end{array}$ & $\begin{array}{c}18.03 * * * \\
(0.834)\end{array}$ & $\begin{array}{c}12.49 * * * \\
(0.780)\end{array}$ & $\begin{array}{c}13.24 * * * \\
(0.788)\end{array}$ & $\begin{array}{c}13.63^{* * * *} \\
(0.758) \\
\end{array}$ \\
\hline Observations & 441 & 441 & 441 & 377 & 377 & 377 & 7,004 & 7,004 & 7,004 \\
\hline R-squared & 0.989 & 0.990 & 0.991 & 0.977 & 0.977 & & 0.959 & 0.961 & 0.961 \\
\hline
\end{tabular}

Notes: Pseudo Maximum Likelihood (PPML) or Generalized Methods of Moments (PGMMs) estimations of Poisson moels. All models contain complete sets of separate exporter and importer fixed effects (exporter $\times$ sector, importer $\times$ sector effects in case of sectoral trade data). Robust standard errors in parentheses, $* * *$ $p<0.01, * * p<0.05, * p<0.1$.

Using the log of road distance or travel time instead of great-circle distance as a proxy of transportation costs (columns (2) and (3)), the estimated border effect increases from -0.804 to -0.547 and to -0.422 , respectively. Hence, international trade is only by $42 \%$ and $34 \%$ smaller, respectively, than intranational trade, holding other determinants of trade constant. ${ }^{47}$ Hence, it appears that, in Europe, using proxies of transportation costs that account for the quality of infrastructure brings down the estimated border effect by between $24 \%$ and $38 \%$.

Sensitivity Analysis. Treating borders as exogenous to sectoral trade shocks $\epsilon_{i j s}$, the identification assumption underlying our analysis can be stated as $\operatorname{cov}\left(\epsilon_{i j s}, T_{i j} \mid B_{i j}, e x_{i s}, i m_{i s}\right)=0$. A high realization of $\epsilon_{i j s}$ could incite countries $i$ and $j$ to invest into reducing $T_{i j}$, which could bias the distance effect $\mu_{1}$ away from zero. How this affects our coefficient of interest, $\mu_{2}$, is not obvious, though. $T_{i j}$ depends on investment $I_{i}$ and $l_{j}$, but also on investment by countries $k \neq i, j$ located on the shortest travel route between $i$ and $j$. So, if $i$ and $j$ boost investment due to a positive shock in $\epsilon_{i j s}$, they also lower $T_{i i}$ and $T_{j j}$, which increases $X_{i i}$ and $X_{j j}$, and this contributes to moving $\mu_{2}$ upwards at given $I_{k}$.

To contain the danger of biased results, we restrict the sample to non-contingent countries, the transport links between which are importantly shaped by countries other than the trade partners themselves. We also instrument trade costs $T_{i j}$ by the weighted sum of $T_{k k}$, where $k$ belongs to the set $K$ of countries through which any transport from $i$ to $j$ has to transit. More precisely,

$\overline{{ }^{47} 1-\exp (-0.547)}=0.42$, and $1-\exp (-0.422)=0.34$, respectively. 
we focus on travel time and apply the average travel speeds measured in within-country $k \in K$ links to the great-circle distance from $i$ to $j$. The partial correlation between this instrument and actual travel time $T_{i j}$ is 0.46 . Columns (4) to (5) of Table 7 show the results. First, note that excluding the 61 contingent pairs strongly increases the absolute value of the border effect (column (4)). ${ }^{48}$ Second, replacing great-circle distance by travel time lowers the absolute value of the border effect quite significantly (column (5)). ${ }^{49}$ Third, instrumenting travel time further slightly reduces the absolute value of the border effect but increases that of travel time (column (6)).

Next, we turn from aggregate to sectoral data. Columns (7) to (9) show that our argument remains robust. Estimated coefficients change only minimally. If we drop all trade relationships of any country that account for more than $5 \%$ of total sector-level trade and which are, thus presumably important enough to affect investment decisions, we find a substantially higher border effect, but replacing great-circle distance by road distance or travel time shrinks the effect; see Table .3 in the Appendix. ${ }^{50}$

Finally, we also check whether our results are driven by the recent eastward enlargement of the EU. Excluding the 10 new eastern European EU member countries present in our data, we find an algebraically smaller border effect. Still, the measured border effect changes upon replacing great-circle distance by road distance or travel time in the way suggested by our model.

\section{Extensions and robustness analysis}

In this section, we discuss some potential extensions of the framework.

\subsection{Toll roads}

Today, many countries operate public toll tax systems for freight traffic. The share of interregional highways subject to decentrally administered toll systems ranges from 6 percent in the U.S. to 52 percent in France. Countries such as Germany and Austria have centrally administered distance dependent road pricing for lorries. User fees may be contingent on a wide array of factors such as the situation of the environment (e.g., smog), the degree of congestion, the time at which a road is traveled, and so on.

How a toll system affects the main argument in this paper depends very much on its specific design. Here we study a particularly interesting and relevant configuration. Suppose governments

\footnotetext{
${ }^{48}$ The common language dummy turns insignificant as we have only very few non-contingent countries with common language in the sample.

${ }^{49} \mathrm{~A}$ similar result obtains when using road distance; see Table .3 in the Appendix. Interestingly, the elasticity of trade with respect to travel time is almost unchanged by restricting the sample to non-contingent pairs.

${ }^{50}$ Table .4 in the Appendix runs sector-level regressions and finds statistically significant border effects in 12 out of 16 sectors. In all of these sectors, the border effect is (algebraically) smaller when road distance or travel time is used instead of great-circle distance.
} 
decide on the infrastructure allocation across space, but rather than taxing consumers through lump-sum taxes, they tax road users per unit of distance. Further assume that the tax varies continuously on the space of addresses and that it works just as our iceberg transportation costs, albeit with the shaved transported good not lost but transferred into the governments coffers and redistributed to households. In that case, the government has two margins of action: it sets a distribution of fees, $f(s)$, where $s \in[0, \bar{s}]$, and decides on the infrastructure allocation,

$i(s)$. Total income from fees will be $B=\int_{0}^{\bar{s}} f(s) \bar{R}(s) d s$, where $\bar{R}(s)$ measures total traffic through location $s$. Note that $R(s)$ depends on the domestic and on the foreign distribution of infrastructure. If the government is free to spend $B$ on whatever infrastructure distribution it prefers, and does not impose any additional tax, it will find it optimal to make fees dependent on the distance to the border, with higher fees the closer the border. Moreover, it will concentrate its spending as before in the central regions of the jurisdiction. The reason for this result is identical to the one discussed above: The government cares only about home welfare, thus taxing foreigners and transferring the receipts to home citizens is a welcome option.

If governments are not allowed to spend toll income on places other than those where the income has been generated, there will be a direct link between infrastructure investment and transit volume, $f(s) \bar{R}(s) / q(s)=i(s)$. Governments will then set $f(s)$ such that native welfare is maximized. By imposing high fees in border regions, governments tax foreign consumers more strongly than domestic ones; however, the implied high investment volumes are of little value for domestic consumers. By imposing high fees in the center, governments affect domestic consumers, but also achieve high utility for them. The implied distribution of infrastructure need not exhibit excessive spatial variation, but it still can; the exact outcome depending on underlying model parameters.

\subsection{Private-public partnerships (PPP)}

Since ancient times, governments have asked private agents to construct and operate roads or railways and allowed them to take fees for road usage. In England, from the 17th century on, Parliament entrusted private companies with concessions to run certain road connections; around 1830 there were about 48,000 km of so called turnpike roads; see Lay (1992). The system was also used in the US. Currently, cash-strapped governments around the world use various types of PPP to finance the construction of transport links.

We provide a simple model of such a situation. Each government in the two countries auctions the exclusive right to run a road segment which coincides with the space of the government's jurisdiction. The firm with the highest bid gets the license. In a competitive auction, the equilibrium bid amounts to exactly the profits that the would-be monopolist can achieve. In principle, the government can let the monopolist choose the preferred investment schedule $i(s)$ and a fee structure $f(s)$. Or it can regulate either $i(s)$ or $f(s)$. Here, we consider an example where two contiguous countries each entrust a private monopolist to choose an optimal $i^{M}(s)$, given a regulated user fee $p$ per unit of traffic. 
The monopolist in Home sets $i^{M}(s)$ to maximize profits

$$
\pi\left(i^{M}\right)=p \int_{0}^{\bar{s}} \bar{R}(x) d x-\int_{0}^{\bar{s}} q(x) i^{M}(x) d x,
$$

where $\bar{R}(x)$ is the measure of the total traffic through location $x, i^{M}(x)$ is infrastructure investment at location $x$, and $q(x)$ denotes the associated cost per unit of investment. ${ }^{51}$

Total traffic through location $x$ is given by

$$
\bar{R}(x)=\int_{0}^{x}\left(\int_{x}^{2 \bar{s}} R(y, z) d z\right) d y+\int_{x}^{2 \bar{s}}\left(\int_{0}^{x} R(y, z) d z\right) d y
$$

where

$$
R(y, z)=(1-\alpha)\left(1-t^{M}\right) \frac{Y(z) T(y, z)^{1-\sigma}}{\int_{0}^{\bar{s}} T(v, z)^{1-\sigma} d v} .
$$

Here, $R(y, z)$ is interpreted as the traffic from $y$ to $z$ : a quantity measure of trade in products produced at $y$ and transported to $z$. It is determined by demand at location $z$ and the transportation costs from $y$ to $z$. Note that in general $R(y, z)$ is not equal to $R(z, y)$. Finally, $t^{M}$ is the income tax imposed by the government to finance the infrastructure investments and $Y(z)$ is the gross income at location $z$. We assume that the monopolist takes the income tax and the location sizes as given. As in the benchmark case, the monopolists at Home and Foreign choose the corresponding infrastructure investments non-cooperatively. In the symmetric Nash equilibrium with no asymmetries in the cost of infrastructure and the location size, the domestic infrastructure profile (in case of the interior solution) is given by

$$
\tilde{\imath}^{M}(x)^{\delta}=\frac{p \gamma(1-\alpha)\left(1-\tilde{t}^{M}\right)(\sigma-1)}{q}\left(\tilde{\phi}^{L, M}(x)+\tilde{\phi}^{R, M}(x)\right)
$$

where as before $\tilde{\phi}^{L, M}(x)\left(\tilde{\phi}^{R, M}(x)\right)$ represents the aggregate marginal profits due to a rise in traffic from the right (the left) to the left (the right) of location $x$.

Similar to the social-planner scenario, the monopolist infrastructure profile has a hump shape in autarky and is skewed towards the border with the foreign country in the open economy case. It is also straightforward to show that the presence of costs associated with crossing the border will redistribute the infrastructure away from the border, amplifying the border effect. However, there is a conceptual difference between $i^{H}(s)$ and $i^{M}(s)$. Under certain parameter constellations, the monopolist finds it optimal to chose zero investment in peripheral locations. This is because higher investment in $s$ has two effects on total traffic. On the one hand, traffic through $s$ goes up, increasing total traffic. On the other hand, traffic through other regions

\footnotetext{
${ }^{51}$ In the above specification, we assume that the government pays a fixed price $p$ per unit of the traffic to the monopolist and finances this with a lump-sum tax. This assumption removes the distortive effects of $p$ on the infrastructure profile.
} 
goes down because of the corresponding changes in the price indices (a substitution or trade diversion effect). This tends to decrease total traffic. In some cases the negative effect prevails over the positive one, so that $i^{M}(s)=0$. In contrast, the social planner sets $i(s)>0$ for all $s$ except $s=0$.

Figure 8 shows the optimal infrastructure distributions chosen by the monopolists under autarky (panel $a$ ), and under international trade (panel $b$ ), and compares them with the Nash socialplanner or the first-best solutions. The parameterization is benchmark with $\tau=1$ and the fee $p$ is set such that the monopolist and social-planner scenarios yield the same overall investment. As can be seen, the monopolist chooses investment schedules that exhibit substantially more spatial variation than the one picked by the social planner. Moreover, as discussed above, there is zero investment at peripheral locations in both panels. In the case of international trade, the monopolist invests much more around the border even compared to the first-best outcome. This can generate a smaller or even no border effect, but comes at cost of zero investments in many peripheral locations (that are in fact driven into autarky).

Figure 8 - Equilibrium investment loci: social planner vs. monopolist.
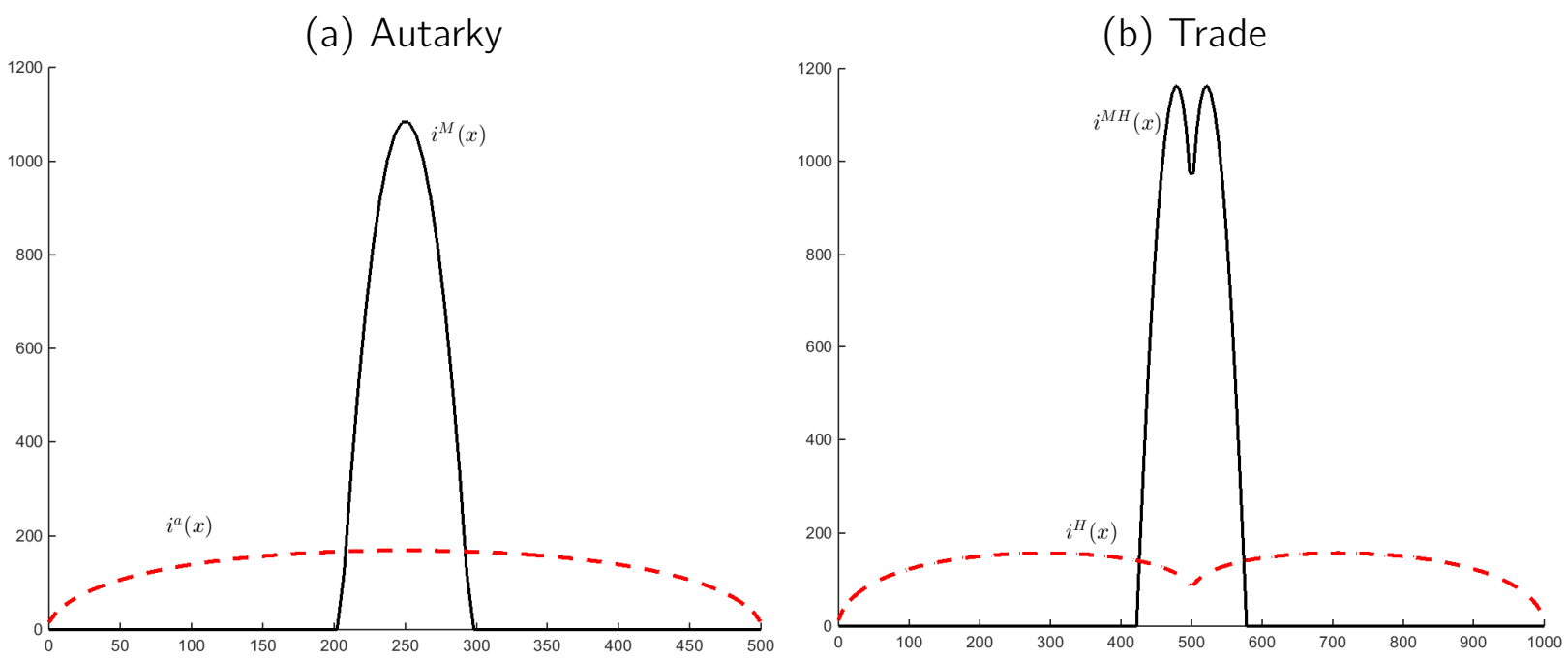

Notes. Solid black curves $\left(i^{M}(x)\right.$ and $\left.i^{M H}(x)\right)$ refer to investment profile resulting from non-cooperative monopolists. Dashed red curves $\left(i^{a}(x)\right.$ and $\left.i^{H}(x)\right)$ refer to (non-cooperative Nash) solutions. The parameterization is as follows: $\sigma=2.7, \delta=1.65, \gamma=0.86, \tau=1, \alpha=0.5, q(x)=q=1, b=1, m(x)=1000$ for all locations, and $\bar{s}=500$. In Figure $(a), p=0.4$. Spending on infrastructure (in terms of the tax rate) in this case is 13.4 percent. In Figure (b), $p=0.275$. Spending on infrastructure in each country in the Nash equilibrium is 13.1 percent.

\subsection{Internal labor mobility}

In the model we assume away the effects of internal labor mobility on the infrastructure profile. Here we offer some discussion. First, note that the underinvestment problem in border regions 
relative to the first-best occurs regardless of the form of a (non-degenerate) distribution of economic activity. This is because the share of non-internalized benefits of investment are higher the closer one gets to the border, regardless of distributional details.

In contrast, how the endogenous adjustment of infrastructure investment shapes the distribution of economic activity and the size of the border effect, is hard to determine analytically as the social planner needs to internalize the effects of infrastructure on the endogenous population density. Moreover, multiple equilibria are possible. At the same time, the intuition behind the impact of labor mobility on the equilibrium infrastructure profile seems to be relatively straightforward.

With internal labor mobility (associated with some adjustment costs to avoid extreme solutions), the equilibrium can be considered as the outcome of the following multi-stage variation of the model. The economy starts with some distribution of population, which results in a certain distribution of infrastructure investment chosen by the social planner. Then, given this infrastructure profile, agents decide about their location and, as a result, the population distribution changes. Given the new distribution of population, the social planner adjusts the distribution of infrastructure and continues doing so until convergence.

To understand the potential effects of labor mobility on the infrastructure profile in the above variation of the model, we distinguish between high and low border frictions, and we assume a uniform distribution of population as the initial one. With relatively high border costs, after the first stage, the distribution of the price index will have a $U$-shaped form with the minimum at some internal location that is relatively close to the central one (see panel $b$ in Figure 4 ). In this case, at the second stage the population will move away from the border to benefit from lower aggregate prices at internal locations. This in turn will move the infrastructure distribution even further from the border as well and so on. As a result, labor mobility will magnify the concentration of infrastructure around internal locations and, therefore, increase the magnitude of the border effect. The opposite happens when the border frictions are low. When the border cost is low, after the first stage the price indexes will be the lowest relatively close to the border (but not necessarily at the border as showed by the simulations), implying that the population will move closer to the border. This will lead to more investment around the border and so on. In this case, labor mobility will magnify the concentration of infrastructure around the border and, thereby, decrease the magnitude of the border effect. However, underinvestment in Nash relative to the first-best in border regions will remain, regardless of the distribution of economic activity.

The reasoning above suggests that there can exist a certain threshold value of the border cost $\hat{\tau}$ such that if $\tau>\hat{\tau}$, labor mobility increases the border effect, otherwise the opposite happens. Further (perhaps, quantitative) analysis is needed to explore the actual effect of labor mobility on infrastructure investments. Meanwhile, if the infrastructure investments were initiated/started in the past when the border costs were quite high, then in the model with labor mobility one might expect a higher border effect, rather than a lower one. 


\subsection{The political economy of infrastructure investment}

An alternative way of modelling the endogenous infrastructure distribution is a majority rule voting system. For any distribution of the transport infrastructure, each household derives a certain utility level which is represented by its indirect utility function. As a result, each household has its own preferences over the continuum of infrastructure distributions that are determined by the geographical location of this household: a household prefers more infrastructure investments around its location. For instance, for a household located at the periphery $(x=0)$, the optimal infrastructure profile on $[0, \bar{s}]$ is a decreasing curve with maximum at $x=0$. It is possible to show that the household preferences defined above are single peaked. As a result, the political equilibrium infrastructure profile is the profile chosen by the median voter, which is the household located at $x=\bar{s} / 2$. So, in the absence of asymmetries across locations, the median household will choose a hump shaped profile with maximum at $\bar{s} / 2$. In other words, the median voter solution is qualitatively equivalent to the social planner solution. Thus, all the qualitative results derived in the paper can be extended to the framework with a majority rule voting system.

\section{Conclusions}

This paper develops a simple theoretical model where consumers demand goods from the entire world, but the world is fragmented into jurisdictions which set infrastructure investment schedules in a non-cooperative way. Governments care only for the welfare of their own constituency and ignore the effects that their decisions have on foreign consumers; this basic externality leads to global underinvestment. The lower the geographical distance of a location is to the political border, the bigger is the externality since a larger share of the benefits caused by investment accrues to foreign consumers. Hence, the externality has a spatial structure: infrastructure underinvestment is stronger in poltically peripheral regions of jurisdictions rather than in central ones.

The local lack of infrastructure investment makes imports from other countries more expensive than imports from other regions from the same country, even if geographical distance or incomes of trading partners are the same. Our infrastructure story may therefore contribute towards unpacking trade costs and explaining the border effect first highlighted by McCallum (1995) and since then discussed in a voluminous empirical literature.

We use intra- and international trade flows data from Europe to calibrate the model. We find that about $20 \%$ of the empirically observable border effect is due to low infrastructure investment around national borders. In our simulations, the border effect is magnified by the emergence of intercontinental trade and appears larger, when countries are asymmetric with respect to their sizes. We argue that privatization of construction and operation of roads may not undo the border underinvestment problem; similarly, it also emerges under a majority voting system.

Information from the Bing Maps Route Service allows us to show that international road distances are about $22 \%$ longer than intranational ones and that travel is $28 \%$ longer, holding 
bird-flight distance constant. The econometrically identified border effect falls from -0.80 in a conventional setup to -0.55 when road distance is used rather than bird-flight distance. Hence, using transportation cost proxies that account for infrastructure brings down the border effect, as implied by our theoretical argument.

Future work should endogenize the distribution of economic activity by allowing intranational migration of workers or/and firms. Moreover, to carry out a full-fledged quantitative analysis, it would be needed to carry out the analysis on a plane rather than a line with realistic topology as in Allen and Arkolakis (2014); this is a non-trivial generalization, since it requires not only to characterize optimal investment schedules for given routes, but also to solve for the layout of optimal transportation networks. 


\section{References}

Allen, T. and C. Arkolakis (2014). Trade and the Topography of the Spatial Economy. Quarterly Journal of Economics, 129(3): 1085-1140.

Anderson, J.E. and E. van Wincoop (2004). Trade costs. Journal of Economic Literature, 42: 691-751.

Anderson, J.E. and E. van Wincoop, E. (2003). Gravity with Gravitas: A Solution to the Border Puzzle. American Economic Review 93(1): 170-92.

Behar, A. and A. Venables (2011). Transport Costs and International Trade. In: de Palma, A., R. Lindsey, E. Quinet, and R. Vickerman, eds., A Handbook Of Transport Economics, Edgar Elgar.

Behrens, K., P. Picard (2011). Transportation, freight rates, and economic geography. Journal of International Economics 85(2): 280-291.

Casella, A., and J. Rauch, Overcoming Informational Barriers to International Resource Allocation: Prices and Ties, Economic Journal 113(1): 21-42.

Chen, N. (2004). Intra-national versus international trade in the European Union: why do national borders matter? Journal of International Economics 63(1): 93-118.

Combes, P-P., M. Lafourcade and T. Mayer, 2005. The Trade Creating Effects of Business and Social Networks: Evidence from France, Journal of International Economics 66:1-29.

Combes, P-P. and M. Lafourcade, 2005. Transport Costs. Measures, Determinants, and Regional Policy Implications for France. Journal of Economic Geography 5:319-349.

Congressional Budget Office, 2010. Public Spending on Transportation and Water Infrastructure. US Congress, Washington, DC.

Cosar, K. and B. Demir (2015). Domestic Road Infrastructure and International Trade: Evidence from Turkey, Journal of Development Economics, forthcoming.

Costinot, A. and A. Rodriguez-Clare (2014), Trade Theory with Numbers: Quantifying the Consequences of Globalization, Handbook of International Economics, Vol. 4, Chapter 4, Gita Gopinath, Elhanan Helpman, and Kenneth Rogoff (eds.), Elsevier: Holland.

Courant, P.N., and A.V. Deardorff (1992). International Trade with Lumpy Countries. Journal of Political Economy 100(1): 198-210.

Donaldson, D. (2014). Railroads and Raj: Estimating the Impact of Transportation Infrastructure. American Review of Economics, forthcoming.

Donaldson, D., and R. Hornbeck, Railroads and American Economic Growth: a "Market Access" Approach, Quarterly Journal of Economics, forthcoming. 
Duranton, G., P. Morrow, and M. A. Turner (2014). Roads and Trade: Evidence from the US. The Review of Economic Studies 81 (2): 681-724.

Gramlich, E.M. (1994). Infrastructure Investment: A Review Essay. Journal of Economic Literature 32(3): 1176-1196.

Head, K., and T. Mayer (2014), "Gravity Equations: Workhorse, Toolkit, and Cookbook", Handbook of International Economics, Vol. 4, Chapter 3, Gita Gopinath, Elhanan Helpman, and Kenneth Rogoff (eds.), Elsevier: Holland.

Head, K., and T. Mayer (2002), Illusory Border Effects: Distance mismeasurement inflates estimates of home bias in trade, CEPII Working Paper 2002-1.

Helliwell, J.F. (1998). How Much Do National Borders Matter? The Brookings Institution.

Hummels, D., V. Lugovskyy and A. Skiba (2009). The trade reducing effects of market power in international shipping, Journal of Development Economics 89: 84-97.

ITF-OECD (International Transport Forum) (2012), Statistics Brief-Infrastructure Investment, Paris.

Krugman, P. (1991). Increasing Returns and Economic Geography. Journal of Political Economy 99: 383-499.

Fujita, M., P.R. Krugman, and A.J. Venables (1999). The Spatial Economy. Cambridge, MA: MIT Press.

Lay, M.G. (1992), Ways of the World: A History of the World's Roads and of the Vehicles That Used Them, New Brunswick: Rutgers University Press.

Limao, N., and A.J. Venables (2001). Infrastructure, Geographical Disadvantage, Transport Costs, and Trade. World Bank Economic Review 15(3): 451-479.

Mayer, T., and S. Zignago (2011), Notes on CEPII's distance measures: the GeoDist Database, CEPII Working Paper 2011-25.

McCallum, J. (1995). National Borders Matter: Canada-U.S. Regional Trade Patterns. American Economic Review 85(3): 615-23.

McCann, Ph. (2005). Transport costs and new economic geography. Journal of Economic Geography 5: 305-318.

Milgrom, P., and C. Shannon (1994). Monotone Comparative Statics. Econometrica 62(1): 157-180.

Nitsch, V. (2000). National Borders and International Trade. Evidence from the European Union. Canadian Journal of Economics 33(4): 1091-1105.

Okubo, T. (2004). Border Effect in the Japanese Market - A Gravity Model Analysis. Journal of the Japanese and International Economies 18: 1-11. 
Persson, J. and D. Song (2010), The Land Transport Sector: Policy and Performance, OECD Economics Department Working Papers, No. 817, OECD Publishing.

Pisu, M. and H. Braconier (2013), Road Connectivity and the Border Effect: Evidence from Europe, GEP Research Paper Series 2013/06.

Rose, A.K., and E. van Wincoop (2001). National Money as a Barrier to International Trade: The Real Case for Currency Union. American Economic Review 91(2): 386-390.

Rossi-Hansberg, E. (2005). A Spatial Theory of Trade. American Economic Review 95(5): 1464-1491.

Samuelson, P. (1952). The Transfer Problem and Transport Costs: the Terms of Trade when Impediments are Absent. Economic Journal 62: 278-304.

Timmer, M., E. Dietzenbacher, B. Los, R. Stehrer, G. de Vries (2015), "An Illustrated User Guide to the World Input-Output Database: the Case of Global Automotive Production", Review of International Economics, doi: 10.1111/roie.12178.

Wei, S. (1996). Intra-National versus International Trade: How Stubborn are Nations in Global Integration? NBER Working Paper 553.

Winston, C. (1985). Conceptual Developments in the Economics of Transportation: An Interpretative Survey. Journal of Economic Literature 23: 57-94.

Wolf, H. (2000). Intranational Home Bias in Trade. Review of Economics and Statistics 82(4): 112-128.

Venables, A. (2005). Spatial disparities in developing countries: cities, regions, and international trade. Journal of Economic Geography 5(1): 3 - 21. 


\section{Appendix}

\section{Appendix A: Proofs}

In the Appendix, we provide all the necessary proofs for the lemmas and propositions in the paper.

\section{Proof of Lemma 1}

Property (i)

For three different locations $x, y$, and $z$ such that $x<y<z$,

$$
\begin{gathered}
T(x, y) T(y, z)=\left(1+\frac{1}{\delta-1} \int_{x}^{y} i(s)^{1-\delta} d s\right)^{\gamma}\left(1+\frac{1}{\delta-1} \int_{y}^{z} i(s)^{1-\delta} d s\right)^{\gamma} \\
=\left(1+\frac{1}{\delta-1} \int_{x}^{y} i(s)^{1-\delta} d s+\frac{1}{\delta-1} \int_{y}^{z} i(s)^{1-\delta} d s+\frac{1}{(\delta-1)^{2}} \int_{x}^{y} i(s)^{1-\delta} d s \int_{y}^{z} i(s)^{1-\delta} d s\right)^{\gamma} \\
>\left(1+\frac{1}{\delta-1} \int_{x}^{y} i(s)^{1-\delta} d s+\frac{1}{\delta-1} \int_{y}^{z} i(s)^{1-\delta} d s\right)^{\gamma} \\
=\left(1+\frac{1}{\delta-1} \int_{x}^{z} i(s)^{1-\delta} d s\right)^{\gamma}=T(x, z) .
\end{gathered}
$$

\section{Property (iv)}

The behavior of $T(x, z)$ with respect to geographical distance can be checked by looking at the derivative of $T(x, z)$ with respect to $z$. Specifically, we have that

$$
\begin{aligned}
T(x, z) & =\left(1+\frac{1}{\delta-1} \int_{x}^{z} i(s)^{1-\delta} d s\right)^{\gamma}, \\
T_{z}(x, z) & =\gamma\left(1+\frac{1}{\delta-1} \int_{x}^{z} i(s)^{1-\delta} d s\right)^{\gamma-1} \frac{1}{\delta-1}\left[i(z)^{1-\delta}\right]>0, \\
T_{z z}(x, z) & =\gamma\left(1+\frac{1}{\delta-1} \int_{x}^{z} i(s)^{1-\delta} d s\right)^{\gamma-1}\left((\gamma-1) \frac{\left(\frac{1}{\delta-1}\left[i(z)^{1-\delta}\right]\right)^{2}}{1+\frac{1}{\delta-1} \int_{x}^{z} i(s)^{1-\delta} d s}-i(z)^{-\delta} i^{\prime}(z)\right) \gtrless 0 \\
& \Longleftrightarrow \frac{(\gamma-1)}{(T(x, z))^{1 / \gamma}}\left(\frac{i(z)^{1-\delta}}{\delta-1}\right)^{2} \gtrless i^{\prime}(z) i(z)^{-\delta} .
\end{aligned}
$$

The left-hand side shows the effect of a marginal increase in distance on $T_{z}(x, z)$ under the assumption that $i(z+d z)=i(z)$. It reflects variation in trade costs due to an increase in distance, holding infrastructure constant. The right-hand side makes the opposite assumption and reports the change in $T_{z}(x, z)$ due to the difference in infrastructure investment between $z$ and $z+d z$, holding the sheer costs of distance constant. $T(x, z)$ is convex (as in Krugman), if the left-hand side dominates. 


\section{Property $(v)$}

We compute the elasticity of substitution between investment at two different locations $s^{\prime}, s^{\prime \prime} \in[x, z]$ as follows

$$
-\frac{d \ln \left[i\left(s^{\prime}\right) / i\left(s^{\prime \prime}\right)\right]}{d \ln \left|\frac{\partial T(x, z)}{\partial i\left(s^{\prime}\right)} / \frac{\partial T(x, z)}{\partial i\left(s^{\prime \prime}\right)}\right|}
$$

where for any $s \in[x, z]$

$$
\frac{\partial T(x, z)}{\partial i(s)} \stackrel{d .}{=} \gamma\left(1+\frac{1}{\delta-1} \int_{x}^{z} i(s)^{1-\delta} d s\right)^{\gamma-1} i(s)^{-\delta}
$$

As a result, the elasticity of substitution is given by

$$
-\frac{d \ln \left[i\left(s^{\prime}\right) / i\left(s^{\prime \prime}\right)\right]}{-d \delta \ln \left|i\left(s^{\prime}\right) / i\left(s^{\prime \prime}\right)\right|}=\frac{1}{\delta}<1
$$

\section{Property $(v i)$}

The Lagrangian for the cost minimizing problem can be written as follows:

$$
\wedge(\{i(s)\}, \lambda)=q \int_{x}^{z} i(s) d s+\lambda\left[1+\frac{1}{\delta-1} \int_{x}^{z} i(s)^{1-\delta} d s-\bar{T}^{1 / \gamma}\right]
$$

where $q$ is the cost of infrastructure investment at location $s$. It is straightforward to see that the first order conditions imply that, for any two locations $k, l \in[x, z]$,

$$
i(k)=i(I) \text {. }
$$

Taking into account the budget constraint, we derive that

$$
i(k)=i(I)=\left\{(z-x) /\left[(\delta-1)\left(\bar{T}^{1 / \gamma}-1\right)\right]\right\}^{1 /(\delta-1)} .
$$

\section{Proof of Proposition 1}

To find the optimal infrastructure investments on $[0, \bar{s}]$, we first formulate and analyze a discrete modification of the social planner's maximization problem (which approximates the actual continuous maximization problem). Remember that the social planner solves

$$
\left\{i^{a}(x), t^{a}\right\}_{x \in S}=\arg \max \left\{(1-t)\left(\int_{x \in S} \tilde{m}(x) v(x) d x\right)^{\frac{1-\alpha}{\sigma-1}} \mid \int_{x \in S} q(x) i(x) d x \leq b t L\right\} .
$$

where

$$
\begin{aligned}
v(x) & =\int_{z \in S} T(x, z)^{1-\sigma} d z \\
& =\int_{0}^{\bar{s}}\left(1+\frac{1}{\delta-1}\left|\int_{x}^{z} i(s)^{1-\delta} d s\right|\right)^{\gamma(1-\sigma)} d z \\
& =\int_{0}^{x}\left(1+\frac{1}{\delta-1} \int_{z}^{x} i(s)^{1-\delta} d s\right)^{\gamma(1-\sigma)} d z+\int_{x}^{\bar{s}}\left(1+\frac{1}{\delta-1} \int_{x}^{z} i(s)^{1-\delta} d s\right)^{\gamma(1-\sigma)} d z .
\end{aligned}
$$


In the discrete version of the problem, we assume that the geography of the economy consists of $n$ points (transportation hubs) uniformly distributed on $[0, \bar{s}]: 0=x_{1}<x_{2} . .<x_{n}=\bar{s}$. We define the distance between location $x_{i}$ and $x_{i+1}$ by $\triangle_{n}$ : that is, $x_{2}-x_{1}=\ldots x_{n}-x_{n-1}=\triangle_{n}$. We also assume that the transportation costs between two locations, $x_{i}$ and $x_{j}$, depend on the level of infrastructure at the location of the producer and the intermediate locations between $x_{i}$ and $x_{j}$ (not including the location of the consumer) and the distance between the locations determined by $\triangle_{n} \cdot{ }^{52}$ Specifically, if a product is sent from $x_{i}$ to $x_{j}\left(x_{i}<x_{j}\right)$, the transportation costs are

$$
T\left(x_{i}, x_{j}\right)=\left(1+\frac{1}{\delta-1} \sum_{k=i}^{j-1} i\left(x_{k}\right)^{1-\delta} \triangle_{n}\right)^{\gamma} .
$$

We then formulate the social planner's problem in the case of the discrete geography in the following way:

$$
\left\{i^{a}\left(x_{i}\right), t^{a}\right\}_{i=1 . . n}=\arg \max \left\{(1-t)\left(\sum_{i=1}^{n} \tilde{m}\left(x_{i}\right) v\left(x_{i}\right) \triangle_{n}\right)^{\frac{1-\alpha}{\sigma-1}}\right\} \text {, }
$$

subject to

$$
\begin{gathered}
\sum_{i=1}^{n} q\left(x_{i}\right) i\left(x_{i}\right) \triangle_{n} \leq b t L, \\
i\left(x_{i}\right) \geq 0, i=1 . . n .
\end{gathered}
$$

Here,

$$
v\left(x_{i}\right)=\triangle_{n}\left(\begin{array}{c}
\sum_{k=1}^{i-1}\left(1+\frac{1}{\delta-1} \sum_{j=k}^{i-1} i\left(x_{j}\right)^{1-\delta} \triangle_{n}\right)^{\gamma(1-\sigma)}+ \\
\sum_{k=i+1}^{n}\left(1+\frac{1}{\delta-1} \sum_{j=i+1}^{k} i\left(x_{j}\right)^{1-\delta} \triangle_{n}\right)^{\gamma(1-\sigma)}+1
\end{array}\right),
$$

where the first term in the brackets describes the welfare derived from trade with locations on the left side of $x_{i}$, the second term describes the welfare derived from trade with locations on the right side of $x_{i}$, and one stands for the transportation costs from $x_{i}$ to $x_{i}$ (that are normalized to unity). In this case, the social planner's problem is to choose the level of transportation infrastructure at each location $x_{i}$ that maximizes the social welfare. This maximization problem is the approximation of the maximization problem in the main text (see (8)). Specifically, taking the limit $(n \rightarrow \infty)$, one can derive the actual maximization problem described in the main text. This in turn implies that the solution of the continuous maximization problem is the limit of the solution of the discrete problem (when $n \rightarrow \infty$ ).

Note that the existence of the global maximum in the above discrete maximization problem follows from the continuity of the objective function and the fact that the objective function is maximized on the compact subset of $R^{n}$ (which is given by the constraints in (22) and (23)). Moreover, it is straightforward

\footnotetext{
52The fact that the transportation costs between $x_{i}$ and $x_{j}$ do not include the level of infrastructure investment at the destination location (the location of the consumer) means non-symmetric transport costs. However, taking the limit $(n \rightarrow \infty)$ will imply symmetric transport costs between any locations, as in this case the contribution of the infrastructure of a single location into the total transport costs will be negligible.
} 
to show that if $\gamma(\sigma-1)(\delta-1)<1$ (as assumed in the paper), $\left(1+\frac{1}{\delta-1} \sum_{j=i+1}^{k} i\left(x_{j}\right)^{1-\delta} \triangle_{n}\right)^{\gamma(1-\sigma)}$ is a concave function in $i(x)=\left\{i\left(x_{j}\right)\right\}_{j=1 . . n}$ for any $i$ and $k$. This in turn implies that $\tilde{v}\left(x_{i}\right)$ is concave in $i(x)$ as the sum of concave functions, but not strictly concave, as $v\left(x_{i}\right)$ does not depend on $i\left(x_{i}\right)$. However, it is straightforward to show that $\sum_{i=1}^{n} \tilde{m}\left(x_{i}\right) v\left(x_{i}\right)$ is strictly concave with respect to $i(x)$. Finally, since $(1-\alpha) /(\sigma-1)$ is assumed to be strictly less than one, the objective function in $(21)$ is strictly concave in infrastructure investments, $i(x)$.

Next, we formulate the corresponding Lagrange function that can be written as follows:

$$
\Lambda \equiv(1-t)\left(\triangle_{n} \sum_{i=1}^{n} \tilde{m}\left(x_{i}\right) v\left(x_{i}\right)\right)^{\frac{1-\alpha}{\sigma-1}}-\lambda_{0}\left(\sum_{i=1}^{n} q\left(x_{i}\right) i\left(x_{i}\right) \triangle_{n}-b t L\right)
$$

where $\lambda_{0}$ is the Lagrange multiplier of the corresponding constraint. The necessary and sufficient condition for the global maximum is that

$$
\begin{aligned}
\frac{\partial \Lambda}{\partial i\left(x_{i}\right)} & =0, i=1 . . n, \\
\frac{\partial \Lambda}{\partial t} & =0 .
\end{aligned}
$$

Next, we find the expression for $\partial \Lambda / \partial i\left(x_{i}\right)$. Specifically,

$$
\frac{\partial \Lambda}{\partial i\left(x_{i}\right)}=\frac{(1-t)(1-\alpha)}{\sigma-1} \triangle_{n}\left(\triangle_{n} \sum_{l=1}^{n} \tilde{m}\left(x_{l}\right) v\left(x_{l}\right)\right)^{\frac{1-\alpha}{\sigma-1}-1} \sum_{l=1}^{n} \tilde{m}\left(x_{l}\right)\left(v\left(x_{l}\right)\right)_{i\left(x_{i}\right)}^{\prime}-\lambda_{0} \triangle_{n} q\left(x_{i}\right) .
$$

One can show that

$$
\begin{aligned}
& \left(v\left(x_{l}\right)\right)_{i\left(x_{i}\right)}^{\prime}=\left(\triangle_{n}\right)^{2} \gamma(\sigma-1) i\left(x_{i}\right)^{-\delta} \sum_{k=1}^{i}\left(1+\frac{1}{\delta-1} \sum_{j=k}^{I-1} i\left(x_{j}\right)^{1-\delta} \triangle_{n}\right)^{\gamma(1-\sigma)-1} \text { if } i<l, \\
& \left(v\left(x_{l}\right)\right)_{i\left(x_{i}\right)}^{\prime}=\left(\triangle_{n}\right)^{2} \gamma(\sigma-1) i\left(x_{i}\right)^{-\delta} \sum_{k=i}^{n}\left(1+\frac{1}{\delta-1} \sum_{j=l+1}^{k} i\left(x_{j}\right)^{1-\delta} \triangle_{n}\right)^{\gamma(1-\sigma)-1} \text { if } i>l, \\
& \left(v\left(x_{l}\right)\right)_{i\left(x_{i}\right)}^{\prime}=0
\end{aligned}
$$

As a result,

$$
\begin{aligned}
\frac{\partial \Lambda}{\partial i\left(x_{i}\right)}= & \frac{\left(\triangle_{n}\right)^{3} \frac{\gamma(1-\alpha)(1-t)}{i\left(x_{i}\right)^{\delta}} \sum_{l=1}^{i-1} \tilde{m}\left(x_{l}\right)\left(\sum_{k=i}^{n}\left(1+\frac{1}{\delta-1} \sum_{j=l+1}^{k} i\left(x_{j}\right)^{1-\delta} \triangle_{n}\right)^{\gamma(1-\sigma)-1}\right)}{\left(\triangle_{n} \sum_{l=1}^{n} \tilde{m}\left(x_{l}\right) v\left(x_{l}\right)\right)^{1-\frac{1-\alpha}{\sigma-1}}} \\
& +\frac{\left(\triangle_{n}\right)^{3} \frac{(1-\alpha)(1-t)}{i\left(x_{i}\right)^{\delta}} \sum_{l=i+1}^{n} \tilde{m}\left(x_{l}\right)\left(\sum_{k=1}^{i}\left(1+\frac{1}{\delta-1} \sum_{j=k}^{l-1} i\left(x_{j}\right)^{1-\delta} \triangle_{n}\right)^{\gamma(1-\sigma)-1}\right)}{\left(\triangle_{n} \sum_{l=1}^{n} \tilde{m}\left(x_{l}\right) v\left(x_{l}\right)\right)^{1-\frac{1-\alpha}{\sigma-1}}} \\
& -\lambda_{0} \triangle_{n} q\left(x_{i}\right) .
\end{aligned}
$$


Finally,

$$
\begin{aligned}
\frac{\partial \Lambda}{\partial t} & =-\left(\triangle_{n} \sum_{l=1}^{n} \tilde{m}\left(x_{l}\right) v\left(x_{l}\right)\right)^{\frac{1-\alpha}{\sigma-1}}+\lambda_{0} b L=0 \Longleftrightarrow \\
\lambda_{0} & =\frac{\left(\triangle_{n} \sum_{l=1}^{n} \tilde{m}\left(x_{l}\right) v\left(x_{l}\right)\right)^{\frac{1-\alpha}{\sigma-1}}}{b L} .
\end{aligned}
$$

Note that since $\left.\frac{\partial \Lambda}{\partial i\left(x_{i}\right)}\right|_{i\left(x_{i}\right)=0}=\infty$ (because of $\left.\gamma(\sigma-1)(\delta-1)<1\right), i^{a}\left(x_{i}\right)$ is strictly greater than zero for all $i=1 . . n$. That is, the global maximum $\left\{i^{a}\left(x_{i}\right), t^{a}\right\}_{i=1 . . n}$ does not include zero investments and, therefore, solves the following system of equations

$$
\begin{aligned}
& \frac{q\left(x_{i}\right) i^{a}\left(x_{i}\right)^{\delta}}{\triangle_{n} b L \gamma(1-\alpha)\left(1-t^{a}\right)}= \frac{\sum_{l=1}^{i-1} \tilde{m}\left(x_{l}\right)\left(\sum_{k=i}^{n}\left(1+\frac{1}{\delta-1} \sum_{j=l+1}^{k} i^{a}\left(x_{j}\right)^{1-\delta} \triangle_{n}\right)^{\gamma(1-\sigma)-1}\right)}{\sum_{i=1}^{n} \tilde{m}\left(x_{i}\right) v\left(x_{i}\right)} \\
&+\frac{\sum_{l=i+1}^{n} \tilde{m}\left(x_{l}\right)\left(\sum_{k=1}^{i}\left(1+\frac{1}{\delta-1} \sum_{j=k}^{l-1} i^{a}\left(x_{j}\right)^{1-\delta} \triangle_{n}\right)^{\gamma(1-\sigma)-1}\right)}{\sum_{i=1}^{n} \tilde{m}\left(x_{i}\right) v\left(x_{i}\right)}, \\
& \sum_{i=1}^{n} q\left(x_{i}\right) i^{a}\left(x_{i}\right) \triangle_{n}=b t^{a} L .
\end{aligned}
$$

As the solution of the continuous maximization problem is the limit of the solution of the discrete problem (when $n \rightarrow \infty$ ), it is straightforward to see that the optimal infrastructure investment function $i^{a}(x)$ and the tax rate $t^{a}$ solve

$$
\begin{aligned}
i^{a}(x)^{\delta} & =\frac{b L \gamma(1-\alpha)\left(1-t^{a}\right)}{q(x)}\left(\phi^{L}(x)+\phi^{R}(x)\right), \\
t^{a} & =\frac{\int_{0}^{\bar{s}} q(s) i^{a}(s) d s}{b},
\end{aligned}
$$

where

$$
\begin{aligned}
\phi^{L}(x) & =\frac{\int_{0}^{x} \tilde{m}(s)\left(\int_{x}^{\bar{s}}\left(1+\frac{1}{\delta-1} \int_{s}^{t} i^{a}(r)^{1-\delta} d r\right)^{\gamma(1-\sigma)-1} d t\right) d s}{\int_{0}^{\bar{s}} \tilde{m}(s) v(s) d s}, \\
\phi^{R}(x) & =\frac{\int_{x}^{\bar{s}} \tilde{m}(s)\left(\int_{0}^{x}\left(1+\frac{1}{\delta-1} \int_{t}^{s} i^{a}(r)^{1-\delta} d r\right)^{\gamma(1-\sigma)-1} d t\right) d s}{\int_{0}^{\bar{s}} \tilde{m}(s) v(s) d s} .
\end{aligned}
$$




\section{Proof of Proposition 2}

\section{Property (ii)}

Note that the derivative of $i^{a}(x)$ with respect to $x$ can be written as follows:

$$
\begin{aligned}
q(x) \delta i^{a}(x)^{\delta-1}\left(i^{a}(x)\right)^{\prime}+q^{\prime}(x) i^{a}(x)^{\delta} & =b L \gamma(1-\alpha)\left(1-t^{a}\right)\left(\left(\phi^{L}(x)\right)^{\prime}+\left(\phi^{R}(x)\right)^{\prime}\right) \Longleftrightarrow \\
\left(i^{a}(x)\right)^{\prime} & =\frac{b L \gamma(1-\alpha)\left(1-t^{a}\right)\left(\left(\phi^{L}(x)\right)^{\prime}+\left(\phi^{R}(x)\right)^{\prime}\right)-q^{\prime}(x) i^{a}(x)^{\delta}}{q(x) \delta i^{a}(x)^{\delta-1}} .
\end{aligned}
$$

We have that

$$
\begin{aligned}
\left(\phi^{L}(x)\right)^{\prime}= & \frac{\tilde{m}(x)\left(\int_{x}^{\bar{s}}\left(1+\frac{1}{\delta-1} \int_{x}^{t} i(r)^{1-\delta} d r\right)^{\gamma(1-\sigma)-1} d t\right)-\int_{0}^{x} \tilde{m}(s)\left(1+\frac{1}{\delta-1} \int_{s}^{x} i(r)^{1-\delta} d r\right)^{\gamma(1-\sigma)-1} d s}{\int_{0}^{\bar{s}} \tilde{m}(s) v(s) d s}, \\
\left(\phi^{R}(x)\right)^{\prime}= & \frac{-\tilde{m}(x)\left(\int_{0}^{x}\left(1+\frac{1}{\delta-1} \int_{t}^{x} i(r)^{1-\delta} d r\right)^{\gamma(1-\sigma)-1} d t\right)+\int_{x}^{\bar{s}} \tilde{m}(s)\left(1+\frac{1}{\delta-1} \int_{x}^{s} i(r)^{1-\delta} d r\right)^{\gamma(1-\sigma)-1} d s}{\int_{0}^{\bar{s}} \tilde{m}(s) v(s) d s} .
\end{aligned}
$$

It is straightforward to see that

$$
\begin{aligned}
& \left(\phi^{L}(0)\right)^{\prime}+\left(\phi^{R}(0)\right)^{\prime}>0 \\
& \left(\phi^{L}(1)\right)^{\prime}+\left(\phi^{R}(1)\right)^{\prime}<0 .
\end{aligned}
$$

Since $q^{\prime}(x)$ is continuous on $[0, \bar{s}]$ and $i^{a}(0)=i^{a}(\bar{s})=0, q^{\prime}(0) i^{a}(0)^{\delta}=q^{\prime}(\bar{s}) i^{a}(\bar{s})^{\delta}=0$. This in turn immediately implies that

$$
\begin{aligned}
& \left(i^{a}(0)\right)^{\prime}=\infty \\
& \left(i^{a}(\bar{s})\right)^{\prime}=-\infty .
\end{aligned}
$$

\section{Property (iii)}

First, we show that $i^{a}(x)$ is symmetric around $x=\bar{s} / 2$. To do so, we use the fact that the objective function of the planner's problem is strictly concave, implying that there is a unique solution of (11). Indeed, if there are two different solutions of (11), then there are two different stationary points, which is not possible with a strictly concave objective function. It is straightforward to see that if there is no variation in the cost of infrastructure investment and the household size across the locations: $q(x)=q$ and $m(x)=m$ for any $x \in[0, \bar{s}]$, symmetric investments indeed solve (11). Taking into account the uniqueness of the solution, we can conclude that the symmetric infrastructure profile delivers the global maximum of the maximization problem. Finally, if $i^{a}(x)$ is symmetric around $x=\bar{s} / 2$, the transportation costs are symmetric and, thereby, $v(x)$ is symmetric as well (this immediately follows from the definition of $v(x)$ (see (9)). 
Next, we prove that $i^{a}(x)$ has a hump shape with the peak at $x=\bar{s} / 2$. Note that the optimal investment profile can be considered as a unique fixed point of a certain functional $J: E \longrightarrow E$. Here, $E$ is the subset of the space of symmetric (around $x=\bar{s} / 2$ ) continuous functions on $[0, \bar{s}]$, which is determined by the constraints in the maximization problem. Specifically, the functional is given by

$$
J\left(i^{a}(x)\right)=\left(\frac{b L \gamma(1-\alpha)\left(1-t^{a}\right)}{q}\left(\phi^{L}(x)+\phi^{R}(x)\right)\right)^{1 / \delta},
$$

where

$$
\begin{aligned}
\phi^{L}(x) & =\frac{\int_{0}^{x}\left(\int_{x}^{\bar{s}}\left(1+\frac{1}{\delta-1} \int_{s}^{t} i^{a}(r)^{1-\delta} d r\right)^{\gamma(1-\sigma)-1} d t\right) d s}{\int_{0}^{\bar{s}} v(s) d s} . \\
\phi^{R}(x) & =\frac{\int_{x}^{\bar{s}}\left(\int_{0}^{x}\left(1+\frac{1}{\delta-1} \int_{t}^{s} i^{a}(r)^{1-\delta} d r\right)^{\gamma(1-\sigma)-1} d t\right) d s}{\int_{0}^{\bar{s}} v(s) d s} .
\end{aligned}
$$

We then show that if $i^{a}(x)$ has a hump shape with the peak at $x=\bar{s} / 2$, then $J\left(i^{a}(x)\right)$ has a hump shape. This in turn means that the fixed point of the functional has a hump shape. That is, the optimal investment profile has a hump shape.

Consider a function $i_{1}^{a}(x) \in E$ that has a hump shape. We define $i_{2}^{a}(x)$ as the value of the functional at $i_{1}^{a}(x)$ : i.e., $i_{2}^{a}(x)=J\left(i_{1}^{a}(x)\right)$. Next, we prove that $i_{2}^{a}(x)$ has a hump shape. To show this, we consider the derivative of $i_{2}^{a}(x)$. It is straightforward to see that

$$
i_{2}^{a}(x)^{\delta-1}\left(i_{2}^{a}(x)\right)^{\prime}=2 \frac{b L \gamma}{q \delta} \frac{(1-\alpha)\left(1-t^{a}\right)}{\int_{0}^{\bar{s}} v(s) d s} H(x),
$$

where

$$
H(x)=\int_{x}^{\bar{s}}\left(1+\frac{1}{\delta-1} \int_{x}^{z} i_{1}^{a}(s)^{1-\delta} d s\right)^{\gamma(1-\sigma)-1} d z-\int_{0}^{x}\left(1+\frac{1}{\delta-1} \int_{z}^{x} i_{1}^{a}(s)^{1-\delta} d s\right)^{\gamma(1-\sigma)-1} d z
$$

The first thing to notice is that $H(\bar{s} / 2)=0$ (which follows from the symmetry of $i_{1}^{a}(x)$ ). Consider any $x<\bar{s} / 2$, then the function $H(x)$ can be written as follows:

$$
\begin{aligned}
H(x)= & \int_{x}^{2 x}\left(1+\frac{1}{\delta-1} \int_{x}^{z} i_{1}^{a}(s)^{1-\delta} d s\right)^{\gamma(1-\sigma)-1} d z-\int_{0}^{x}\left(1+\frac{1}{\delta-1} \int_{z}^{x} i_{1}^{a}(s)^{1-\delta} d s\right)^{\gamma(1-\sigma)-1} d z \\
& +\int_{2 x}^{\bar{s}}\left(1+\frac{1}{\delta-1} \int_{x}^{z} i_{1}^{a}(s)^{1-\delta} d s\right)^{\gamma(1-\sigma)-1} d z,
\end{aligned}
$$

where

$$
\int_{2 x}^{\bar{s}}\left(1+\frac{1}{\delta-1} \int_{x}^{z} i_{1}^{a}(s)^{1-\delta} d s\right)^{\gamma(1-\sigma)-1} d z>0 .
$$

Note that as $i_{1}^{a}(s)$ is symmetric around $x=\bar{s} / 2$ and has a hump shape at $\bar{s} / 2$, for any $\triangle \in(0, x]$

$$
i_{1}^{a}(x+\triangle)>i_{1}^{a}(x-\triangle) .
$$


This in turn means that for any $\triangle \in(0, x]$,

$$
1+\frac{1}{\delta-1} \int_{x}^{x+\triangle} i_{1}^{a}(s)^{1-\delta} d s<1+\frac{1}{\delta-1} \int_{x-\triangle}^{x} i_{1}^{a}(s)^{1-\delta} d s
$$

implying that

$$
\left(1+\frac{1}{\delta-1} \int_{x}^{x+\Delta} i_{1}^{a}(s)^{1-\delta} d s\right)^{\gamma(1-\sigma)-1}>\left(1+\frac{1}{\delta-1} \int_{x-\Delta}^{x} i_{1}^{a}(s)^{1-\delta} d s\right)^{\gamma(1-\sigma)-1},
$$

as $\gamma(1-\sigma)-1$ is negative. As a result, it is straightforward to see that

$$
\int_{x}^{2 x}\left(1+\frac{1}{\delta-1} \int_{x}^{z} i_{1}^{a}(s)^{1-\delta} d s\right)^{\gamma(1-\sigma)-1} d z>\int_{0}^{x}\left(1+\frac{1}{\delta-1} \int_{z}^{x} i_{1}^{a}(s)^{1-\delta} d s\right)^{\gamma(1-\sigma)-1} d z
$$

That is, for any $x<\bar{s} / 2, H(x)>0$. Similarly, it is possible to show that for any $x>\bar{s} / 2, H(x)<0$. Thus, $\left(i_{2}^{a}(x)\right)^{\prime}$ is strictly greater than zero 0 on $x \in[0, \bar{s} / 2)$ and strictly less than zero on $(\bar{s} / 2,1]$. This means that $i_{2}^{a}(x)$ has a hump shape. Therefore, the solution of (11) has a hump shape.

Finally, we show that $v(x)$ has a hump shape as well. We have that

$$
\begin{gathered}
v^{\prime}(x)=\left(\int_{0}^{x}\left(1+\frac{1}{\delta-1} \int_{z}^{x} i(s)^{1-\delta} d s\right)^{\gamma(1-\sigma)} d z+\int_{x}^{\bar{s}}\left(1+\frac{1}{\delta-1} \int_{x}^{z} i(s)^{1-\delta} d s\right)^{\gamma(1-\sigma)} d z\right)^{\prime} \\
=\frac{\gamma(\sigma-1) i(x)^{1-\delta}}{\delta-1}\left(\int_{x}^{\bar{s}}\left(1+\frac{1}{\delta-1} \int_{x}^{z} i(s)^{1-\delta} d s\right)^{\gamma(1-\sigma)-1} d z-\int_{0}^{x}\left(1+\frac{1}{\delta-1} \int_{z}^{x} i_{1}^{a}(s)^{1-\delta} d s\right)^{\gamma(1-\sigma)-1} d z\right) \\
=\frac{\gamma(\sigma-1) i(x)^{1-\delta}}{\delta-1} H(x) .
\end{gathered}
$$

Taking into account the properties of $H(x)$, we can conclude that $v(x)$ has a hump shape.

\section{Proof of Proposition 3}

Recall that when $m(x)=m$ and $q(x)=q$, the optimal infrastructure profile $i^{a}(x)$ maximizes the following function (up to an irrelevant constant):

$$
W(I, A)=\left(1-A \int_{x \in S} i(x) d x\right)\left(\int_{x \in S} v(x) d x\right)^{(1-\alpha) /(\sigma-1)},
$$

where $I=\{i(x)\}_{x \in\{0, \bar{s}\}}$ and $A=q / b L$ (where $\left.L=m \bar{s}\right)$. The partial derivative of $W(I, A)$ with respect to $A$ is given by

$$
\frac{\partial W(I, A)}{\partial A}=-\left(\int_{x \in S} i(x) d x\right)\left(\int_{x \in S} v(x) d x\right)^{(1-\alpha) /(\sigma-1)}<0 .
$$

We say that $I^{\prime} \succsim I^{\prime \prime}$ if and only if $i^{\prime}(x) \geq i^{\prime \prime}(x)$ for all $x \in S$. It is straightforward to see that if $I^{\prime} \succsim I^{\prime \prime}$, then

$$
\frac{\partial W\left(I^{\prime}, A\right)}{\partial A} \leq \frac{\partial W\left(I^{\prime \prime}, A\right)}{\partial A} \text { for any } A \text {. }
$$


The latter follows from the fact that $v(x)$ is increasing in infrastructure investment. Thus, $W(I, A)$ is submodular and satisfies single crossing property. This in turn implies that a rise in $A$ decreases the optimal infrastructure profile $I^{a}$ (see details in Milgrom and Shannon, 1994). That is, $i^{a}(x)$ falls for all $x$. This proves statements (i)-(iii) in Proposition 3.

As noted above, if $m(x)$ is the same at all locations, then $L=m \bar{s}$ and

$$
i^{a}(x)=\left(\frac{\gamma(1-\alpha)\left(b m \bar{s}-\int_{0}^{\bar{s}} q(s) i^{a}(s) d s\right)}{q(x)}\left(\phi^{L}(x)+\phi^{R}(x)\right)\right)^{1 / \delta} .
$$

In this case, the partial derivative of $i^{a}(x)$ with respect to $\bar{s}$ is given by (here we use the fact that $\left.i^{a}(\bar{s})=0\right)$

$$
\frac{\partial i^{a}(x)}{\partial \bar{s}}=\frac{\gamma(1-\alpha)}{q(x) \delta}\left(i^{a}(x)\right)^{1-\delta}\left(\left(\phi^{L}(x)+\phi^{R}(x)\right)_{\bar{s}}^{\prime}\left(b m \bar{s}-\int_{0}^{\bar{s}} q(s) i^{a}(s) d s\right)+b m\left(\phi^{L}(x)+\phi^{R}(x)\right)\right) .
$$

The derivatives of $\phi^{L}(x)$ and $\phi^{R}(x)$ with respect to $\bar{s}$ are given by

$$
\left(\phi^{j}(x)\right)_{\bar{s}}^{\prime}=\frac{\int_{0}^{x}\left(1+\frac{1}{\delta-1} \int_{s}^{\bar{s}} j^{a}(r)^{1-\delta} d r\right)^{\gamma(1-\sigma)-1} d s-v(\bar{s}) \phi^{j}(x)}{\int_{0}^{\bar{s}} v(s) d s},
$$

where $j \in\{L, R\}$. Thus,

$$
\frac{\partial i^{a}(x)}{\partial \bar{s}}=\frac{b m \gamma(1-\alpha)}{q(x) \delta}\left(i^{a}(x)\right)^{1-\delta}\left(\begin{array}{c}
\frac{2 \bar{s}\left(1-t^{a}\right) \int_{0}^{x}\left(1+\frac{1}{\delta-1} \int_{s}^{\bar{s}} i^{a}(r)^{1-\delta} d r\right)^{\gamma(1-\sigma)-1} d s}{\int_{0}^{\bar{s}} v(s) d s} \\
+\left(\phi^{L}(x)+\phi^{R}(x)\right)\left(1-\frac{\bar{s} v(\bar{s})\left(1-t^{a}\right)}{\int_{0}^{s} v(s) d s}\right)
\end{array}\right) .
$$

As can be seen, if $x$ is sufficiently close to $\bar{s}$, then $\left(\phi^{j}(x)\right)_{\bar{s}}^{\prime}>0\left(\right.$ as $\left.\phi^{j}(\bar{s})=0\right)$ and, thereby, $\partial i^{a}(x) / \partial \bar{s}>$ 0 . Moreover, if the cost of infrastructure is uniform,

$$
\frac{\partial i^{a}(x)}{\partial \bar{s}}>0 \text { for all } x \text {. }
$$

This is due to fact that if $q(x)=q$ for all $x, v(x)$ is symmetric around $x=\bar{s} / 2$ and has a hump shape. As a result, $v(\bar{s}) \leq v(s)$ for any $s \in S$. This in turn means that

$$
\begin{aligned}
\int_{0}^{\bar{s}} v(s) d s & >\bar{s} v(\bar{s}) \Longrightarrow \\
1-\frac{\bar{s} v(\bar{s})\left(1-t^{a}\right)}{\int_{0}^{\bar{s}} v(s) d s} & >0 .
\end{aligned}
$$

\section{The World Planner Solution}

Recall that the world planner solution is given by

$$
i^{w}(x)^{\delta}=\frac{2 b L \gamma(1-\alpha)\left(1-t^{w}\right)}{q}\left(\phi^{L, w}(x, \tau)+\phi^{R, w}(x, \tau)\right),
$$


where

$$
\begin{aligned}
\phi^{L, w}(x, \tau) & =\frac{\int_{0}^{x}\left[\int_{x}^{2 \bar{s}} \tau^{(1-\sigma) l(t, s)}\left(1+\frac{1}{\delta-1} \int_{s}^{t} i^{w}(r)^{1-\delta} d r\right)^{\gamma(1-\sigma)-1} d t\right] d s}{\int_{0}^{2 \bar{s}} v(s) d s}, \\
\phi^{R, w}(x, \tau) & =\frac{\int_{x}^{2 \bar{s}}\left[\int_{0}^{x} \tau^{(1-\sigma) l(t, s)}\left(1+\frac{1}{\delta-1} \int_{t}^{s} i^{w}(r)^{1-\delta} d r\right)^{\gamma(1-\sigma)-1} d t\right] d s}{\int_{0}^{2 \bar{s}} v(s) d s} .
\end{aligned}
$$

The derivative of $\phi^{L, w}(x, \tau)$ with respect to $x$ is given by

$$
\begin{aligned}
& \left(\phi^{L, w}(x, \tau)\right)_{x}^{\prime}= \\
& \frac{\int_{x}^{2 \bar{s}} \tau^{(1-\sigma) l(t, x)}\left(1+\frac{1}{\delta-1} \int_{x}^{t} i^{w}(r)^{1-\delta} d r\right)^{\gamma(1-\sigma)-1} d t-\int_{0}^{x} \tau^{(1-\sigma) l(x, s)}\left(1+\frac{1}{\delta-1} \int_{s}^{x} i^{w}(r)^{1-\delta} d r\right)^{\gamma(1-\sigma)-1} d s}{\int_{0}^{2 \bar{s}} v(s) d s} .
\end{aligned}
$$

Similarly,

$$
\begin{aligned}
& \left(\phi^{R, w}(x, \tau)\right)_{x}^{\prime}= \\
& -\int_{0}^{x} \tau^{(1-\sigma) l(t, x)}\left(1+\frac{1}{\delta-1} \int_{t}^{x} i^{w}(r)^{1-\delta} d r\right)^{\gamma(1-\sigma)-1} d t+\int_{x}^{2 \bar{s}} \tau^{(1-\sigma) l(x, s)}\left(1+\frac{1}{\delta-1} \int_{x}^{s} i^{w}(r)^{1-\delta} d r\right)^{\gamma(1-\sigma)-1} d s \\
\int_{0}^{2 \bar{s}} v(s) d s & .
\end{aligned}
$$

This implies that if $\tau>1$, then

$$
\begin{aligned}
& \lim _{x \rightarrow \bar{s}-0}\left(\phi^{L, w}(x, \tau)\right)_{x}^{\prime}= \\
& \frac{\tau^{1-\sigma} \int_{\bar{s}}^{2 \bar{s}}\left(1+\frac{1}{\delta-1} \int_{\bar{s}}^{t} i^{w}(r)^{1-\delta} d r\right)^{\gamma(1-\sigma)-1} d t-\int_{0}^{\bar{s}}\left(1+\frac{1}{\delta-1} \int_{s}^{\bar{s}} i^{w}(r)^{1-\delta} d r\right)^{\gamma(1-\sigma)-1} d s}{\int_{0}^{2 \bar{s}} v(s) d s}<0 \text {, and } \\
& \frac{\left.-\int_{0}^{\bar{s}}\left(1+\frac{1}{\delta-1} \int_{t}^{\bar{s}} i^{w}(r)^{1-\delta} d r\right)^{\gamma(1-\sigma)-1} d t+\tau^{R, w}(x, \tau)\right)_{x}^{\prime}=}{\int_{0}^{2 \bar{s}} v(s) d s}<0 .
\end{aligned}
$$

In the same way, one can show that $\lim _{x \rightarrow \bar{s}+0}\left(\phi^{L, w}(x, \tau)\right)_{x}^{\prime}$ and $\lim _{x \rightarrow \bar{s}+0}\left(\phi^{R, w}(x, \tau)\right)_{x}^{\prime}$ are positive. As a result, the infrastructure profile has a double-hump shape. At Home, it is decreasing around $\bar{s}$, at Foreign it is increasing.

\section{Proof of Lemma 2}

As in the proof of Proposition 1, we first formulate and analyze a discrete modification of the social planner's maximization problem, which approximates the actual continuos maximization problem, and then take the limit. Recall that the home social planner solves

$$
\left\{i^{H}(x), t^{H}\right\}_{x \in[0, \bar{s}]}=\arg \max _{t, i(x)}\left\{(1-t)\left(\int_{0}^{\bar{s}} v(x) d x\right)^{\frac{1-\alpha}{\sigma-1}} \mid q \int_{0}^{\bar{s}} i(x) d x \leq b L t^{H}\right\} .
$$


where

$$
\begin{aligned}
v(x)= & \int_{0}^{2 \bar{s}} \tau^{(1-\sigma) l(x, z)} T(x, z)^{1-\sigma} d z \\
= & \begin{array}{l}
\int_{0}^{x}\left(1+\frac{1}{\delta-1} \int_{z}^{x} i(r)^{1-\delta} d r\right)^{\gamma(1-\sigma)} d z+\int_{x}^{\bar{s}}\left(1+\frac{1}{\delta-1} \int_{x}^{z} i(r)^{1-\delta} d r\right)^{\gamma(1-\sigma)} d z \\
\quad+\tau^{1-\sigma} \int_{\bar{s}}^{2 \bar{s}}\left(1+\frac{1}{\delta-1} \int_{x}^{\bar{s}} i(s)^{1-\delta} d s+\frac{1}{\delta-1} \int_{\bar{s}}^{z} i^{F}(s)^{1-\delta} d s\right)^{\gamma(1-\sigma)} d z
\end{array}
\end{aligned}
$$

To formulate the corresponding discrete maximization problem, we consider a uniform partition of the $[0,2 \bar{s}]$-interval given by $\left\{x_{i}\right\}_{i=0 . .2 n}$, where $x_{0}=0, x_{n}=\bar{s}$, and $x_{2 n}=2 \bar{s}$. Then, the discrete analogue of the continuos maximization problem can be written as follows (without loss of generality, we assume that location $n$ belongs to the home country):

$$
\left\{i^{H}\left(x_{i}\right), t^{H}\right\}_{i=0 . . n}=\arg \max _{t, i\left(x_{i}\right)}\left\{(1-t)\left(\sum_{i=0}^{n} v\left(x_{i}\right) \triangle_{n}\right)^{\frac{1-\alpha}{\sigma-1}}\right\} .
$$

subject to

$$
q \sum_{i=0}^{n} i\left(x_{i}\right) \triangle_{n} \leq b L t
$$

where

$$
\begin{aligned}
& v\left(x_{i}\right)=\triangle_{n} 1+\sum_{k=0}^{i-1}\left(1+\frac{1}{\delta-1} \sum_{j=k}^{i-1} i\left(x_{j}\right)^{1-\delta} \triangle_{n}\right)^{\gamma(1-\sigma)}+\sum_{k=i+1}^{n}\left(1+\frac{1}{\delta-1} \sum_{j=i+1}^{k} i\left(x_{j}\right)^{1-\delta} \triangle_{n}\right)^{\gamma(1-\sigma)} \\
& +\tau^{1-\sigma} \sum_{k=n+1}^{2 n}\left(1+\frac{1}{\delta-1} \sum_{j=i+1}^{n} i\left(x_{j}\right)^{1-\delta} \triangle_{n}+\frac{1}{\delta-1} \sum_{j=n+1}^{k} i^{F}\left(x_{j}\right)^{1-\delta} \triangle_{n}\right)^{\gamma(1-\sigma)}
\end{aligned}
$$

and $\triangle_{n}=1 / n$.

The first order conditions are given by

$$
\begin{aligned}
\frac{\partial \Lambda}{\partial i\left(x_{i}\right)} & =0, i=0 . . n, \\
\frac{\partial \Lambda}{\partial t} & =0,
\end{aligned}
$$

where $\Lambda$ is the corresponding Lagrange function. It is straightforward to see that

$$
\begin{aligned}
\frac{\partial \Lambda}{\partial i\left(x_{i}\right)} & =\frac{(1-t)(1-\alpha)}{\sigma-1}\left(\sum_{i=0}^{n} v\left(x_{i}\right) \triangle_{n}\right)^{\frac{1-\alpha}{\sigma-1}-1} \triangle_{n} \sum_{l=0}^{n}\left(v\left(x_{l}\right)\right)_{i\left(x_{i}\right)}^{\prime}-\lambda_{0} \triangle_{n} q, \\
\frac{\partial \Lambda}{\partial t} & =-\left(\sum_{i=0}^{n} v\left(x_{i}\right) \triangle_{n}\right)^{\frac{1-\alpha}{\sigma-1}}+\lambda_{0} b L .
\end{aligned}
$$

We have that for $i<1$,

$$
\left(v\left(x_{l}\right)\right)_{i\left(x_{i}\right)}^{\prime}=\left(\triangle_{n}\right)^{2} \gamma(\sigma-1) i\left(x_{i}\right)^{-\delta} \sum_{k=0}^{i}\left(1+\frac{1}{\delta-1} \sum_{j=k}^{l-1} i\left(x_{j}\right)^{1-\delta} \triangle_{n}\right)^{\gamma(1-\sigma)-1}
$$


for $i>1$,

$$
\begin{gathered}
\left(v\left(x_{l}\right)\right)_{i\left(x_{i}\right)}^{\prime}=\left(\triangle_{n}\right)^{2} \gamma(\sigma-1) i\left(x_{i}\right)^{-\delta} \sum_{k=i}^{n}\left(1+\frac{1}{\delta-1} \sum_{j=I+1}^{k} i\left(x_{j}\right)^{1-\delta} \triangle_{n}\right)^{\gamma(1-\sigma)-1} \\
+\left(\triangle_{n}\right)^{2} \gamma(\sigma-1) i\left(x_{i}\right)^{-\delta} \tau^{1-\sigma} \sum_{k=n+1}^{2 n}\left(1+\frac{1}{\delta-1} \sum_{j=I+1}^{n} i\left(x_{j}\right)^{1-\delta} \triangle_{n}+\frac{1}{\delta-1} \sum_{j=n+1}^{k} i^{F}\left(x_{j}\right)^{1-\delta} \triangle_{n}\right)^{\gamma(1-\sigma)-1} .
\end{gathered}
$$

Finally, $\left(v\left(x_{l}\right)\right)_{i\left(x_{i}\right)}^{\prime}=0$ if $i=l$.

Thus, the optimal infrastructure profile, $\left\{i^{H}\left(x_{i}\right)\right\}_{i=0 . . n}$, solves the following system of equations:

$$
\begin{gathered}
\frac{q i^{H}\left(x_{i}\right)^{\delta}}{\triangle_{n} b L \gamma(1-\alpha)\left(1-t^{H}\right)}=\frac{\sum_{l=0}^{i-1}\left(\sum_{k=i}^{n}\left(1+\frac{1}{\delta-1} \sum_{j=l+1}^{k} i^{H}\left(x_{j}\right)^{1-\delta} \triangle_{n}\right)^{\gamma(1-\sigma)-1}\right)}{\sum_{i=0}^{n} v\left(x_{i}\right)} \\
\left.+\frac{\sum_{l=0}^{i-1}\left(\sum_{k=n+1}^{2 n} \tau^{1-\sigma}\left(1+\frac{1}{\delta-1} \sum_{j=l+1}^{n} i^{H}\left(x_{j}\right)^{1-\delta} \triangle_{n}+\frac{1}{\delta-1} \sum_{j=n+1}^{k} i^{F}\left(x_{j}\right)^{1-\delta} \triangle_{n}\right)^{\gamma(1-\sigma)-1}\right)}{\sum_{i=0}^{n} v\left(x_{i}\right)}\right) \\
+\frac{\sum_{l=i+1}^{n}\left(\sum_{k=0}^{i}\left(1+\frac{1}{\delta-1} \sum_{j=k}^{l-1} i^{H}\left(x_{j}\right)^{1-\delta} \triangle_{n}\right)^{\gamma(1-\sigma)-1}\right)}{\sum_{i=0}^{n} v\left(x_{i}\right)} .
\end{gathered}
$$

Taking the limit, we obtain the solution of the continuous maximization problem:

$$
\begin{aligned}
\frac{q i^{H}(x)^{\delta}}{b L \gamma(1-\alpha)\left(1-t^{H}\right)}= & \frac{\int_{0}^{x}\left(\int_{x}^{\bar{s}}\left(1+\frac{1}{\delta-1} \int_{s}^{t} i^{H}(r)^{1-\delta} d r\right)^{\gamma(1-\sigma)-1} d t\right) d s}{\int_{0}^{\bar{s}} v(s) d s} \\
& +\frac{\int_{x}^{\bar{s}}\left(\int_{0}^{x}\left(1+\frac{1}{\delta-1} \int_{t}^{s} i^{H}(r)^{1-\delta} d r\right)^{\gamma(1-\sigma)-1} d t\right) d s}{\int_{0}^{\bar{s}} v(s) d s} . \\
& +\frac{\tau^{1-\sigma} \int_{0}^{x}\left(\int_{\bar{s}}^{2 \bar{s}}\left(1+\frac{1}{\delta-1} \int_{s}^{\bar{s}} i^{H}(r)^{1-\delta} d r+\frac{1}{\delta-1} \int_{\bar{s}}^{t} i^{F}(r)^{1-\delta} d r\right)^{\gamma(1-\sigma)-1} d t\right) d s}{\int_{0}^{\bar{s}} v(s) d s} .
\end{aligned}
$$

Finally, the optimal tax rate solves

$$
t^{H}=\frac{q \int_{0}^{\bar{s}} i^{H}(s) d s}{b L}
$$

\section{Proof of Proposition 6}

From the expression for $i^{H}(x)$, we can see that

$$
\delta i^{H}(x)^{\delta-1}\left(i^{H}(x)\right)^{\prime}=\frac{b L \gamma(1-\alpha)\left(1-t^{H}\right)}{q}\left(\tilde{\phi}^{L, N}(x, \tau)+\tilde{\phi}^{R, N}(x, \tau)\right)^{\prime} .
$$


It is straightforward to see that

$$
\left(\tilde{\phi}^{R, N}(x, \tau)\right)_{x=0}^{\prime}>0 \text { and }\left(\tilde{\phi}^{R, N}(x, \tau)\right)_{x=\bar{s}}^{\prime}<0 .
$$

Consider the derivative of $\tilde{\phi}^{L, N}(x, \tau)$ with respect to $x$. We have that

$$
\begin{aligned}
\left(\tilde{\phi}^{L, N}(x, \tau)\right)^{\prime}= & \frac{\int_{x}^{\bar{s}}\left(1+\frac{1}{\delta-1} \int_{x}^{t} i^{H}(r)^{1-\delta} d r\right)^{\gamma(1-\sigma)-1} d t}{\int_{0}^{\bar{s}} v(s) d s}-\frac{\int_{0}^{x}\left(1+\frac{1}{\delta-1} \int_{s}^{x} i^{H}(r)^{1-\delta} d r\right)^{\gamma(1-\sigma)-1} d s}{\int_{0}^{\bar{s}} v(s) d s} \\
& +\frac{\tau^{1-\sigma} \int_{\bar{s}}^{2 \bar{s}}\left(1+\frac{1}{\delta-1} \int_{x}^{\bar{s}} i^{H}(r)^{1-\delta} d r+\frac{1}{\delta-1} \int_{\bar{s}}^{t} i^{H}(2 \bar{s}-r)^{1-\delta} d r\right)^{\gamma(1-\sigma)-1} d t}{\int_{0}^{\bar{s}} v(s) d s} .
\end{aligned}
$$

As can be inferred from the above expression, $\left(\tilde{\phi}^{L, N}(x)\right)_{x=0}^{\prime}>0$. Moreover, as $\tau^{1-\sigma} \leq 1$,

$\tau^{1-\sigma} \int_{\bar{s}}^{2 \bar{s}}\left(1+\frac{1}{\delta-1} \int_{\bar{s}}^{t} i^{H}(2 \bar{s}-r)^{1-\delta} d r\right)^{\gamma(1-\sigma)-1} d t-\int_{0}^{\bar{s}}\left(1+\frac{1}{\delta-1} \int_{s}^{\bar{s}} i^{H}(r)^{1-\delta} d r\right)^{\gamma(1-\sigma)-1} d s \leq 0$,

implying that $\left(\tilde{\phi}^{L, N}(x)\right)_{x=\bar{s}}^{\prime} \leq 0$. Hence, we can conclude that $\left(i^{H}(x)\right)_{x=0}^{\prime}=\infty\left(\right.$ as $\left.i^{H}(0)^{\delta-1}=0\right)$ and $\left(i^{H}(x)\right)_{x=\bar{s}}^{\prime}$ is negative, but finite (as $\left.i^{H}(\bar{s})^{\delta-1}>0\right)$.

\section{Proof of Proposition 7}

Recall that the infrastructure profile is determined by

$$
i^{H}(x)^{\delta}=\frac{b L \gamma(1-\alpha)\left(1-t^{H}\right)}{q}\left(\tilde{\phi}^{L, N}(x, \tau)+\tilde{\phi}^{R, N}(x, \tau)\right) .
$$

It is straightforward to see that if there are additional transport costs for products produced in the foreign country, then

$$
\begin{aligned}
\tilde{\phi}^{L, N}(x, \tau)= & \frac{\int_{0}^{x}\left(\int_{x}^{\bar{s}}\left(1+\frac{1}{\delta-1} \int_{s}^{t} i^{H}(r)^{1-\delta} d r\right)^{\gamma(1-\sigma)-1} d t\right) d s}{\int_{0}^{\bar{s}}\left(\int_{0}^{\bar{s}} T(s, z)^{1-\sigma} d z\right) d s+\tau^{1-\sigma} \int_{0}^{\bar{s}}\left(\int_{\bar{s}}^{2 \bar{s}} T(s, z)^{1-\sigma} d z\right) d s} \\
& +\frac{\tau^{1-\sigma} \int_{0}^{x}\left(\int_{\bar{s}}^{2 \bar{s}}\left(1+\frac{1}{\delta-1} \int_{s}^{\bar{s}} i^{H}(r)^{1-\delta} d r+\frac{1}{\delta-1} \int_{\bar{s}}^{t} i^{H}(2-r)^{1-\delta} d r\right)^{\gamma(1-\sigma)-1} d t\right) d s}{\int_{0}^{\bar{s}}\left(\int_{0}^{\bar{s}} T(s, z)^{1-\sigma} d z\right) d s+\tau^{1-\sigma} \int_{0}^{\bar{s}}\left(\int_{\bar{s}}^{2 \bar{s}} T(s, z)^{1-\sigma} d z\right) d s}, \\
\tilde{\phi}^{R, N}(x, \tau)= & \frac{\int_{x}^{\bar{s}}\left(\int_{0}^{x}\left(1+\frac{1}{\delta-1} \int_{t}^{s} i^{H}(r)^{1-\delta} d r\right)^{\gamma(1-\sigma)-1} d t\right) d s}{\int_{0}^{\bar{s}}\left(\int_{0}^{\bar{s}} T(s, z)^{1-\sigma} d z\right) d s+\tau^{1-\sigma} \int_{0}^{\bar{s}}\left(\int_{\bar{s}}^{2 \bar{s}} T(s, z)^{1-\sigma} d z\right) d s} .
\end{aligned}
$$

Therefore, to explore the direct effect of $\tau$ on $i^{H}(x)$, we need to analyze how changes in $\tau$ affect $\tilde{\phi}^{L, N}(x, \tau)+\tilde{\phi}^{R, N}(x, \tau)$. Specifically, we find that the sign of $\left(\tilde{\phi}^{L, N}(x, \tau)+\tilde{\phi}^{R, N}(x, \tau)\right)_{\tau}^{\prime}$ is the same 
as the sign of the following expression (remember that taking the derivative, we ignore all the indirect effects):

$$
\begin{aligned}
& R(x) \stackrel{d}{=} \int_{0}^{x}\left(\int_{x}^{\bar{s}}\left(1+\frac{1}{\delta-1} \int_{s}^{t} i^{H}(r)^{1-\delta} d r\right)^{\gamma(1-\sigma)-1} d t\right) d s \int_{0}^{\bar{s}}\left(\int_{\bar{s}}^{2 \bar{s}} T(s, z)^{1-\sigma} d z\right) d s \\
& +\int_{x}^{\bar{s}}\left(\int_{0}^{x}\left(1+\frac{1}{\delta-1} \int_{t}^{s} i^{H}(r)^{1-\delta} d r\right)^{\gamma(1-\sigma)-1} d t\right) d s \int_{0}^{\bar{s}}\left(\int_{\bar{s}}^{2 \bar{s}} T(s, z)^{1-\sigma} d z\right) d s \\
& -\int_{0}^{x}\left(\int_{\bar{s}}^{2 \bar{s}}\left(1+\frac{1}{\delta-1} \int_{s}^{\bar{s}} i^{H}(r)^{1-\delta} d r+\frac{1}{\delta-1} \int_{\bar{s}}^{t} i^{H}(2 \bar{s}-r)^{1-\delta} d r\right)^{\gamma(1-\sigma)-1} d t\right) d s \\
& \times \int_{0}^{\bar{s}}\left(\int_{0}^{\bar{s}} T(s, z)^{1-\sigma} d z\right) d s .
\end{aligned}
$$

As can be seen, $R(x)$ is negative in some left neighborhood of $x=\bar{s}$, implying that $i^{H}(x)$ falls for all $x$ from this neighborhood. Finally, as $\int_{0}^{\bar{s}} i^{H}(x) d x$ remains the same, $i^{H}(x)$ must rise at some locations that are relatively far from the border. 


\section{Appendix B: Discrete variant of the model}

To match the moments, we consider a discrete version of our framework. We assume that there are $2 n$ locations uniformly distributed on $[0,2 \bar{s}]$, with $n$ locations in each country. We define $\triangle_{n}=2 \bar{s} /(2 n-1)$ as the distance between any two adjacent locations. In discrete space, the costs of transportation costs between $i$ and $j(i<j)$ are

$$
T(i, j)=\left(1+\frac{\triangle_{n}}{\delta-1} \sum_{k=i}^{j-1} i(k)^{1-\delta}\right)^{\gamma},
$$

which can be rewritten as

$$
T(i, j)=\left(1+\triangle_{n}(j-i) \frac{\frac{1}{\delta-1} \sum_{k=i}^{j-1} i(k)^{1-\delta}}{j-i}\right)^{\gamma},
$$

such that transportation costs from $i$ and $j$ are determined by the product of distance between $i$ and $j$ and the average level of infrastructure between the locations. For sufficiently large $n$, the above discrete version of the model approximates the continuous specification (see the proof of Lemma 2 in the Appendix for more details). In our exercise we set $n$ at 100, meaning that there are 100 regions within each country which trade with each other and foreign locations. Note that given $n=100$ and $\bar{s}=500$, the discrete version of the model does not perfectly approximate the continuous one and, therefore, should be considered as a discrete variation of the benchmark continuous model which is used to fit the data. ${ }^{53}$

\footnotetext{
${ }^{53} \ln (29) T(i, j)$ does not depend on the level of infrastructure at location $j$. The reason behind is that when $n$ approaches infinity, it is not quantitatively important whether $i(j)^{1-\delta}$ is included into the definition of $T(i, j)$ or not. In our exercise we found that when $n$ is equal to 100 , the inclusion of $i(j)^{1-\delta}$ into $T(i, j)$ does not substantially affect the calibrated values of the parameters and the quantitative implications of the model.
} 


\section{Appendix C: Further empirical results}

Table .1 - Explaining variance in transportation costs in France

\begin{tabular}{|c|c|c|c|c|c|c|}
\hline & (1) & (2) & (3) & (4) & (5) & (6) \\
\hline In distance to Paris & & & & & $\begin{array}{l}0.034^{* *} \\
(0.015)\end{array}$ & \\
\hline In GTC to Paris & & & & & & $\begin{array}{c}0.039 * * \\
(0.015)\end{array}$ \\
\hline In geography & $\begin{array}{c}0.041^{* * *} \\
(0.013)\end{array}$ & $\begin{array}{c}0.029 * * * \\
(0.011)\end{array}$ & $\begin{array}{c}0.032 * * * \\
(0.010)\end{array}$ & $\begin{array}{c}0.020 * * \\
(0.008)\end{array}$ & $\begin{array}{c}0.004 \\
(0.011)\end{array}$ & $\begin{array}{c}0.001 \\
(0.011)\end{array}$ \\
\hline In GDP & & $\begin{array}{c}-0.048 * * * \\
(0.013)\end{array}$ & $\begin{array}{c}-0.186 * * * \\
(0.050)\end{array}$ & $\begin{array}{l}-0.028 \\
(0.052)\end{array}$ & $\begin{array}{l}-0.019 \\
(0.048)\end{array}$ & $\begin{array}{l}-0.018 \\
(0.047)\end{array}$ \\
\hline In population & & & $\begin{array}{c}0.167^{* * *} \\
(0.056)\end{array}$ & $\begin{array}{l}-0.002 \\
(0.059)\end{array}$ & $\begin{array}{l}-0.006 \\
(0.056)\end{array}$ & $\begin{array}{l}-0.007 \\
(0.055)\end{array}$ \\
\hline In area $(\mathrm{km} 2)$ & & & & $\begin{array}{c}0.087^{* * *} \\
(0.013)\end{array}$ & $\begin{array}{c}0.068 * * * \\
(0.015)\end{array}$ & $\begin{array}{c}0.067 * * * \\
(0.014)\end{array}$ \\
\hline Constant & $\begin{array}{c}1.590 * * * \\
(0.009)\end{array}$ & $\begin{array}{c}2.026 * * * \\
(0.118)\end{array}$ & $\begin{array}{c}1.112^{* * * *} \\
(0.334)\end{array}$ & $\begin{array}{c}1.110 * * * \\
(0.299)\end{array}$ & $\begin{array}{l}1.059 * * \\
(0.285)\end{array}$ & $\begin{array}{c}0.967 * * * \\
(0.288)\end{array}$ \\
\hline$N$ & 94 & 94 & 94 & 94 & 94 & 94 \\
\hline $\operatorname{adj} . R^{2}$ & 0.158 & 0.289 & 0.333 & 0.583 & 0.609 & 0.616 \\
\hline$F-$ stat. & 10.06 & 9.443 & 10.66 & 41.91 & 41.25 & 45.17 \\
\hline RMSE & 0.097 & 0.090 & 0.088 & 0.070 & 0.068 & 0.067 \\
\hline
\end{tabular}


Table .2 - The border effect and the role of infrastructure: OLS regressions

\begin{tabular}{|c|c|c|c|c|c|c|}
\hline \multirow[b]{2}{*}{ Dep.var.: } & (1) & (2) & (3) & (4) & (5) & $(6)$ \\
\hline & \multicolumn{3}{|c|}{ aggregate trade } & \multicolumn{3}{|c|}{ sectoral trade } \\
\hline Border $(0,1)$ & $\begin{array}{c}-1.419 * * * \\
(0.333)\end{array}$ & $\begin{array}{c}-1.003 * * * \\
(0.335)\end{array}$ & $\begin{array}{c}-0.784 * * \\
(0.334)\end{array}$ & $\begin{array}{c}-1.092 * * * \\
(0.144)\end{array}$ & $\begin{array}{c}-0.614 * * * \\
(0.148)\end{array}$ & $\begin{array}{c}-0.405 * * * \\
(0.148)\end{array}$ \\
\hline In bird-flight distance & $\begin{array}{c}-1.707^{* * * *} \\
(0.136)\end{array}$ & & & $\begin{array}{c}-2.069 * * * \\
(0.0521)\end{array}$ & & \\
\hline In road distance & & $\begin{array}{c}-1.708^{* * *} \\
(0.147)\end{array}$ & & & $\begin{array}{c}-2.053 * * * \\
(0.0551)\end{array}$ & \\
\hline In travel time & & & $\begin{array}{c}-1.917^{* * *} \\
(0.136)\end{array}$ & & & $\begin{array}{c}-2.255 * * * \\
(0.0560)\end{array}$ \\
\hline Contiguity $(0,1)$ & $\begin{array}{c}0.130 \\
(0.135)\end{array}$ & $\begin{array}{c}0.117 \\
(0.146)\end{array}$ & $\begin{array}{l}0.0400 \\
(0.127)\end{array}$ & $\begin{array}{l}0.122 * * \\
(0.0563)\end{array}$ & $\begin{array}{l}0.124 * * \\
(0.0590)\end{array}$ & $\begin{array}{c}0.0781 \\
(0.0565)\end{array}$ \\
\hline Common language $(0,1)$ & $\begin{array}{l}-0.189 \\
(0.171)\end{array}$ & $\begin{array}{r}-0.0959 \\
(0.169)\end{array}$ & $\begin{array}{l}-0.0201 \\
(0.171)\end{array}$ & $\begin{array}{c}-0.276 * * * \\
(0.0760)\end{array}$ & $\begin{array}{c}-0.161 * * \\
(0.0761)\end{array}$ & $\begin{array}{c}-0.0689 \\
(0.0766)\end{array}$ \\
\hline Constant & $\begin{array}{c}18.36 * * * \\
(0.909)\end{array}$ & $\begin{array}{c}18.76^{* * *} \\
(1.015)\end{array}$ & $\begin{array}{c}19.06 * * * \\
(0.868)\end{array}$ & $\begin{array}{c}16.33^{* * *} \\
(0.476)\end{array}$ & $\begin{array}{c}16.70 * * * \\
(0.502)\end{array}$ & $\begin{array}{c}16.74 * * * \\
(0.478)\end{array}$ \\
\hline Observations & 441 & 441 & 441 & 6,975 & 6,975 & 6,975 \\
\hline R-squared & 0.949 & 0.949 & 0.950 & 0.894 & 0.893 & 0.892 \\
\hline
\end{tabular}

Notes: OLS regressions. All models contain complete sets of separate exporter and importer fixed effects (exporter $*$ sector, importer $*$ sector effects in case of sectoral trade data). Robust standard errors in parentheses, $* * * p<0.01, * * p<0.05, * p<0.1$. 


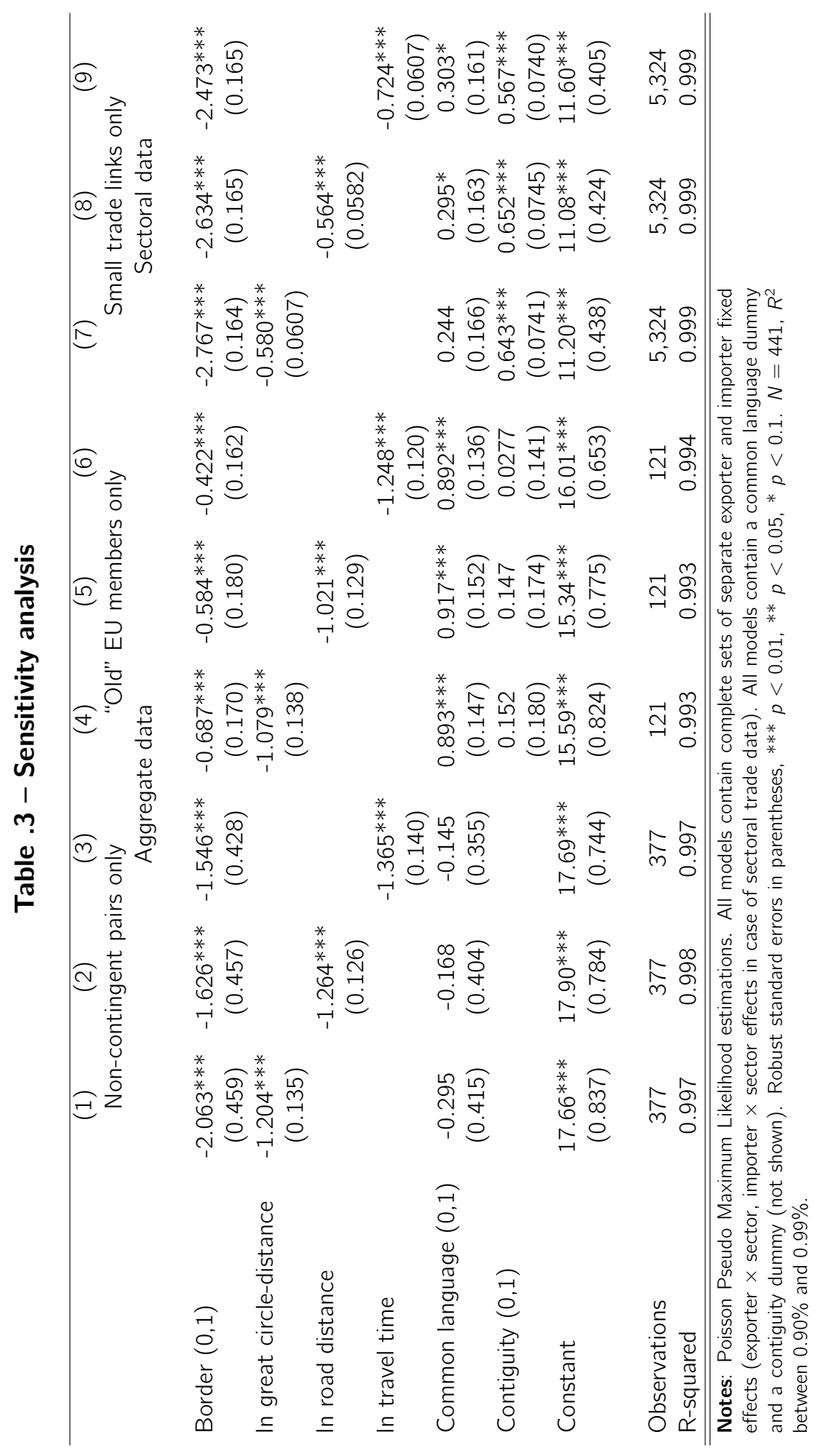




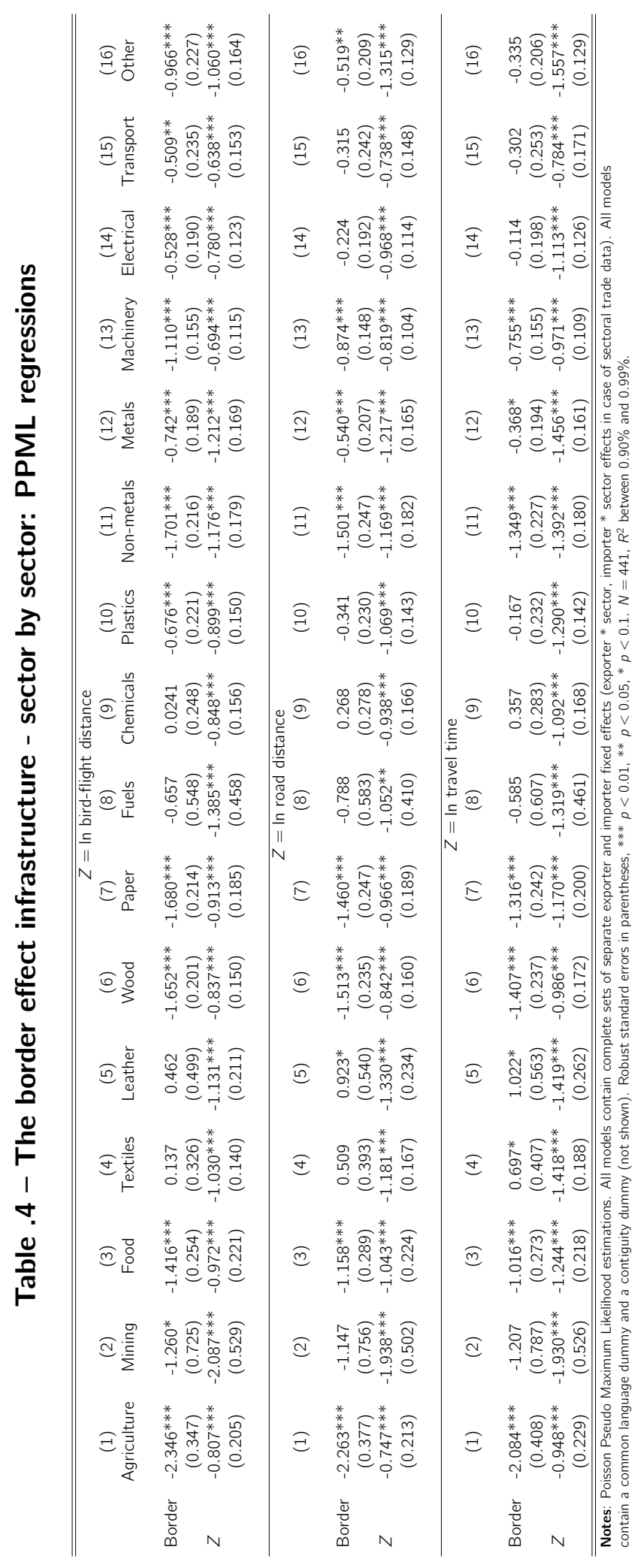

